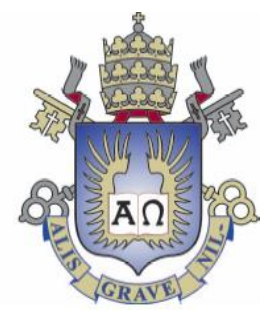

Thais Rosa da Silva

\title{
Uma Ferramenta de Medição de Maturidade Aplicada à Cadeia de Suprimentos
}

Dissertação de Mestrado

Dissertação apresentada ao Programa de Pós-graduação em Engenharia de Produção da PUC-Rio como requisito parcial para obtenção do grau de Mestre em Engenharia de Produção.

Orientador: Prof. Antônio Márcio Tavares Thomé 


\section{Pontifícia Universidade Católica \\ DO RIO DE JANEIRO}

Thais Rosa da Silva

\section{Uma Ferramenta de Medição de Maturidade Aplicada à \\ Cadeia de Suprimentos}

Dissertação apresentada como requisito parcial para obtenção do grau de Mestre (opção profissional) pelo Programa de Pós-Graduação em Engenharia de Produção da PUC-Rio. Aprovada pela Comissão Examinadora abaixo assinada.

Prof. Antônio Márcio Tavares Thomé Orientador

Departamento de Engenharia Industrial - PUC-Rio

Prof. José Eugênio Leal

Departamento de Engenharia Industrial - PUC-Rio

Prof. Rodolfo Cardoso

Universidade Federal Fluminense - UFF

Prof. Marcio da Silveira Carvalho

Coordenador Setorial do Centro Técnico Científico - PUC-Rio

Rio de Janeiro, 11 de Setembro de 2018 
Todos os direitos reservados. É proibida a reprodução total ou parcial do trabalho sem autorização da universidade, do autor e do orientador.

\section{Thais Rosa da Silva}

Profissional de Gerenciamento de Projetos (PMP)® com mais de 10 anos de experiência em projetos de Tecnologia da Informação e Logística. Graduou-se em Administração de Empresas pela Pontifícia Universidade Católica do Rio de Janeiro em 2009. Concluiu o curso de especialização em Gerenciamento de Projetos em 2012, também pela Pontifícia Universidade Católica do Rio de Janeiro.

Ficha Catalográfica

Silva, Thais Rosa da

Uma ferramenta de medição de maturidade aplicada à cadeia de suprimentos / Thais Rosa da Silva ; orientador: Antônio Márcio Tavares Thomé. - 2018.

123 f. : il. color. ; $30 \mathrm{~cm}$

Dissertação (mestrado)-Pontifícia Universidade Católica do Rio de Janeiro, Departamento de Engenharia Industrial, 2018.

Inclui bibliografia

1. Engenharia Industrial - Teses. 2. Maturidade. 3. Modelo de maturidade. 4. Gestão da cadeia de suprimentos. 5. Logística. 6. Ferramenta empresarial. I. Thomé, Antônio Márcio Tavares. II. Pontifícia Universidade Católica do Rio de Janeiro. Departamento de Engenharia Industrial. III. Título. 
Dedico esta dissertação ao pequeno Ignacio e ao grande Ismael, meus amores. 


\section{Agradecimentos}

À Deus por todos os dons que me deste. Um dia espero poder devolver ao mundo tanto bem e tanta graça.

Ao meu marido, Ismael, por estar ao meu lado e me dedicar um amor tão imenso que faz viver.

Ao meu pequeno Ignácio, nascido durante este trabalho, por me lembrar da gratuidade do amor verdadeiro e por me fazer uma pessoa melhor todos os dias.

À minha incansável mãe, Guaraciara, pelo apoio incondicional e pelo amor dedicado a mim e aos meus.

Ao meu irmão Thiago, por me ensinar que a vida pode ser mais simples do que imaginamos.

Aos meus amigos, por caminharem comigo tão generosamente nesta vida, em especial àqueles que de tão amigos, chamo de irmãos.

Aos Jesuítas, Ir. Davison e Pe. Francys, por iluminarem minha alma, sempre apontando para o caminho do amor, do bem e da verdade.

À minha comunidade de vida pelas orações e carinho diário.

Aos amigos de mestrado, pela troca de experiência e contribuições.

Ao meu orientador, por ser meu guia durante essa jornada.

O presente trabalho foi realizado com apoio da Coordenação de Aperfeiçoamento de Pessoal de Nível Superior - Brasil (CAPES) - Código do Financiamento 001. 


\section{Resumo}

Rosa da Silva, Thais; Tavares Thomé, Antônio Márcio. Uma Ferramenta de Medição de Maturidade Aplicada à Cadeia de Suprimentos. Rio de Janeiro, 2018. 123 p. Dissertação de Mestrado - Departamento de Engenharia Industrial, Pontifícia Universidade Católica do Rio de Janeiro.

O mercado competitivo exige sistematicamente custos reduzidos e mais flexibilidade das organizações contemporâneas que, por sua vez, podem alcançar melhores resultados ao focarem no desenvolvimento de suas cadeias de suprimento. Sendo assim, os modelos de maturidade em supply chain se apresentam como aliados no processo de alavancagem das organizações. Apesar do crescente número de modelos neste campo de conhecimento, a literatura aponta para uma lacuna na criação de modelos híbridos, adaptativos e que se predispõem a medir a cadeia de suprimentos de forma ampla. A partir desta carência, o objetivo desta dissertação foi desenvolver um modelo de maturidade em gestão de cadeias de suprimentos com uma ferramenta de medição associada. Para isso, foi desenvolvida uma metodologia subdividida em três fases, abrangendo: os estudos introdutórios, a pesquisa bibliográfica e o desenvolvimento efetivo do modelo e ferramenta. $\mathrm{O}$ resultado desta pesquisa foi a criação do produto tecnológico, com registro no Instituto Nacional da Propriedade Industrial (INPI), Supply Chain Management Maturity Model (SCM3). SCM3 é um modelo de caráter interdisciplinar, multidimensional e composto por 6 dimensões de aplicação: gestão de fornecedores, gestão da operação e clientes, gestão das atividades logísticas, recursos humanos, sistemas tecnológicos e sistema de medição de performance. O SCM3 utiliza o conceito de pontos chave de transição para mudança de nível de maturidade, o que confere maior pragmatismo ao modelo. A operacionalização deste modelo exigiu também o desenvolvimento de um método de apoio às organizações para sua implantação. O protótipo de ferramenta computacional associada ao SCM3 gera resultados compatíveis e comparáveis, reunindo 153 questões e 5 funcionalidades. A etapa de validação do modelo contou com a participação de especialista tanto do mercado, quanto da academia, que avaliaram aspectos inerentes à interface, conteúdo, encadeamento lógico, viabilidade e aceitabilidade do modelo. $\mathrm{O}$ modelo foi aplicado em ambiente organizacional em duas grandes empresas, líderes do setor de telecomunicações brasileiro, contando com a participação da camada 
gerencial das companhias. A aplicação se demonstrou relevante para organizações e acadêmicos, sendo capaz de realizar inúmeras análises para organizações alavancarem suas cadeias e apoiar estudo futuros de benchmarking em maturidade em supply chain.

\section{Palavras-chave}

Maturidade; Modelo de Maturidade; Gestão da Cadeia de Suprimentos; Logística; Ferramenta Empresarial. 


\section{Abstract}

Rosa da Silva, Thais; Tavares Thomé, Antônio Márcio (Advisor). A Supply Chain Maturity Model Tool. Rio de Janeiro, 2018. 123 p. Dissertação de Mestrado - Departamento de Engenharia Industrial, Pontifícia Universidade Católica do Rio de Janeiro.

The competitive marketplace systematically demands reduced costs and more flexibility from contemporary organizations which, in turn, can achieve better results by focusing on the development of their supply chains. Thus, supply chain maturity models present themselves as allies in the leverage process of organizations. Despite the increasing number of models in this field of knowledge, the literature points to a gap in the creation of hybrid, adaptive models that are predisposed to measure the supply chain in a broad way. From this gap, the objective of this dissertation was to develop a maturity model in supply chain management with an associated measurement tool. For this, a methodology was developed subdivided in three phases, covering: the introductory studies, the bibliographical research and the effective development of the model and tool. The result of this research was the creation of the technological product, with registration in the National Institute of Industrial Property (INPI), Supply Chain Management Maturity Model (SCM3). SCM3 is interdisciplinary, multidimensional and composed of 6 application dimensions: supplier management, operation and customer management, logistic activities management, human resources, technological systems and performance measurement system. The SCM3 uses the concept of turning points to change maturity level, which confers greater pragmatism to the model. The operationalization of this model also required the development of a method to support organizations for the implementation. The computational tool prototype associated to SCM3 generates compatible and comparable results, gathering 153 questions and 5 functionalities. The validation stage of the model was attended by specialists from both the market and academy, who evaluated aspects inherent to the interface, content, logical linkage, viability and acceptability of the model. The model was applied in an organizational environment in two large companies, leaders of the Brazilian telecommunications sector, counting with the participation of the managerial layer of the companies. The application has proved to be relevant for organizations and academics, being able to perform numerous 
analyzes for organizations to leverage their chains and support future benchmarking studies in supply chain maturity.

\section{Keywords}

Maturity; Maturity Model. Supply Chain Management. Logistics. Business Tool. 


\section{Sumário}

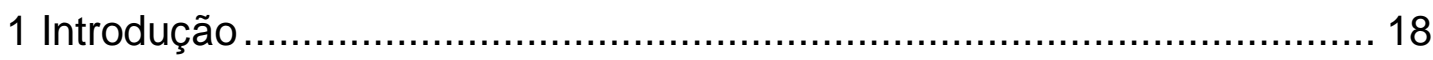

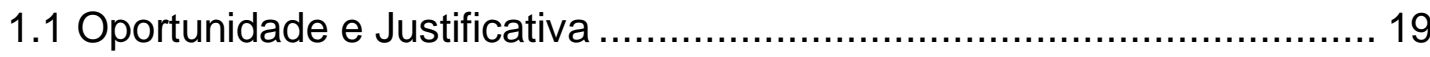

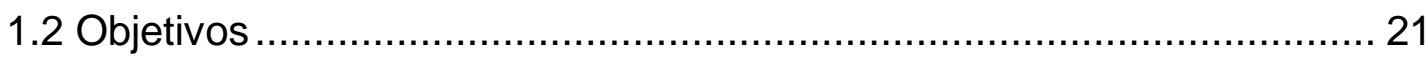

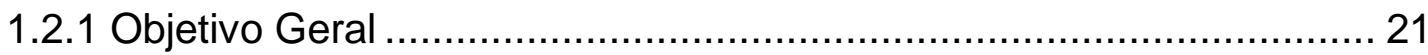

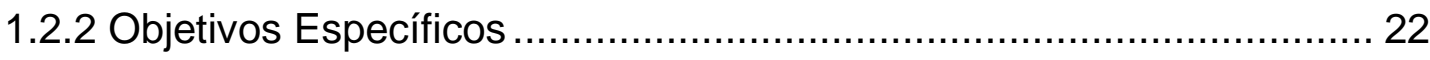

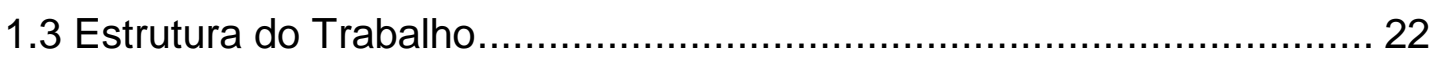

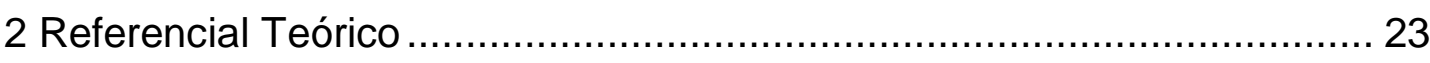

2.1 Fundamentos em Cadeias de Suprimentos ........................................ 23

2.2 Gestão da Cadeia de Suprimentos e sua Evolução Conceitual.............. 24

2.3 Maturidade em Cadeia de Suprimentos …………............................. 26

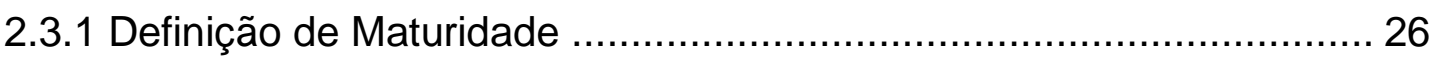

2.3.2 Modelos de Maturidade em Processos ............................................. 27

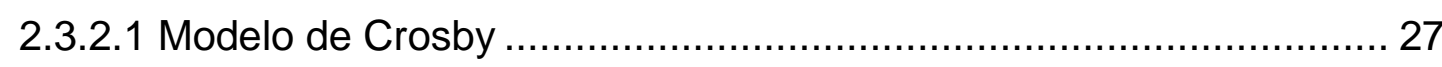

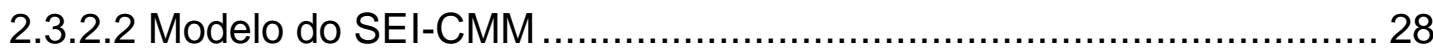

2.3.2.3 Modelo do PMI (Project Management Institute) .............................. 29

2.3.2.4 Business Process Orientation Maturity Model (BPOMM) ................. 30

2.3.2.5 Modelo de Referência para Operações em cadeias de

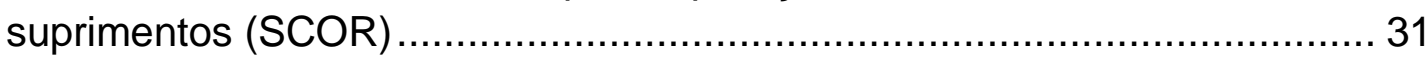

2.3.2.6 Outros Modelos de Maturidade em Processos .............................. 33

2.4 Modelos de Maturidade em Gestão de Cadeia de Suprimentos ............. 34

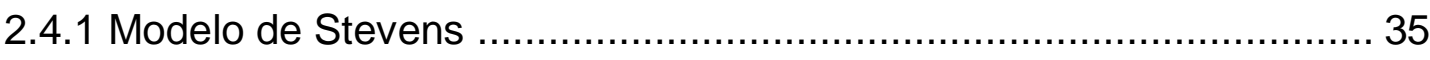

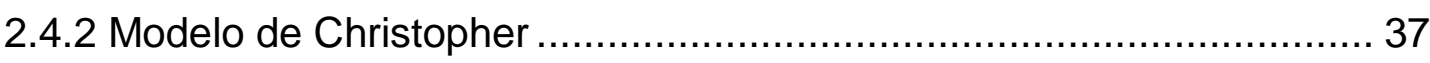

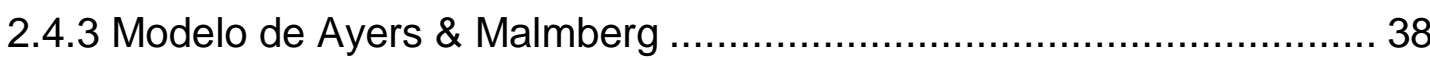

2.4.4 Modelo de Computer Sciences Corporation Framework - CSC ......... 38

2.4.5 Modelo de Lockamy \& McCormack ................................................ 40

2.4.6 Modelo de Daozhi et al. (2006) ................................................... 42

2.4.7 Modelo do Performance Measurement Group - PMG....................... 44

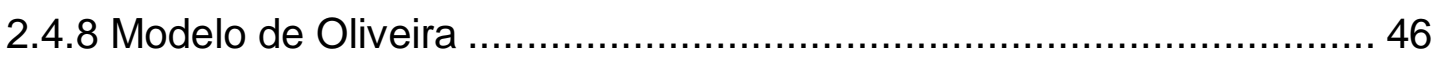

2.4.9 Modelo de Reyes \& Gianchetti ..................................................... 48

2.4.10 Modelo de Mendes ................................................................. 52

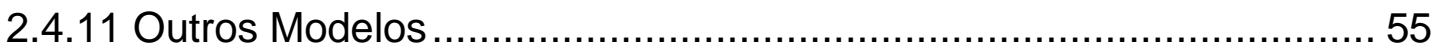

2.5 Processo de Desenvolvimento de Modelos de Maturidade ................... 57 


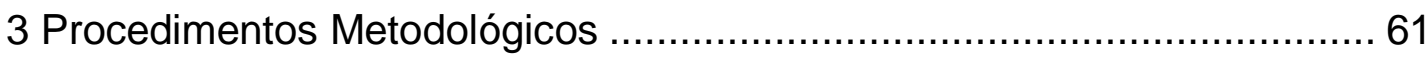

3.1 Processo de Desenvolvimento do Modelo de Maturidade ....................... 61

3.2 Detalhamento do Desenvolvimento da Pesquisa ................................ 63

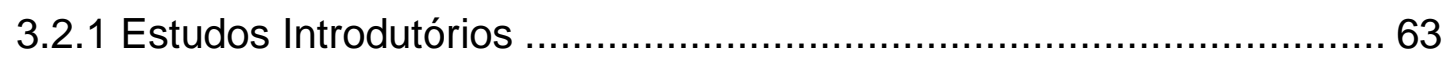

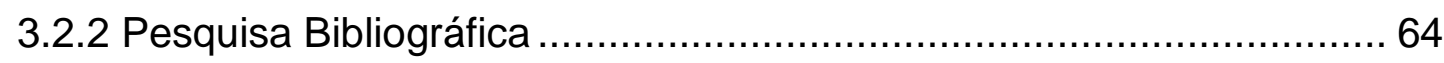

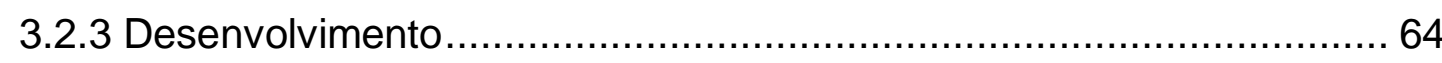

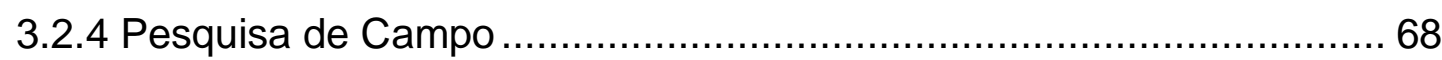

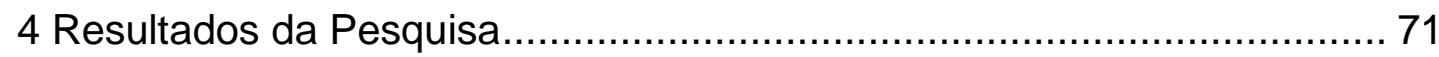

4.1 Escolha dos Modelos de Maturidade .................................................... 71

4.1.1 Análise dos Modelos de Maturidade ................................................... 71

4.2 Modelo de Maturidade Proposto .................................................... 78

4.2.1 Visão Conceitual e Padrão Representativo ……………………....... 78

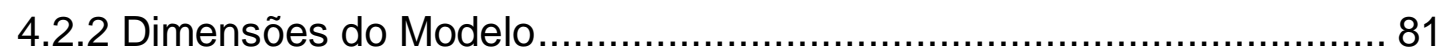

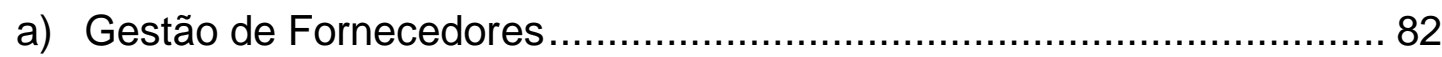

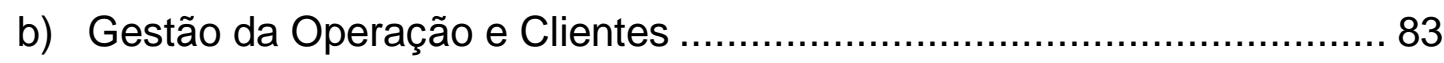

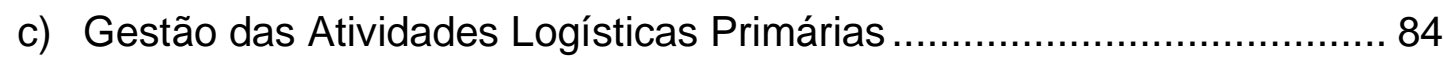

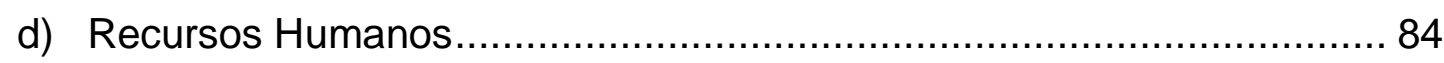

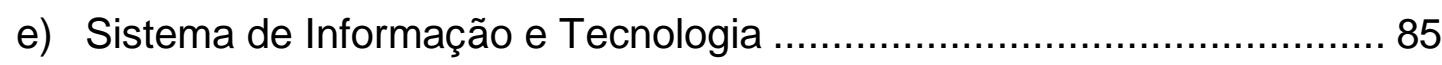

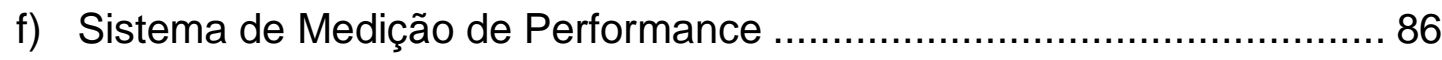

4.2.3 Os Atributos de Maturidade nas Dimensões do Modelo …………...... 87

4.2.4 Especificação dos Níveis de Maturidade ......................................... 91

4.2.5 Determinando o Nível de Maturidade .............................................. 93

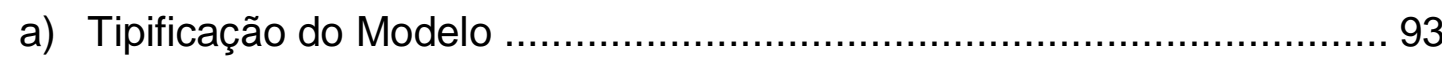

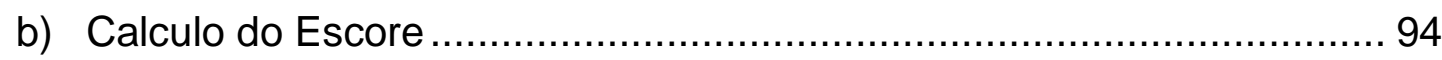

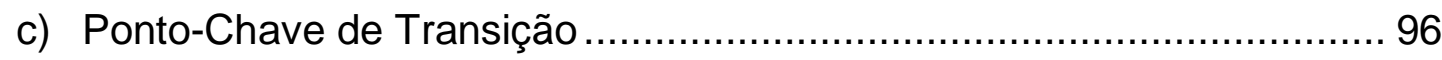

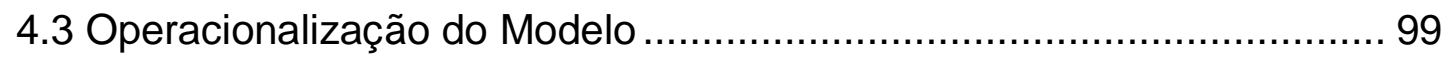

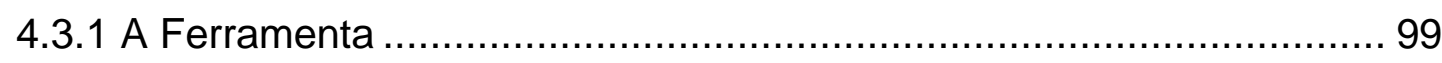

4.3.1.1 Funcionalidades da Ferramenta ................................................ 99

4.3.1.2 Relatório de Resultados Primários ............................................... 102

4.3.1.3 Relatório de Resultados Benchmarking....................................... 104

4.3.2 Método de Implantação do Modelo ………………...................... 107

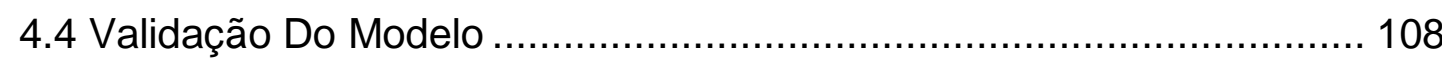

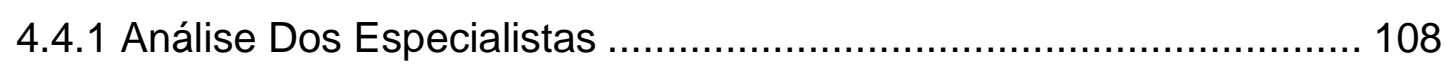


4.4.2 Aplicação em Ambiente Organizacional ......................................... 110

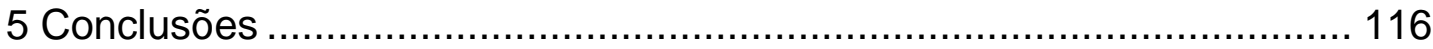

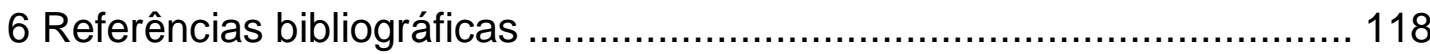

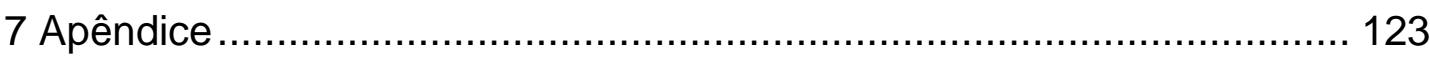

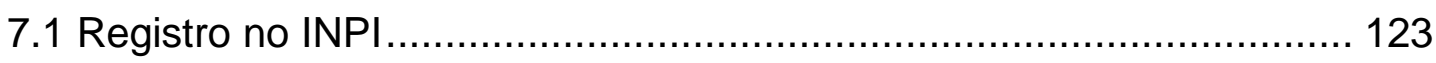




\section{Lista de Figuras}

Figura 1: Gestão da Cadeia de Suprimentos e seus processos de negócios

Figura 2: Representação de uma Cadeia de Suprimentos ......................... 25

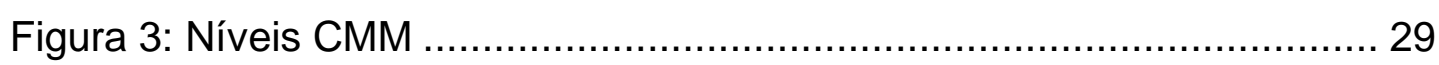

Figura 4: Etapas de Desenvolvimento do Processo de Maturidade ............ 31

Figura 5: Modelo hierárquico em níveis do SCOR ................................. 32

Figura 6: Alcançando uma Cadeia de Suprimentos Integrada...................... 35

Figura 7: Representação do modelo Supply Chain Maturity Model ............. 39

Figura 8: Modelo de Daozhi et al. (2006) e suas três dimensões ................. 43

Figura 9: Modelo do PMG - Competências e o Desempenho da Cadeia .... 45

Figura 10: Modelo de Maturidade da Gestão Logística de Oliveira (2009) .. 47

Figura 11: Cubo de representação de Reyes \& Gianchetti (2010) .............. 50

Figura 12: Fases do desenvolvimento e aplicação .................................... 58

Figura 13: Parâmetros de decisão para o delineamento ............................. 59

Figura 14: Etapas para o Desenvolvimento da Pesquisa ............................ 62

Figura 15: Autores mais citados em modelos de maturidade em SC ......... 77

Figura 16: Dimensões de aplicação do modelo em 3D ............................. 79

Figura 17: Dimensões de aplicação do modelo em 2D .............................. 81

Figura 18: Aplicação do SCOR no modelo de referência ............................. 82

Figura 19: Níveis de maturidade do modelo ........................................... 93

Figura 20: Principais características dos níveis de maturidade do modelo.. 93

Figura 21: Pontos-chave de transição baseado nos centroides .................. 98

Figura 22: Tela Inicial da Ferramenta.................................................. 100

Figura 23: Tela Inicial de Dados Gerais ................................................ 100

Figura 24: Tela de Abertura da Dimensão Fornecedores ......................... 101

Figura 25: Tela 1 de Avaliação da Dimensão Fornecedores ...................... 101

Figura 26: Primeira Tela de Resultados ................................................. 102

Figura 27: Tela de Resultados por Dimensão ....................................... 103

Figura 28: Maturidade dos Atributos por Dimensão .................................. 104

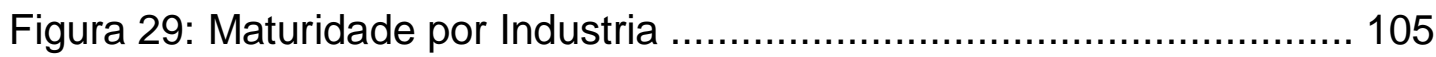

Figura 30: Maturidade por Porte das Empresas ..................................... 105 


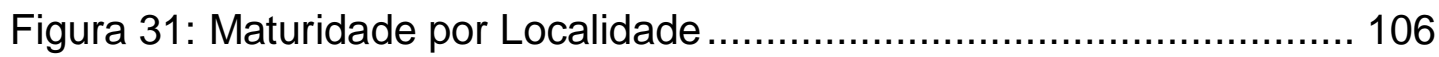

Figura 32: Dimensões Detalhadas por Industria.................................... 106

Figura 33: Etapas de implantação do modelo ....................................... 107

Figura 34: Escores por Dimensão das empresas A e B-......................... 111

Figura 35: Escores dos atributos de Gestão de Fornecedor ..................... 111

Figura 36: Escores dos atributos de Gestão das Atividades Logísticas

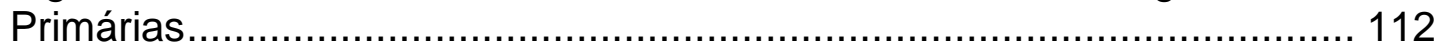

Figura 37: Escores dos atributos de Gestão da Operação e Clientes ....... 113

Figura 38: Escores dos atributos de Recursos Humanos ......................... 113

Figura 39: Escores dos atributos de Sistemas de Informação e

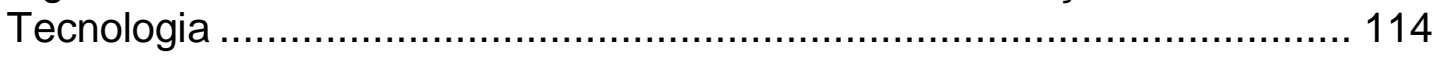

Figura 40: Escores dos atributos de Sistema de Medição e Performance. 115 


\section{Lista de Tabelas}

Tabela 1: Análise de modelos de maturidade aplicados ao SCM conforme

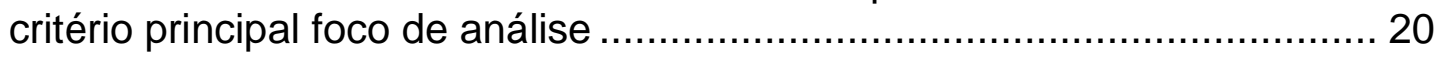

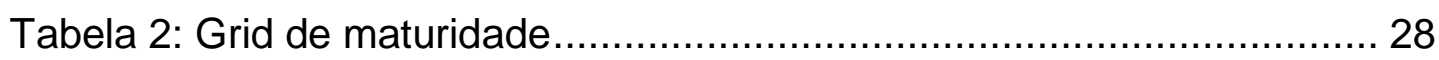

Tabela 3: Modelos de Maturidade em Processos........................................ 33

Tabela 4: Etapas de Integração da Cadeia de Suprimentos ....................... 36

Tabela 5: Estágio de maturidade da Cadeia de Suprimentos ....................... 37

Tabela 6: Estágios de Maturidade do Modelo de Ayers \& Malmberg

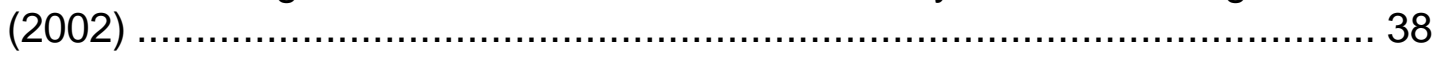

Tabela 7: Estágios de Evolução CSC Framework.................................... 39

Tabela 8: Estágios de Maturidade do Modelo de Lockamy \& McCormack

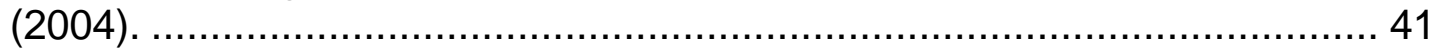

Tabela 9: Estágios de Maturidade do Modelo de Daozhi et al. (2006)......... 43

Tabela 10: Estágios de Maturidade do Modelo de PMG ........................... 45

Tabela 11: Características das Empresas em cada nível de Maturidade .... 47

Tabela 12: Níveis de maturidade de Reyes \& Gianchetti (2010) ................. 52

Tabela 13: Níveis de maturidade do modelo de Mendes Jr. et al. (2016).... 54

Tabela 14: Modelos de Maturidade em Cadeia de Suprimentos ................. 55

Tabela 15: Os 8 requisitos para o desenvolvimento de Modelos de Maturidade

Tabela 16: Definição das características do modelo da pesquisa segundo

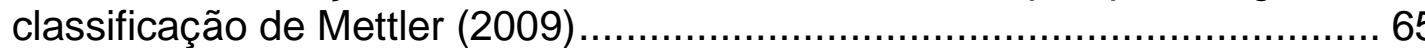

Tabela 17: Análise de modelos de maturidade SCM conforme formas de aplicação

Tabela 18: Roteiro para Validação da Estrutura do Modelo e Instrumento

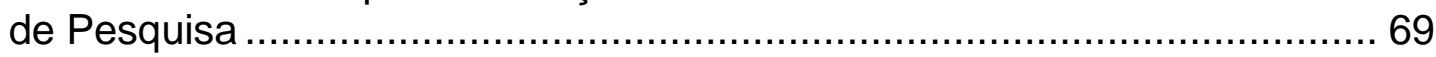

Tabela 19: Amostra dos entrevistados para validação do modelo................ 70

Tabela 20: Práticas avaliadas relativas à dimensão Gestão de Fornecedores.

Tabela 21: Práticas avaliadas relativas à dimensão Gestão da Operação e Clientes

Tabela 22: Práticas avaliadas relativas à dimensão Gestão das Atividades

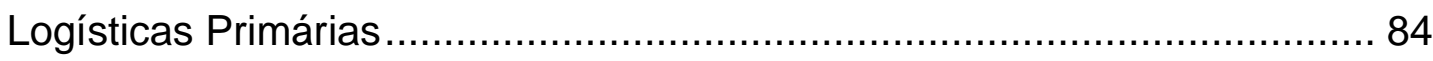

Tabela 23: Práticas avaliadas relativas à dimensão Recursos Humanos .... 85 
Tabela 24: Práticas avaliadas relativas à dimensão Sistema de Informação e Tecnologia.

Tabela 25: Práticas avaliadas relativas à dimensão Sistema de Medição de Performance 86

Tabela 26: Matriz "Dimensões X Atributos do modelo de maturidade" ........ 87

Tabela 27: Níveis de Maturidade ............................................................. 91

Tabela 28: Pontos-chave de transição do modelo..................................... 97

Tabela 29: Resultado da avalição do modelo por especialistas ................ 109 
"A renúncia é o que nos humaniza"

(Pe. Adroaldo, sj) 


\section{1 \\ Introdução}

A realidade que permeia as organizações contemporâneas é um ambiente complexo. As empresas estão inseridas em um contexto competitivo globalizado, sofrendo fortes pressões em seus mercados e seus clientes, que por sua vez, demandam progressivamente mais flexibilidade e menores custos (Christopher, 2007). O tempo de vida dos produtos é cada vez mais curto, demandando um tempo de resposta no mercado cada vez mais restrito. Com isso, os ativos estratégicos se apresentam como pilares fundamentais para vencer a competição em muitos setores, uma vez que a competição não tem ocorrido mais somente entre as empresas, mas entre as cadeias de suprimentos ampliadas (Pires, 2009).

Neste advento, as empresas são cada vez mais convidadas a desenvolverem suas capabilidades, que se definem como um conjunto complexo de habilidades e conhecimento acumulado exercitado ao longo dos processos organizacionais, alinhados com as organizações que fazem parte da sua rede de valor (Lockamy \& McCormack, 2004). E devido à oportunidade de sinergia entre cadeias se torna necessário o desenvolvimento de teorias, métodos e instrumentos que colaborem para o exercício de suas práticas e que comportem a complexidade de uma rede (Lambert, 2008).

Neste contexto, avaliar a maturidade da cadeia de suprimentos se destaca como um elemento de apoio à decisão na gestão das organizações. Diante disso, nos últimos anos um crescente número de pesquisas tem buscado investigar modelos de maturidade para a gestão estratégica dos processos em cadeias de suprimentos (McCormack e et al., 2008).

Empresas de diversos portes e segmentos têm alcançado melhorias significativas em seus indicadores de desempenho ao focarem no redesenho dos seus processos e o desenvolvimento de capabilidades (Hammer, 2007). Porém, a habilidade dos administradores para identificar, gerenciar e modificar seus recursos é limitada. Além disso, pela complexidade das cadeias, a identificação exata do que precisa ser feito, em quais proporções ainda é imprecisa e dificultada pela carência de teorias que sustentem as investigações. (Lockamy \& McCormack, 2004). 
No que se refere à prática do diagnóstico em cadeias de suprimentos, a maioria das iniciativas ainda se encontram no campo estático das medidas de desempenho, e não em maturidade, que são lidos como os meios pelos quais se gera este desempenho (Oliveira, 2009). Sendo assim, os Modelos de Maturidade vêm preencher uma lacuna existente no campo da avaliação do desempenho e desenvolvimento das cadeias de suprimento, ajudando gestores a identificar gaps e entraves para sua evolução.

O desenvolvimento de modelos de maturidade tem recebido um crescente interesse entre acadêmicos e profissionais, e são aplicados em diversos campos do conhecimento, como processos organizacionais (Hammer, 2007), mas apesar de também existirem estudos que investigam a maturidade em cadeias de suprimentos, eles são poucos, a sua maioria é parcial no que se refere à totalidade da cadeia de suprimentos e muitos foram desenvolvidos apenas para um setor específico da indústria (Netland e Alfnes, 2011).

Um estudo liderado por Bowersox (2010), conhecido como 'Logística de Classe Mundial' (The Global Logistics Research Team) ampliou conhecimento em maturidade de cadeias de suprimentos, mas o estudo não se caracterizou como um modelo de maturidade com instrumento tangível e padronizado que pudesse ser utilizado em avaliação de empresas, apesar do estudo ter concluído que as organizações participantes eram maduras e desenvolvidas.

Diante de todo esse cenário, foi identificada a oportunidade de se desenvolver um modelo standard de medição da maturidade em cadeias de suprimentos agregando tanto as funções da cadeia de suprimentos, bem como os processos gerenciais a ela pertencentes, contribuindo para o desenvolvimento acadêmico do tema e permitindo que gestores logísticos acompanhem o crescimento da maturidade de suas cadeias de forma mais integrada e participativa.

\section{1}

\section{Oportunidade e Justificativa}

A gestão da cadeia de suprimentos desempenha papel extremamente relevante na estratégia e no alcance dos objetivos empresariais. Estudos apontam que quanto mais evoluída é a gestão da cadeia, mais ela pode contribuir para agregar valor aos clientes (Lockamy \& McCormack, 2004). A comprovação empírica de que os modelos de maturidade melhoram o desempenho operacional e financeiro 
das empresas sugere que toda empresa deveria dedicar esforço para implantar tais modelos (Aryee, 2008).

Isto posto, a mensuração da maturidade da cadeia de suprimentos consiste, por si só, em uma oportunidade para uma empresa alinhar suas medidas e ações de melhoria dos processos com suas políticas e estratégias mais amplas. Os modelos de maturidade constituem-se como valiosos instrumentos para a liderança corporativa (McCormack et al., 2009). Sendo assim, ao explorar essa relação entre maturidade e cadeia de suprimentos, o presente trabalho poderá tornar-se uma valiosa contribuição para gerentes e pesquisadores envolvidos em estudos que analisam melhores práticas no campo da gestão da cadeia de suprimentos.

Outra oportunidade identificada está na ampliação de modelos no qual o foco da análise esteja na maturidade da gestão da cadeia de suprimentos. O trabalho desenvolvido por Paes (2011) estratificou diversos modelos de maturidade e uma das conclusões evidenciou que o foco principal da maior parte dos modelos de maturidade avalia apenas as atividades logísticas básicas e apenas 14,29\% dos modelos possuem foco na avaliação ampla da cadeia de suprimentos, conforme apresentado na tabela 1. Dados estes que corroboram com a relevância do modelo desenvolvido por esta dissertação, uma vez que se predispõe a realizar uma avaliação completa, incluindo não apenas os processos das atividades logísticas, mas todos os aspectos específicos que tangem a cadeia.

Tabela 1: Análise de modelos de maturidade aplicados ao SCM conforme critério principal foco de análise

\begin{tabular}{|ccc|}
\hline Principal Foco da Análise & Quantidade & $\%$ \\
\hline Atividades Logísticas & 6 & $21,43 \%$ \\
\hline Sistemas e Tecnologia & 6 & $21,43 \%$ \\
\hline Aspectos Específicos & 5 & $17,86 \%$ \\
\hline Avaliação Ampla da Cadeia de Suprimentos & 4 & $14,29 \%$ \\
\hline Relacionamento na Cadeia de Suprimentos & 4 & $14,29 \%$ \\
\hline Processos da Cadeia de Suprimentos & 3 & $10,71 \%$ \\
\hline Total de Modelos Analisados & 28 & $100 \%$ \\
\hline
\end{tabular}

Fonte: Paes (2011)

A realização desta pesquisa também trará importante contribuição para a área de conhecimento, uma vez que compila conceitos e teorias necessárias para o desenvolvimento do modelo. Quanto à originalidade, o valor desta dissertação reside na associação entre dois modelos teóricos distintos, criando um modelo único em medição de maturidade em gestão de cadeia de suprimentos. 
Netland e Alfnes (2011) afirmam que medir a maturidade das operações da cadeia de suprimentos é essencial para o desenvolvimento de estratégias operacionais coerentes com a estratégia global da empresa, envolvendo clientes e fornecedores. Nesse contexto, este trabalho justifica-se por permitir que as empresas construam este conhecimento que permitirá um melhor alinhamento de suas estratégias, possibilitando melhorias no desempenho dos processos logísticos e na gestão da cadeia.

Em outro estudo, Netland e Alfnes (2008) defendem uma abordagem que possua uma contribuição ampla tanto quanto para os processos de gestão, bem como que contribuam para ampliação das capabilidades da organização, com um instrumento sistemático para aplicação do modelo.

Outra oportunidade identificada baseia-se na carência apresentada pela literatura por modelos adaptativos, como sugere o estudo de Mettler (2009) e Becker et al. (2009), em suas propostas, defendem que os novos modelos de maturidade tenham estruturas que possam ser constantemente adaptadas à realidade das empresas, atendendo a vários setores da economia. De acordo com Slack et. al. (2009), um pré-requisito chave para o uso efetivo de informações de processos é um modelo adaptativo. Para o autor os modelos precisam acompanhar a evolução das empresas de maneira dinâmica.

O estudo também deverá inspirar gerentes e pesquisadores, oferecendo dados detalhados sobre a estruturação do modelo e seu desempenho. Também poderá apresentar utilidade para pesquisadores envolvidos em estudos sobre melhores práticas em gestão da cadeia de suprimentos ao explorar o complexo contexto das relações logísticas.

E por fim, o desenvolvimento desta dissertação oferecerá aos participantes da pesquisa a oportunidade de conhecer melhor suas cadeias e as vantagens competitivas que podem ser propiciadas aos membros de sua rede logística.

\section{2 \\ Objetivos}

\subsection{1}

Objetivo Geral

A partir da lacuna identificada tanto no mercado, quanto na literatura, o objetivo principal deste trabalho será o desenvolvimento de um modelo de 
maturidade em gestão de cadeias de suprimentos e uma ferramenta de medição de maturidade associada.

\section{2 .2}

\section{Objetivos Específicos}

A realização do objetivo geral apresentado compreende os seguintes objetivos específicos:

A. Identificar os modelos de maturidade em cadeia de suprimentos disponíveis na literatura;

B. Apresentar os resultados de um esforço bibliográfico orientado para o desenvolvimento do modelo hipotético-conceitual de medição de maturidade;

C. Desenvolver um protótipo de ferramenta de medição a partir do modelo conceitual de maturidade proposto, acessível e disponível para gestores logísticos e acadêmicos;

D. Realizar uma aplicação no mundo real a fim de validar e ajustar o modelo conceitual proposto e o protótipo de ferramenta de medição.

\section{3}

\section{Estrutura do Trabalho}

Este trabalho é composto essencialmente por cinco capítulos: introdução, referencial teórico e revisão da literatura, metodologia, resultados e conclusões. O presente capítulo contém uma discussão inicial com o intuito de contextualizar o tema da pesquisa, além de introduzir o conteúdo principal da dissertação, onde estão apresentados seus objetivos e a justificativa.

O segundo capítulo contempla um resumo teórico dos conceitos que norteiam esse trabalho. Nessa parte, discorre-se sobre cadeias de suprimentos, gestão da cadeia de suprimentos, maturidade, modelos de maturidade e abordagens metodológicas para o desenvolvimento de um modelo de maturidade.

No terceiro capítulo, é apresentada a metodologia construída para o desenvolvimento deste trabalho.

No capítulo de resultados, é apresentado o modelo conceitual, a ferramenta desenvolvida e os resultados encontrados na aplicação no mundo real. Por fim, são apresentadas as conclusões. 


\section{2 \\ Referencial Teórico}

Este capítulo é dedicado a revisar conceitos fundamentais para o desenvolvimento deste trabalho. Aqui serão abordados os conceitos de cadeia de suprimentos, gestão da cadeia de suprimentos, definição de maturidade em processos e maturidade em cadeias de suprimentos, bem como os modelos de maturidade da literatura e seus processos de desenvolvimento.

\section{1}

\section{Fundamentos em Cadeias de Suprimentos}

Raras sãos as áreas do conhecimento que têm um impacto tão significativo no padrão de vida da sociedade quanto a logística, entretanto, as pessoas não percebem o seu importante papel até que ocorram problemas no processo logístico que impactem a disponibilidade de um produto (Lambert et. al, 1998b).

A conceituação mais recorrente e recente nas publicações acadêmicas sobre logística é a do Council of Supply Chain Management Professionals (CSCMP, 2017), a qual também foi adotada pela Associação Brasileira de Logística (ASLOG), e se define como:

"Logística é uma parte da cadeia de abastecimento que planeja, implementa e controla com eficácia o fluxo e a armazenagem dos bens, dos serviços e das informações entre o ponto da origem e o ponto de consumo destes itens, a fim de satisfazer todas as exigências dos consumidores em geral.”

Pires (2009) argumenta que basicamente todas as definições presentes na literatura sobre cadeia de suprimentos são convergentes, em termos gerais, considerado a cadeia como uma rede de entidades autônomas, ou semiautônomas, que são responsáveis pela obtenção, produção e envio de um determinado produto ou serviço ao cliente final. 


\section{2 \\ Gestão da Cadeia de Suprimentos e sua Evolução Conceitual}

O dicionário APICS (American Production and Inventory Control Society) define a Gestão da Cadeia de Suprimentos como "o desenho, planejamento, execução, controle e monitoramento de atividades de cadeia de suprimento, com o objetivo de criar valor, construindo uma estrutura competitiva, sincronizando o fornecimento com a demanda e medindo o desempenho global" (Blackstone, 2013, p.172).

Um dos conceitos mais difundidos em Gestão da Cadeia de Suprimentos é o de Lambert et. al. (1998a) que esquematizaram a gestão e integração de processos chaves, desde o usuário final até os fornecedores de última camada, do fluxo de produtos, serviços e informações que adicionam valor para todos os entes da cadeia. Para os autores, a gestão da cadeia é a forma pela qual se sustenta a geração de vantagem competitiva para os stakeholders. A figura 1 traz a visão esquemática dos autores para a Gestão da Cadeia de Suprimentos e seus processos de negócios.

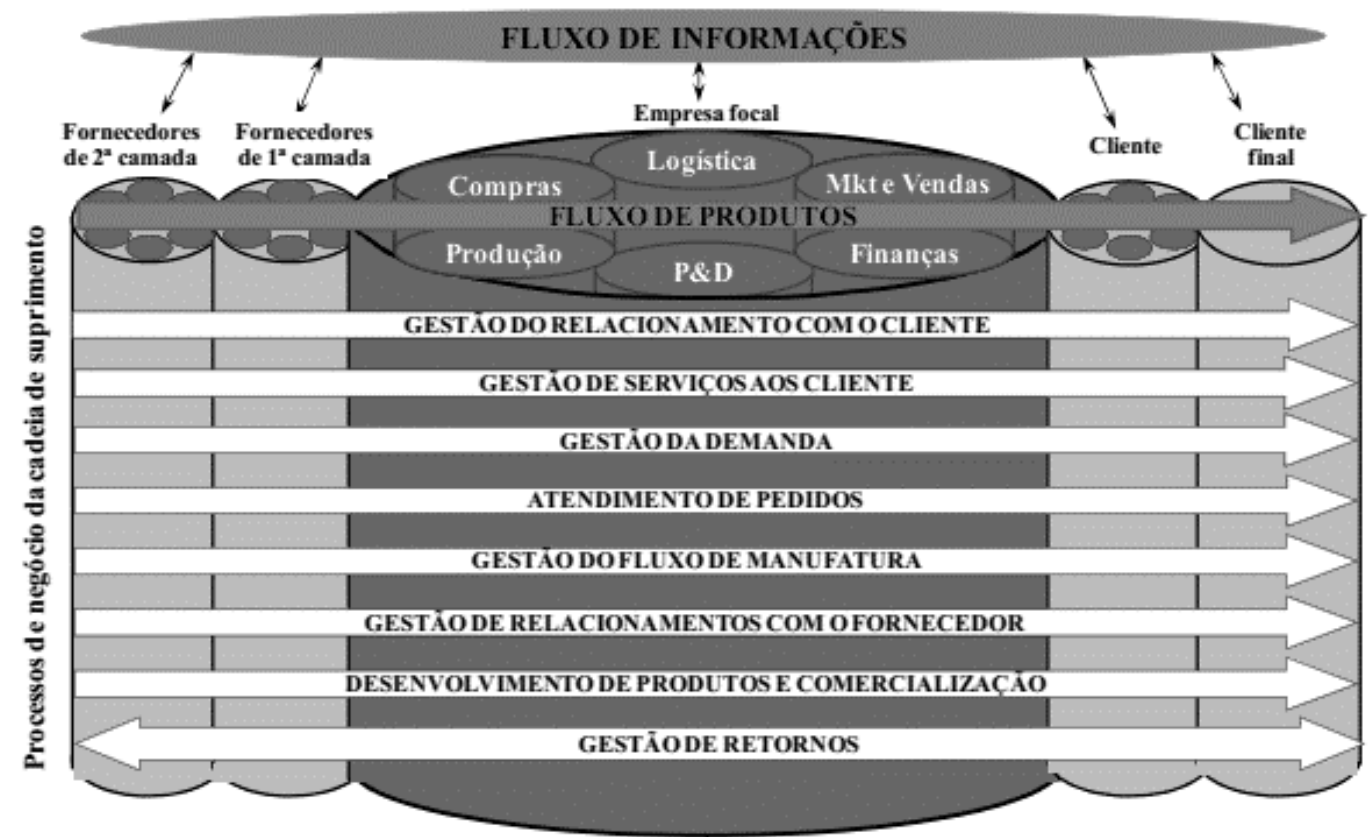

Figura 1: Gestão da Cadeia de Suprimentos e seus processos de negócios Fonte: Lambert et. al. (1998a)

Pires (2009) chama a atenção para o caráter multidisciplinar desta área de conhecimento e considera que no escopo da gestão da cadeia de suprimentos 
existem ao menos três grandes eixos de atuação: processos de negócios; tecnologia, iniciativas, práticas e sistemas; e organizações e pessoas.

Neste mesmo trabalho, Pires (2009) sintetiza diversas referências e define cadeia de suprimentos como o fluxo de materiais e informações que se dão no sentido direto e reverso da cadeia. Quanto maior for o número de entidades dentro da cadeia, maior será a complexidade na relação entre elos da cadeia e mais complexa será a gestão dos membros. A figura 2 ilustra uma cadeia de suprimentos, com ênfase na empresa foco e em seus caminhos para negociações: montante (no sentido dos fornecedores) e jusante (no sentido do cliente final).

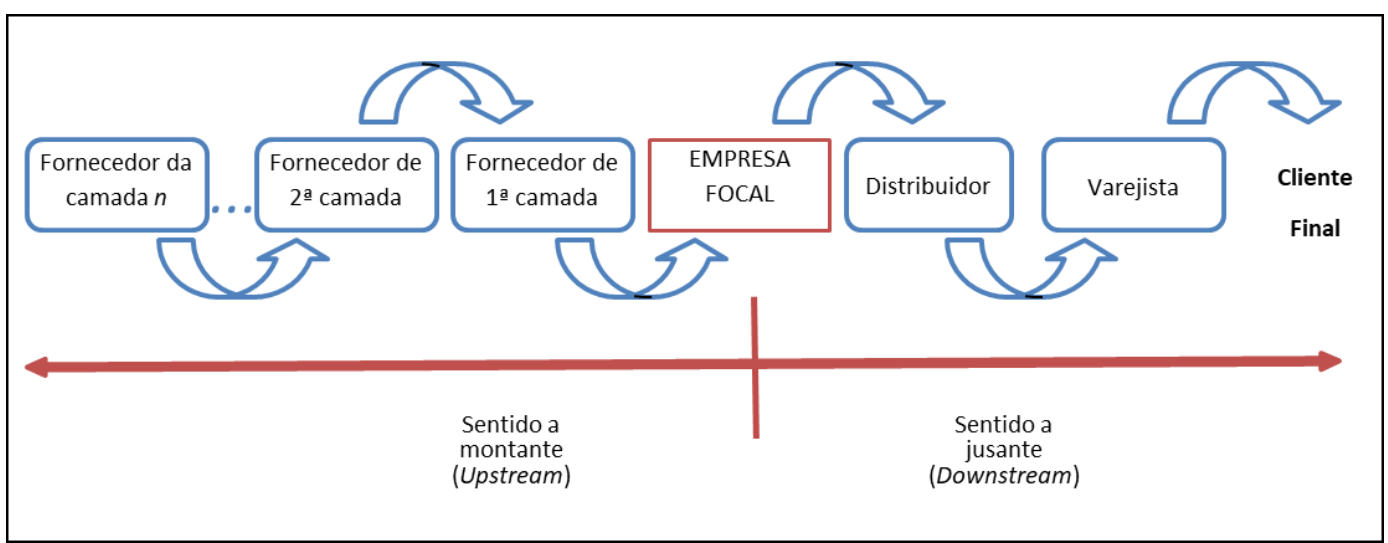

Figura 2: Representação de uma Cadeia de Suprimentos

Fonte: Adaptado de Pires (2009).

Slack et al. (2009) observam que quando se busca efetuar o controle do fluxo de informações e materiais, é possível obter benefícios em termos de velocidade, credibilidade, flexibilidade, custos e qualidade, em comparação à situação de gestão simples apenas de fluxos internos. Há benefícios estratégicos que podem ser conquistados por meio da gestão dos fluxos desde fornecedores primários até os clientes finais. A gestão das operações desta natureza é denominada de Gestão da Cadeia de Suprimentos e será discutida a seguir.

A definição de Gestão da Cadeia de Suprimentos mais recente, consolidada pelo Global Supply Chain Forum (GSCF), conceituou a GCS como: “Gestão da Cadeia de Suprimentos é a integração de processos de negócios chaves desde o usuário final até os fornecedores primários, providenciando produtos, serviços e informações que adicionem valor aos clientes”. Já no Council of Supply Chain Management Professionals - CSCMP (2017), o conceito de gestão da cadeia de suprimentos foi atualizado para: 
“[...] o planejamento e a gestão de todas as atividades envolvidas no fornecimento e aquisição, conversão, e todas as atividades da gestão logística. Importante também inclui a coordenação e colaboração com os parceiros de canal, que podem ser fornecedores, intermediários, prestadores de serviços terceirizados e clientes. Em essência, o gerenciamento da cadeia de suprimentos integra a gestão da oferta e demanda dentro e entre as empresas. ",

\section{3 \\ Maturidade em Cadeia de Suprimentos}

\subsection{1 \\ Definição de Maturidade}

O dicionário Larousse (2007) define o termo maturidade como desenvolvimento completo ou condição perfeita de algum processo ou atividade, ou ainda, os motivos pelos quais o sucesso é alcançado e os caminhos para corrigir ou prevenir problemas comuns que impediriam a melhoria dos processos. Seguindo tal premissa, McCormack et al. (2008) corrobora o conceito de maturidade organizacional como a capacidade de uma empresa para desenvolver seus processos em conformidade com metas previamente definidas no âmbito do seu planejamento estratégico e funcional.

Lahti, Shamsuzzoha e Helo em 2009, apresentam o termo maturidade como o desenvolvimento de um estágio inicial a um estágio final, dentre o qual inclui uma evolução incremental dos processos, de estágios intermediários à plena maturidade. Quando aplicado ao contexto dos negócios, atingir a maturidade significa a obtenção de um nível de excelência, com o intuito de alcançar o alinhamento das diretrizes do negócio com a dinâmica do mercado.

Muitas áreas de conhecimento utilizam o conceito de maturidade, mas ao longo da década de 90 um grande número de modelos foi desenvolvido para as mais diversas áreas e propósitos (Lockamy \& McCormack, 2004). Surgiram modelos que visam incrementar a capacidade de uma empresa em uma determinada área, desenvolver e gerenciar softwares, proporcionar a integração de equipes, prover o desenvolvimento dos recursos humanos e gerenciar processos logísticos. 


\subsection{2 Modelos de Maturidade em Processos}

Para Lockamy et. al. (2008), o conceito de maturidade de processos está embasado na ideia de que um processo possui um ciclo de vida claramente definido, gerenciado, medido e controlado ao longo do tempo. Para Bronzo e Oliveira (2006) são necessárias quatro condições para se alcançar um patamar mais alto de maturidade em algum processo empresarial, são eles: a) maior controle sobre os resultados; b) maior previsibilidade em relação aos objetivos; c) maior efetividade em relação ao alcance das metas definidas; e d) capacidade da gerência de propor novos patamares de desempenho.

Inúmeros são os desafios de um gestor contemporâneo e os modelos de maturidade atuam no sentido de auxiliá-lo na avaliação da definição de ações prioritárias para evolução da empresa, respeitando suas capabilidades, restrições de recursos e metas de desempenho (Bronzo e Oliveira, 2005).

Para Metler et al. (2010), maturidade implica na demonstração de uma habilidade específica em um progresso evolutivo, onde o objetivo dos modelos de maturidade é orientar esse processo evolutivo, incorporando formalidade às atividades de melhoria. E este conceito de modelo de maturidade é o adotado por este trabalho.

A seguir, são apresentados alguns modelos de maturidade em gestão de processos e sua evolução ao longo do tempo.

\subsubsection{1}

Modelo de Crosby

Os modelos de maturidade tiveram início com o modelo de Crosby (1979), que ficou conhecido como "grid de maturidade em gerência da qualidade" e tinha função de criar uma metodologia de avaliação da maturidade na gestão de processos de qualidade. O grid de Crosby referencia cinco estágios: Incerteza, Despertar, Esclarecimento, Sabedoria e Certeza. Os níveis atravessam seis categorias gerenciais: Compreensão e atitude da gerência; Status de qualidade da empresa; Sistemática para a resolução de problemas; Custo da qualidade como percentual das vendas; Medidas da melhoria da qualidade; e Sumário de possibilidades da companhia no setor da qualidade (Crosby, 1979). 
Os cinco níveis de maturidade propostos no modelo de Crosby (1979), evidenciam, como na totalidade dos modelos de maturidade, a ideia de progressão da capacitação empresarial na gestão de seus processos e estão melhores evidenciados na tabela 2 a seguir:

Tabela 2: Grid de maturidade

\begin{tabular}{|c|c|c|}
\hline No & Nível & Descrição \\
\hline 1 & Incerteza & $\begin{array}{l}\text { Falta de compreensão e apreço pelo problema de gestão em } \\
\text { geral. }\end{array}$ \\
\hline 2 & Despertar & $\begin{array}{l}\text { Reconhecer o problema e o valor do processo para os } \\
\text { negócios. }\end{array}$ \\
\hline 3 & Esclarecimento & $\begin{array}{l}\text { Inicia melhorias e aprende mais sobre novas ou existentes } \\
\text { formas de promover avanços adicionais aos esforços de } \\
\text { trabalho. }\end{array}$ \\
\hline 4 & Sabedoria & $\begin{array}{l}\text { Participação pessoal nos processos e nas melhorias. Valoriza } \\
\text { continuamente o aprimoramento do processo. }\end{array}$ \\
\hline 5 & Certeza & $\begin{array}{l}\text { Considera a gerência do processo como sendo uma parte } \\
\text { essencial do sistema organizacional. }\end{array}$ \\
\hline
\end{tabular}

Fonte: Crosby (1979).

O modelo de Crosby se tornou referência para diversos modelos de maturidade, por seu caráter genérico e estrutura intrínseca de evolução. Um dos mais difundido deles foi o Capability Maturity Model (CMM), desenvolvido e publicado pelo Instituto de Engenharia de Software (SEI) da universidade americana Carnegie Mellon.

\subsubsection{2 \\ Modelo do SEI-CMM}

Entre 1987 e 1997, o grupo Software Engineering Institute (SEI), ligado à universidade de Carnegeire Mellon, Pittsburgh, desenvolveu um estudo que resultou em um modelo de maturidade especializado para a indústria de software. O modelo surgiu em decorrência da necessidade de sistematizar os processos críticos de concepção e desenvolvimento de softwares. O modelo foi denominado Capability Maturity Model (SEI-CMM), e sua versão 1.1 foi lançada em 2001. Para o modelo, à medida que os processos críticos dos sistemas tornavam-se mais complexos e integrados, alcançava-se em estágios de desenvolvimento mais avançados. (SEI, 2001)

O SEI-CMM segue a lógica do modelo de Crosby, com uma estrutura de cinco níveis que estratificam a posição ocupada pela empresa desenvolvedora de 
softwares com relação à maturidade de seus processos gerenciais. A figura 3 ilustra o conteúdo dos cinco níveis propostos pelo SEI-CMM. (SEI, 2001)

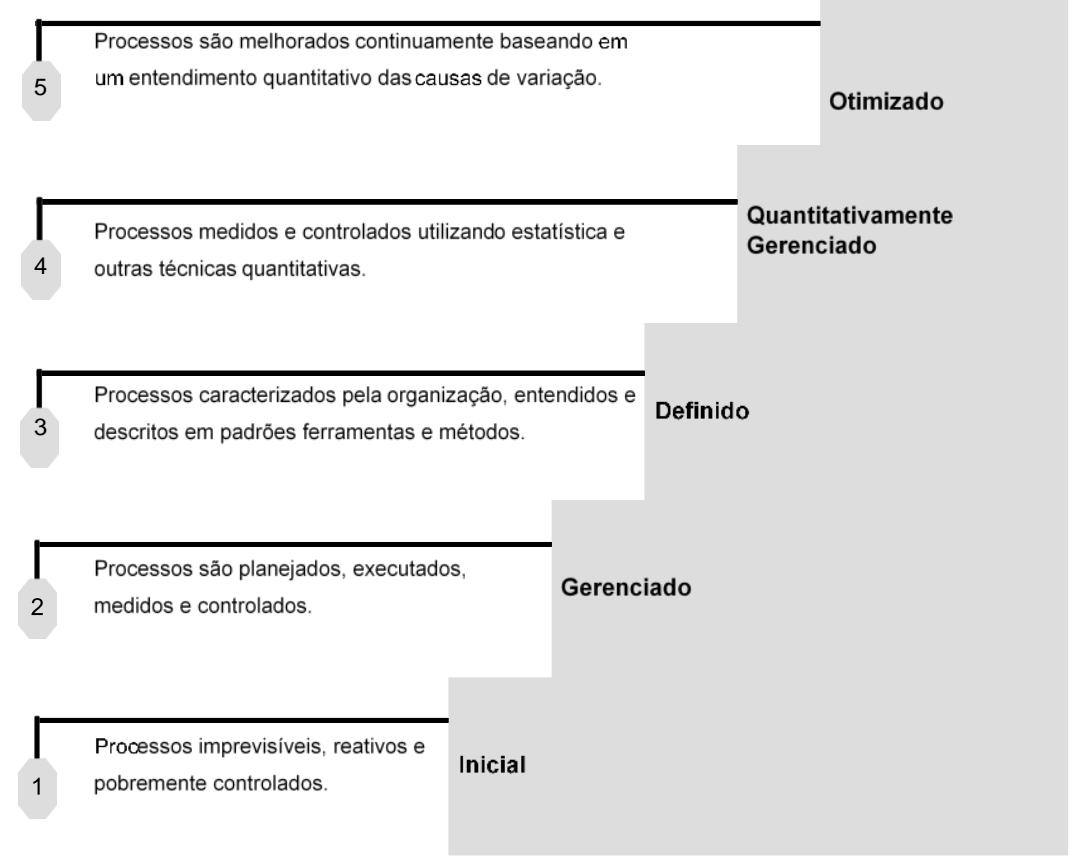

Figura 3: Níveis CMM

Fonte: SEI (2000).

Após o SEI-CMM, um grande número de modelos foram lançados em gerência de processos e de projetos. Os modelos, em sua totalidade, sugerem um caminho lógico de desenvolvimento progressivo na capacitação de gerenciamento de processos. Importante salientar que para os modelos, o relevante não é apenas definir o patamar de maturidade que se encontra a empresa, mas sim as ações que irão assegurar e manter sua evolução ao longo do tempo.

\subsubsection{3}

\section{Modelo do PMI (Project Management Institute)}

Outro relevante de modelos de maturidade foi o desenvolvido pelo Project Management Institute (PMI), no ano de 2003, o Organizational Project Management Maturity Model (OPM3) que permite as organizações mensurarem seus níveis de desempenho em gerenciamento de projetos, orientando suas capacidades para implementação de estratégias com consistência e previsibilidade (PMI, 2003). 
O OPM3 é adaptativo, pode ser aplicado em várias industrias, e se estratifica em várias dimensões e associa as melhores práticas com estágios progressivos de processos: a padronização, a medição, o controle e por fim, ao alcance da melhoria contínua. Outras dimensões tangem aos domínios da gerência de projetos, a gerência de programas e a gerência de portfólio. Por seu caráter multifacetado na avaliação da maturidade, o OPM3 produz resultados detalhados e robustos para seus processos decisórios e para planos de melhoria contínua (PMI, 2003).

\subsubsection{4}

\section{Business Process Orientation Maturity Model (BPOMM)}

O BPOMM foi construído a partir dos conceitos de maturidade do processo, Business Process Orientation (BPO) e do Capability Maturity Model (CMM) do Instituto de Engenharia de Software da Universidade Carnegie Mellon (Lockamy et al., 2008), já apresentado neste trabalho na seção 28SEI-CMM.

O BPO foi desenvolvido por McCormack, Johnson e Walker (2003), com o conceito de que uma organização deve priorizar os processos em detrimento da hierarquia, com ênfase na obtenção de resultados e na satisfação dos clientes. O conceito de BPO indica que ao adotar uma visão estratégica de seus processos, uma empresa pode obter um incremento no seu desempenho global (Lockamy \& McCormack, 2004).

O BPOMM é formado com base em cinco níveis de maturidade, conforme ilustrado na figura 4 Os autores são categóricos afirmando que cada nível de maturidade sustenta o alcance do nível seguinte, sendo assim, a tentativa das organizações de pular os níveis de maturidade é improdutiva e acrescentam que para as empresas constituírem uma cultura de excelência em processos devem avançar através dos níveis evolutivos (Lockamy \& McCormack, 2004). 


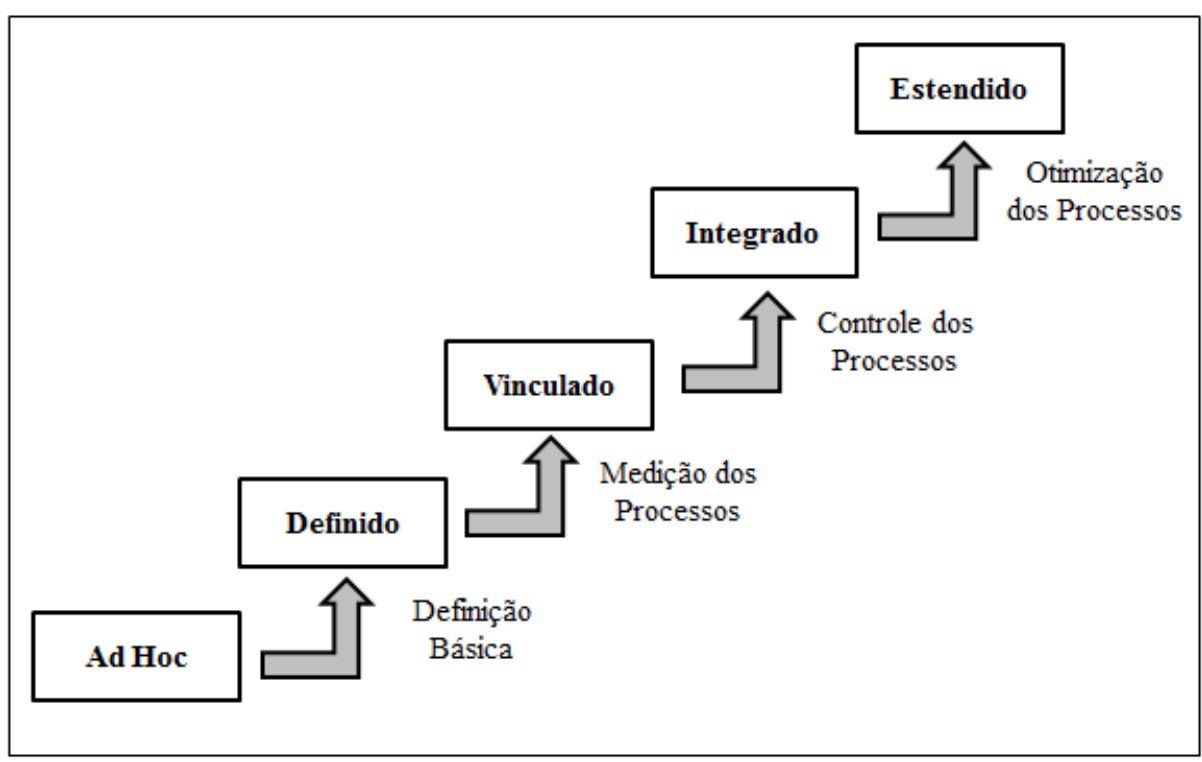

Figura 4: Etapas de Desenvolvimento do Processo de Maturidade Fonte: Lockamy \& McCormack (2004).

\subsubsection{5 \\ Modelo de Referência para Operações em cadeias de suprimentos (SCOR)}

O Supply-Chain Council, fundado pelas empresas Pittiglio, Robin, Todd \& McGrath Management Consultants (PRTM) e a AMR Research, reuniu, em 1996 desenvolveram um modelo de referência para a gestão do desempenho de cadeias de suprimento, com a colaboração de 66 empresas. Essa iniciativa deu origem ao modelo SCOR. Hoje, o modelo está na sua $11^{\mathrm{a}}$ versão e é mantido pela APICS (SCC, 2012; Prakash et al., 2013).

O SCOR é definido como um modelo de referência, que se define como um framework apresentado de forma estruturada que é utilizado a ser utilizado por gestores de uma organização, que agrega práticas, recomendações, processos, arquiteturas organizacionais, sistemas e entre outros (Van Der Aalst, et al. 2005). Já para Becker et al. 2007, se define como uma representação genérica, devendo servir apenas como ponto de partida para a elaboração de soluções específicas e adaptadas ao contexto organizacional.

O modelo SCOR é baseado na estratégia de operações e considera as seguintes atividades relacionadas ao fluxo de produtos (entrada/saída): planejamento, fornecimento, fabricação, entrega e retorno. Em relação a sua estrutura o SCOR é composto por processos, métricas de desempenho, práticas e pessoas. 
O modelo permite a descrição de padrões de gerenciamento de processos, a associação entre processos padrões, a utilização de métricas de desempenho e de práticas de gerenciamento para melhorar o desempenho e, finalmente, o alinhamento entre características e funcionalidades. Contem quatro níveis distintos, conforme pode ser observado na figura 5: (SCC, 2012).

○ Nível 1 - define o escopo e o conteúdo do SCOR;

○ Nível 2 - define a categoria de processos que são componentes em potencial de uma cadeia de suprimentos;

- No nível 3 - define os elementos de processos necessários para planejar com sucesso a cadeia de suprimentos e estabelecer objetivos de melhoria;

○ Nível 4 - foca na implementação, empreendendo ações específicas para a melhoria da cadeia e definindo práticas para obtenção de vantagem competitiva. (Prakash et al., 2013).

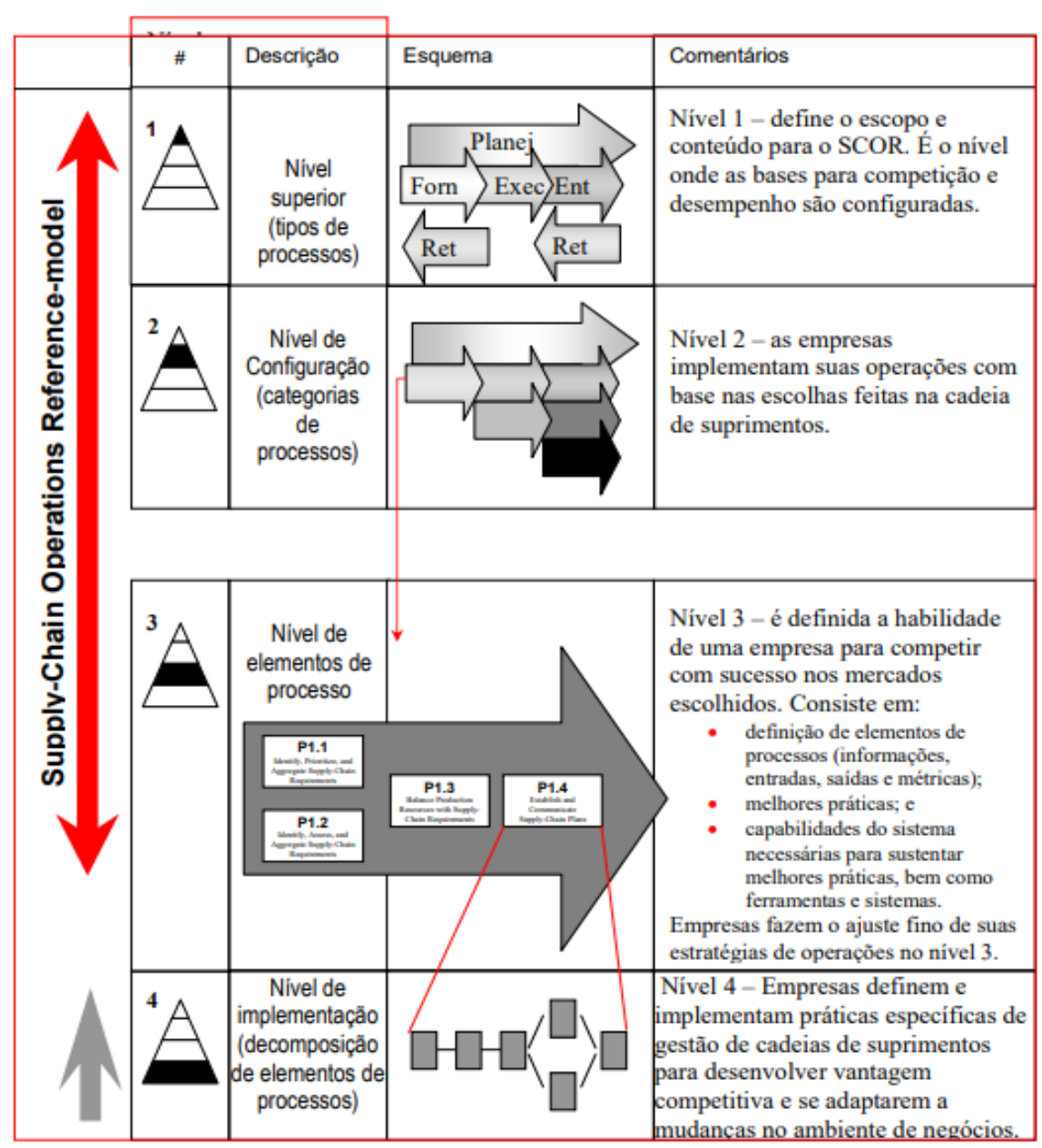

Figura 5: Modelo hierárquico em níveis do SCOR Fonte: Oliveira, 2009 
O SCOR integra os conceitos de reengenharia de processo de negócio, benchmarking e análise de melhores práticas. Focaliza a eficiência transacional, ao invés das relações com clientes e fornecedores. Mas o modelo SCOR está prioritariamente orientado para os processos, e não para as funções organizacionais. O modelo foca a atividade envolvida, e não o grupo profissional ou o elemento organizacional que executará tal atividade. (Lambert et. al., 2005). Lambert et al. (2005) afirmam que diversos pesquisadores ressaltam a necessidade de se utilizar o SCOR em conjunto com outros modelos objetivando obter um entendimento mais abrangente dos fenômenos a serem gerenciados no contexto de suprimentos.

\subsubsection{6}

\section{Outros Modelos de Maturidade em Processos}

Outros modelos de maturidade com foco em gestão de processos foram lançados ao longo dos anos, mas como foco deste trabalho se restringe aos modelos de maturidade aplicados à cadeia de suprimentos, os mesmos foram citados, mas não detalhados nesta revisão bibliográfica.

Barra e Ladeira (2017) listaram em seu estudo os 10 modelos de maturidade contemporâneos em gestão de processos mais relevantes. A tabela 3 descreve os modelos de maturidade estudados pelos autores, destacando o primeiro e último níveis e escopo.

Tabela 3: Modelos de Maturidade em Processos

\begin{tabular}{llll}
$\begin{array}{l}\text { Modelo de } \\
\text { maturidade }\end{array}$ & Nível inicial de maturidade & Último nível de maturidade & Escopo \\
\hline $\begin{array}{l}\text { BPM Maturity } \\
\text { Model(Rosemann \& }\end{array}$ & $\begin{array}{l}\text { Inicial (1): Premissas BPM não } \\
\text { existem ou são } \\
\text { desestruturadas e não } \\
\text { coordenadas }\end{array}$ & $\begin{array}{l}\text { Aprimorado (5): BPM é central } \\
\text { na gestão estratégica e } \\
\text { operacional }\end{array}$ & $\begin{array}{l}\text { Descritivo e } \\
\text { prescritivo }\end{array}$ \\
$\begin{array}{l}\text { Process Performance } \\
\text { Index (Rummler \& }\end{array}$ & $\begin{array}{l}\text { Iniciação de gestão de } \\
\text { processos (1): Há interesse em } \\
\text { Brache, 1990) }\end{array}$ & $\begin{array}{l}\text { Domínio de gestão de } \\
\text { processos (3): BPM é um modo } \\
\text { de ser da organização }\end{array}$ & Descritivo \\
$\begin{array}{l}\text { BPR Maturity } \\
\text { Model (Maull, }\end{array}$ & $\begin{array}{l}\text { Grupo 1 (1): fase inicial de } \\
\text { Tranfield, \& Maull, } \\
\text { projeto BPR }\end{array}$ & $\begin{array}{l}\text { Grupo 5 (5): Projetos BPR } \\
\text { redesenham o negócio } \\
\text { completamente }\end{array}$ & Descritivo \\
$\begin{array}{l}\text { Business Process } \\
\begin{array}{l}\text { Maturity Model } \\
\text { (Fisher, 2004) }\end{array}\end{array}$ & $\begin{array}{l}\text { Silos (1): Grupos aprimorar } \\
\text { apenas a sua própria área }\end{array}$ & $\begin{array}{l}\text { Rede de operação inteligente } \\
\text { (5): Aprimoramento atravessa } \\
\text { a cadeia de valor }\end{array}$ & $\begin{array}{l}\text { Descritivo e } \\
\text { prescritivo }\end{array}$
\end{tabular}




\begin{tabular}{|c|c|c|c|}
\hline $\begin{array}{l}\text { Modelo de } \\
\text { maturidade }\end{array}$ & Nível inicial de maturidade & Último nível de maturidade & Escopo \\
\hline $\begin{array}{l}\text { Process } \\
\text { Management } \\
\text { Maturity } \\
\text { Assessement } \\
\text { (Rodholff, 2009) }\end{array}$ & $\begin{array}{l}\text { Inicial (1): Processos não são } \\
\text { definidos }\end{array}$ & $\begin{array}{l}\text { Aprimorado (5): Processos são } \\
\text { analisados, aprimorados e } \\
\text { ajustados às mudanças do } \\
\text { mercado }\end{array}$ & $\begin{array}{l}\text { Descritivo e } \\
\text { prescritivo }\end{array}$ \\
\hline $\begin{array}{l}\text { BPO Maturity } \\
\text { Model(McCormack, } \\
\text { 2007; Mccormack et } \\
\text { al., 2009) }\end{array}$ & $\begin{array}{l}\text { Ad hoc (1): Medições dos } \\
\text { processos ocorrem em âmbito } \\
\text { funcional }\end{array}$ & $\begin{array}{l}\text { Integrado (4): Os parceiros } \\
\text { cooperam no nível de } \\
\text { processo. As estruturas e } \\
\text { funções são baseadas no SCM. } \\
\text { Os sistemas de medição são } \\
\text { implantados }\end{array}$ & $\begin{array}{l}\text { Descritivo e } \\
\text { prescritivo }\end{array}$ \\
\hline $\begin{array}{l}\text { Process and } \\
\text { Enterprise Maturity } \\
\text { Model(Hammer, } \\
\text { 2007) }\end{array}$ & $\begin{array}{l}\text { P-1 E-1 (1): Processos não são } \\
\text { desenhados numa base ponta a } \\
\text { ponta }\end{array}$ & $\begin{array}{l}\text { P-4 E-4 (5): Processos } \\
\text { desenhados para adequação } \\
\text { com clientes e fornecedores }\end{array}$ & Descritivo \\
\hline $\begin{array}{l}\text { Process Maturity } \\
\text { Ladder (Harmon, } \\
\text { 2004) }\end{array}$ & $\begin{array}{l}\text { Inicial (1): Processos não são } \\
\text { definidos }\end{array}$ & $\begin{array}{l}\text { Aprimorado (5): Processos são } \\
\text { medidos e gerenciados }\end{array}$ & Descritivo \\
\hline $\begin{array}{l}\text { Business Process } \\
\text { Maturity Model } \\
\text { (Weber et al., 2008) }\end{array}$ & $\begin{array}{l}\text { Inicial (1): Gestão do tipo } \\
\text { "apagar incêndios" }\end{array}$ & $\begin{array}{l}\text { Inovador (5): "gestão da } \\
\text { mudança" }\end{array}$ & $\begin{array}{l}\text { Descritivo e } \\
\text { prescritivo }\end{array}$ \\
\hline $\begin{array}{l}\text { Business Process } \\
\text { Maturity Model } \\
\text { (Lee et al., 2007) }\end{array}$ & $\begin{array}{l}\text { Inicial (1): Processos são } \\
\text { gerenciados de forma ad hoc }\end{array}$ & $\begin{array}{l}\text { Aprimorado (5): Processos são } \\
\text { monitorados e controlados de } \\
\text { forma proativa }\end{array}$ & $\begin{array}{l}\text { Descritivo e } \\
\text { prescritivo }\end{array}$ \\
\hline
\end{tabular}

Fonte: Barra e Ladeira (2017)

Barra e Ladeira (2017) identificam que os modelos de maturidade em cadeias de suprimentos, tem como grande inspiração os modelos de maturidade em processos.

\section{4 \\ Modelos de Maturidade em Gestão de Cadeia de Suprimentos}

Segundo Oliveira (2006), o uso do conceito de maturidade e a aplicação de modelos de referência em Cadeia de Suprimentos são relativamente recentes no Brasil e no mundo, menor que 30 anos. No contexto da gestão da cadeia de suprimentos, a maturidade se baseia no conceito de maturidade na gestão, nos processos e no ciclo de vida, onde os estágios estão claramente definidos e podem ser geridos, mensurados e controlados.

Com isso, níveis mais elevados de maturidade propiciam melhor controle dos resultados. Uma cadeia mais madura também gera uma maior eficácia no 
alcance das metas de desempenho e na capacidade de estabelecê-las. (Lockamy \& McCormack, 2004). Esse pensamento corrobora com Lahti et. al. (2009) que comprovaram em seus estudos que com uma cadeia de suprimentos madura, as empresas obtêm um melhor posicionamento frente às suas concorrentes, respondendo melhor as mudanças típicas de mercados cada vez mais globais. Os principais modelos revistos neste trabalho são apresentados a seguir.

\subsection{1 \\ Modelo de Stevens}

Stevens, em 1989, formulou um dos primeiros modelos com a abordagem voltada para maturidade em cadeia de suprimentos. O modelo pressupõe uma evolução em quatro estágios e propõe medir o nível de integração da cadeia de suprimentos. O nível 1 parte da ausência de integração intrafirma até a completa integração da cadeia.

Os quatro estágios de maturidade do modelo são: (1) linha base; (2) integração funcional; (3) integração interna; e (4) integração externa, onde os estágios do processo logístico partem de um ambiente primário, em que as atividades e os objetivos das diversas áreas funcionais não estão integrados, e alcançam o maior nível de maturidade quando os parceiros da cadeia de valor compartilham informações estratégicas e desenvolvem parcerias de longo prazo objetivando gerar valor para o cliente. (Stevens, 1989). O processo evolutivo do modelo desenvolvido por Stevens é ilustrado na figura 6.

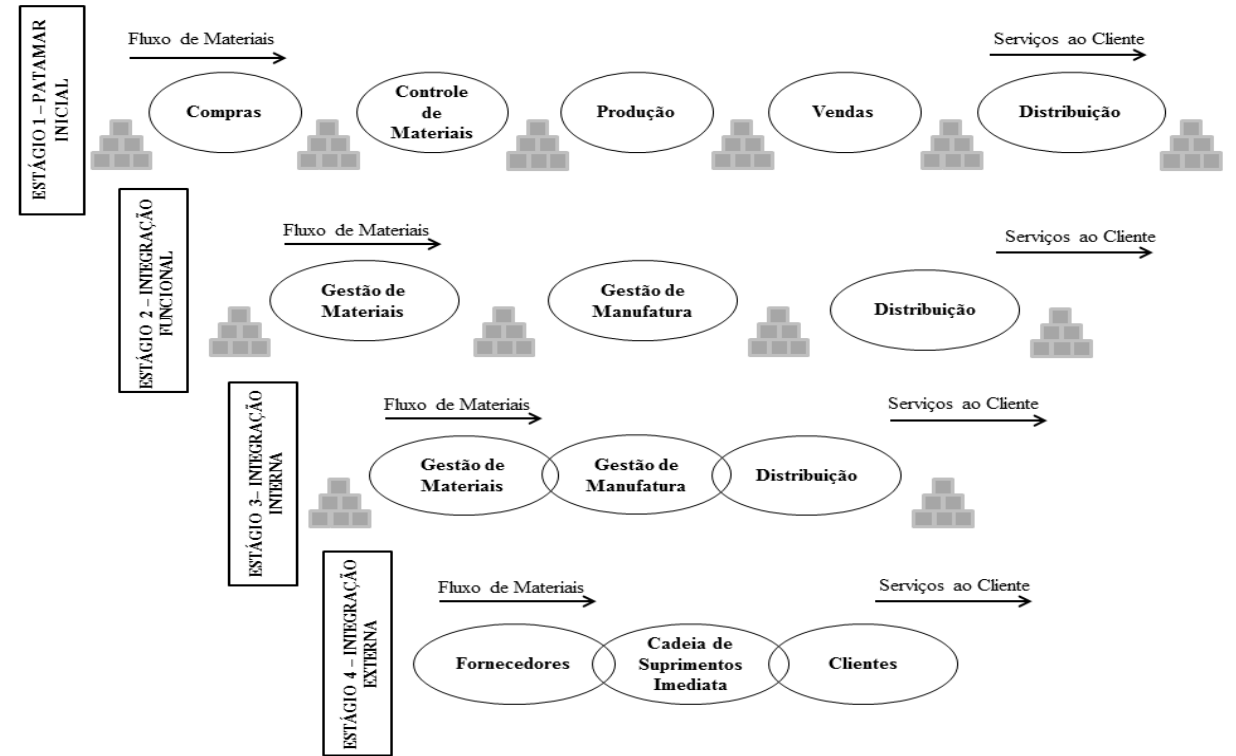

Figura 6: Alcançando uma Cadeia de Suprimentos Integrada Fonte: Stevens (1989). 
Stevens (1989) sustenta que uma cadeia de suprimentos consegue maior vantagem competitiva ao passo que há um aumento no seu nível de integração, onde essa integração é conduzida pelas necessidades do negócio e demandas do mercado.

Os estágios do modelo de Stevens e suas principais características estão sintetizados na tabela 4.

Tabela 4: Etapas de Integração da Cadeia de Suprimentos

\begin{tabular}{|c|c|c|}
\hline NÍVEL & & DESCRIÇÃO \\
\hline 1 & $\begin{array}{l}\text { PATAMAR } \\
\text { INICIAL }\end{array}$ & $\begin{array}{l}\text { - Acúmulo de estoques em decorrência da ausência de sincronização dos entes da } \\
\text { cadeia e atividades; } \\
\text { - Atividades da cadeia de suprimentos são executadas de modo isolado; } \\
\text { - Procedimentos e sistemas de controle não são integrados e incompatíveis; } \\
\text { - Há uma segregação funcional (departamentos); } \\
\text { - Resolução reativa aos problemas; } \\
\text { - Ausência de planejamento de longo prazo; } \\
\text { - Grande número de ineficiências ao longo da cadeia; } \\
\text { - Cadeia de suprimentos é vulnerável aos efeitos de alterações nos padrões de } \\
\text { demanda e suprimentos. }\end{array}$ \\
\hline 2 & $\begin{array}{l}\text { INTEGRAÇÃO } \\
\text { FUNCIONAL }\end{array}$ & $\begin{array}{l}\text { - Foco no fluxo interno de materiais; } \\
\text { - Execução de avaliações das funções internas, tais como produção e gestão de } \\
\text { materiais; } \\
\text { - Esforço voltado para redução de custos em detrimento da melhoria do } \\
\text { desempenho; } \\
\text { - Reatividade nos serviços aos clientes; } \\
\text { - Existência de estoques de segurança; } \\
\text { - Pequena visibilidade da demanda, planejamento inadequado e, } \\
\text { consequentemente, baixo desempenho. }\end{array}$ \\
\hline 3 & $\begin{array}{l}\text { INTEGRAÇÃO } \\
\text { INTERNA }\end{array}$ & $\begin{array}{l}\text { - Os sistemas de planejamento e controle são largamente utilizados; } \\
\text { - Presença forte de tecnologia no compartilhamento de dados com os clientes; } \\
\text { - Integração interna com visibilidade total da cadeia de suprimentos, desde } \\
\text { compras até distribuição; } \\
\text { - Presença das técnicas de Just in Time; } \\
\text { - O planejamento é de médio prazo e o foco está mais no nível tático do que no } \\
\text { nível estratégico; } \\
\text { - Os serviços aos clientes ainda se dão de forma reativa. }\end{array}$ \\
\hline 4 & $\begin{array}{l}\text { INTEGRAÇÃO } \\
\text { EXTERNA }\end{array}$ & $\begin{array}{l}\text { - A visão da cadeia de suprimentos é estendida além das fronteiras } \\
\text { organizacionais, incluindo fornecedores e clientes; } \\
\text { - O relacionamento com os fornecedores passa a ser cooperativo, envolvendo-o } \\
\text { desde o início do desenvolvimento do produto; } \\
\text { - Centralidade da operação nos serviços para o cliente, procurando compreender } \\
\text { seus produtos, sua cultura, seu mercado e sua estrutura; } \\
\text { - O planejamento logístico é de longo prazo; } \\
\text { - As informações estratégicas, como: especificações de produtos, processos e } \\
\text { tecnologias são compartilhadas com os fornecedores. }\end{array}$ \\
\hline
\end{tabular}

Fonte: Adaptado de Stevens (1989). 


\section{4 .2 \\ Modelo de Christopher}

O modelo de Christopher foi desenvolvido em 1997 como um amadurecimento do modelo de Stevens (Christopher, 2011). O modelo se baseia no conceito de logística integrada, que segundo Lambert et. al. (1998b), objetiva administrar as diversas atividades logísticas como um sistema integrado e empresas que não adotam esta abordagem têm seus sistemas e atividades descoordenados e com todas as funções individuais isoladas, por exemplo, com metas próprias de orçamentos e medidas de desempenho desintegrados (Lamber e Stock, 1998).

Para o autor, o conceito de logística integrada se baseia em dois componentes centrais: nível de serviço e custo total. O modelo de Christopher defende que para uma organização se desenvolver e atingir maturidade, ela deve sair da posição onde áreas funcionais operam isoladamente para o nível em que cada agente no canal possua o entendimento dos relacionamentos necessários para a geração de valor de seus clientes, agindo de forma colaborativa, associada aos objetivos globais da cadeia (Christopher, 2011).

Nessa perspectiva, Christopher (2007) desenvolveu um modelo de maturidade adaptado de Stevens (1989) para a logística integrada sob quatro estágios evolutivos e consecutivos, conforme descrito em tabela 5.

Tabela 5: Estágio de maturidade da Cadeia de Suprimentos

\begin{tabular}{|c|c|c|}
\hline ESTÁGIO & & CARACTERÍSTICAS \\
\hline Estágio 1 & $\begin{array}{l}\text { Informal ou } \\
\text { Básico }\end{array}$ & $\begin{array}{l}\text { - Mecanicismo funcional; } \\
\text { - Cada função da empresa age em isolamento em relação às outras; } \\
\text { - Predominância dos silos funcionais. }\end{array}$ \\
\hline Estágio 2 & $\begin{array}{l}\text { Integração } \\
\text { Funcional }\end{array}$ & $\begin{array}{l}\text { - Organizações reconheceram a necessidade de integração funcional; } \\
\text { - Promovem início de relação entre as funções centrais e as áreas de apoio; }\end{array}$ \\
\hline Estágio 3 & $\begin{array}{l}\text { Integração } \\
\text { Interna }\end{array}$ & $\begin{array}{l}\text { - Estabelecimento e implementação de estrutura de planejamento } \\
\text { integrado entre as funções; } \\
\text { - Extinção dos silos funcionais. }\end{array}$ \\
\hline Estágio 4 & Externa & $\begin{array}{l}\text { - Organização tem a visão de si como parte de um fluxo físico e de } \\
\text { informações globais; } \\
\text { - Agrega valor aos seus produtos na visão do cliente final; } \\
\text { - Maximiza o lucro da cadeia de suprimentos como um todo. }\end{array}$ \\
\hline
\end{tabular}

Fonte: Adaptado de Christopher (2007). 


\subsection{3 \\ Modelo de Ayers \& Malmberg}

Ayers \& Malmberg em 2002, desenvolveram um modelo composto por cinco estágios de evolução em maturidade na gestão da cadeia de suprimentos. Segundo os autores, o alcance de estágios superiores requer novas competências, a partir do estágio atual em que a organização está posicionada em relação às suas práticas de gestão da cadeia de suprimentos. A tabela 6 apresenta os estágios de maturidade desse modelo e as suas respectivas características.

Tabela 6: Estágios de Maturidade do Modelo de Ayers \& Malmberg (2002)

\begin{tabular}{|c|c|c|}
\hline NÍVEL & & CARACTERÍSTICAS \\
\hline 1 & DISFUNCIONAL & $\begin{array}{l}\text { - O conceito de cadeia de suprimentos não é utilizado pelos gestores } \\
\text { - Inexistência de planejamento estratégico; } \\
\text { - A maioria dos processos não são contínuos; } \\
\text { - A comunicação e cooperação entre os parceiros da cadeia é quase } \\
\text { inexistente; }\end{array}$ \\
\hline 2 & INFRAESTRUTURA & $\begin{array}{l}\text { - A equipe de gestão inicia a visão em termos da cadeia de suprimentos; } \\
\text { - Esforços entre os parceiros são não cooperativos; } \\
\text { - Foco funcional com nível de implantação departamental; } \\
\text { - Habilidade na implementação de alguns projetos com êxito. }\end{array}$ \\
\hline 3 & $\begin{array}{l}\text { REDUÇÃO DE } \\
\text { CUSTOS }\end{array}$ & $\begin{array}{l}\text { - A meta dos projetos consiste apenas em reduzir custos; } \\
\text { - A cadeia de suprimentos ainda é considerada como um centro de custo, } \\
\text { ao invés de um elemento estratégico essencial; } \\
\text { - Grande parte dos projetos, ainda com complexidade baixa, são } \\
\text { implementados com êxito. }\end{array}$ \\
\hline 4 & COLABORAÇÃO & $\begin{array}{l}\text { - Existência de um departamento tradicional responsável pela cadeia de } \\
\text { suprimentos; } \\
\text { - Troca de informações consistentes com alguns parceiros da cadeia; } \\
\text { - Existência de projetos operacionais entre os parceiros pertencentes à } \\
\text { mesma cadeia de suprimentos; } \\
\text { - Tem-se a padronização dos processos de gestão de projetos. }\end{array}$ \\
\hline 5 & $\begin{array}{l}\text { CONTRIBUIÇÃO } \\
\text { ESTRATÉGICA }\end{array}$ & $\begin{array}{l}\text { - Implementação de projetos estratégicos entre empresas da cadeia; } \\
\text { - Os ganhos são compartilhados entre os parceiros; } \\
\text { - Os processos de tecnologia da informação são horizontais na extensão das } \\
\text { empresas que compõem a cadeia; } \\
\text { - As competências relacionadas à gerência de projetos obtêm resultados } \\
\text { excelentes. }\end{array}$ \\
\hline
\end{tabular}

Fonte: Elaborado a partir de Ayers \& Malmberg (2002).

\subsection{4 \\ Modelo de Computer Sciences Corporation Framework - CSC}

No ano de 2003, o grupo Computer Sciences Corporation (CSC) testou o já então desenvolvido, CSC Framework, por meio de uma pesquisa envolvendo 142 representantes e gestores na área de cadeia de suprimentos, dentre esses: especialistas oriundos de empresas de consultoria, consultores independentes, 
gestores advindos de unidades estratégicas de seus negócios. A amostragem foi selecionada entre leitores da Supply Chain Management Review e clientes da CSC. (Poirier et. al., 2009).

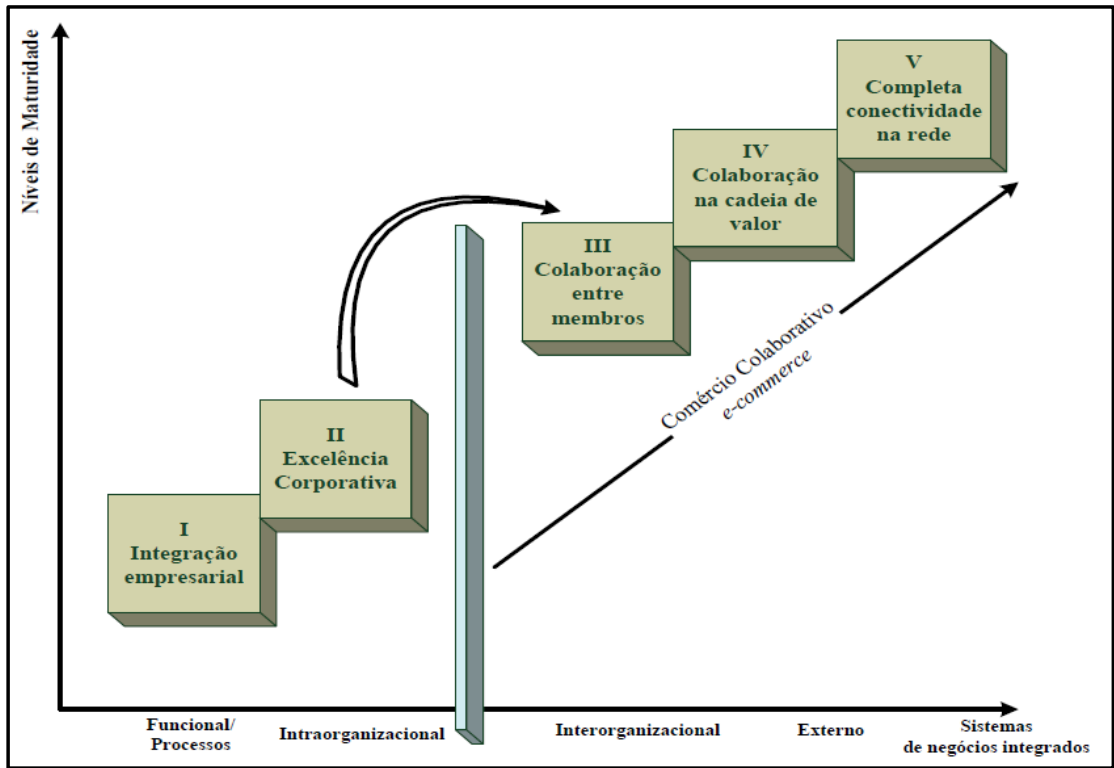

Figura 7: Representação do modelo Supply Chain Maturity Model Fonte: Poirier et. al. (2009)

O CSC desenvolveu um modelo de maturidade que agrega cinco estágios evolutivos dentro da cadeia de suprimentos. O objetivo principal do trabalho desenvolvido pelo grupo foi mapear o estágio de desenvolvimento da função logística nas organizações que fizeram parte da pesquisa, tendo em conta os níveis de excelência. Como resultado do trabalho o grupo criou um esquema evolutivo, ilustrado na figura 7. Uma síntese das características de cada nível do modelo segue apresentada na tabela 7 (Poirier e Quinn, 2004).

Tabela 7: Estágios de Evolução CSC Framework

$\begin{array}{ll}\text { ESTÁGIO } & \text { CARACTERÍSTICAS } \\ & \text { • A empresa prioriza a melhoria de seus processos funcionais; } \\ & \text { - Esforços são direcionados para o ambiente interno e orientados para a } \\ & \text { integração das áreas funcionais em cada empresa que integra a cadeia de } \\ & \text { suprimentos, separadamente; } \\ & \text { - Inicia-se a utilização do modelo SCOR com ênfase nas áreas de } \\ & \text { fornecimento e de logística; }\end{array}$




\begin{tabular}{|c|c|c|}
\hline ESTÁGIO & & CARACTERÍSTICAS \\
\hline 2 & Excelência & $\begin{array}{l}\text { - A Cadeia de suprimentos ganha destaque, com foco na eficácia em } \\
\text { utilização dos ativos e na efetividade da distribuição física; } \\
\text { - O gerenciamento da demanda passa a ser um fator crítico para a cadeia; } \\
\text { - Acurácia das previsões visto como impulsor para as operações das áreas de } \\
\text { planejamento, programação e controle da produção. } \\
\text { - Gerenciamento mais estratégico da cadeia de suprimentos, com } \\
\text { segmentação da base de fornecedores e clientes imediatos. }\end{array}$ \\
\hline 3 & $\begin{array}{l}\text { Colaboração } \\
\text { entre } \\
\text { membros }\end{array}$ & $\begin{array}{l}\text { - A organização desenvolve ou redesenha seus processos } \\
\text { interorganizacionais; } \\
\text { - Inicia-se um uma rede de negócios com alguns parceiros estratégicos; } \\
\text { - São implantadas sessões S\&OP - Sales and Operation Planning } \\
\text { (Planejamento de Operações e Vendas), aproximando a área de suprimento } \\
\text { da demanda; } \\
\text { - Fortalecimento das relações com os parceiros logísticos qualificados em } \\
\text { relação às funções de transporte, logística e armazenagem; } \\
\text { - Uso de ferramentas e técnicas colaborativas, iniciativas mútuas e } \\
\text { resultados compartilhados, objetivando redução do tempo de ciclo e } \\
\text { utilização mais eficiente dos ativos. }\end{array}$ \\
\hline 4 & $\begin{array}{l}\text { Colaboração } \\
\text { na cadeia de } \\
\text { valor }\end{array}$ & $\begin{array}{l}\text { - Uso de metodologias como o ABC (Activity Based Costing) e o Balanced } \\
\text { Scorecard para transformar a cadeia de suprimentos em uma cadeia de valor } \\
\text { com os mesmos objetivos estratégicos; } \\
\text { - Compartilhamento de informações de forma eletrônica; } \\
\text { - Equipes com membros das diferentes empresas são criadas focando em } \\
\text { soluções para os clientes; } \\
\text { - Uso de tecnologias de e-commerce, garantindo o compartilhamento em } \\
\text { tempo real de todas as informações para cada nó da cadeia de valor; } \\
\text { - Utilização de modelos para colaboração nas atividades de design, } \\
\text { planejamento e reabastecimento. }\end{array}$ \\
\hline 5 & $\begin{array}{c}\text { Completa } \\
\text { conectividade } \\
\text { na rede }\end{array}$ & $\begin{array}{l}\text { - Presença de completa conectividade entre agentes ao longo de toda a } \\
\text { cadeia de suprimentos; } \\
\text { - Colaboração utilizada em todo seu potencial ao longo da rede; } \\
\text { - Uso estratégico de tecnologia da informação para conquistar posições de } \\
\text { licença no mercado competitivo; } \\
\text { - Organizações alcançam extraordinários níveis de previsão de pedidos e } \\
\text { redução do tempo de ciclo; } \\
\text { - Poucas organizações e poucos setores alcançam este estágio. }\end{array}$ \\
\hline
\end{tabular}

Fonte: Adaptado de Poirier et. al. (2009)

\subsection{5 \\ Modelo de Lockamy \& McCormack}

Em 2004, Lockamy \& McCormack (2004) propuseram o modelo baseado na evolução do Business Process Orientation Maturity Model (BPOMM), unidos aos conceitos do SCOR (Supply Chain Operations Reference) e consolidado com resultados de pesquisas que agregaram variáveis relativas a diferentes níveis de maturidade (Lockamy \& McCormack, 2004).

O modelo dos autores relaciona os cinco estágios de maturidade do BPOMM com quatro processos básicos do modelo SCOR (Supply Chain Operations 
Reference) que são Planejamento, Suprimento, Fabricação/Transformação e Entrega. Os estágios progressivos mostram a direção para uma gestão da cadeia de suprimentos eficaz e madura em processo e cada nível contém características associadas com a maturidade de cada grupo de processo (Lockamy \& McCormack, 2004).

O Modelo de Lockamy \& McCormack (2004) possibilita que as empresas identifiquem quantitativamente a sua posição dentro de uma estrutura de maturidade, assim como as melhores práticas disponíveis na indústria, com foco em quatro processos básicos do modelo SCOR.

A seguir, a tabela 8 com uma breve descrição e os principais pontos sobre cada nível do modelo de maturidade de Lockamy \& McCormack (2004):

Tabela 8: Estágios de Maturidade do Modelo de Lockamy \& McCormack (2004).

\begin{tabular}{|c|c|c|}
\hline NÍVEL & & DESCRIÇÃO \\
\hline 1 & Ad Hoc & $\begin{array}{l}\text { - Caracterizado pelo fato da cadeia de suprimentos e suas práticas serem } \\
\text { desestruturadas e indefinidas e não existirem métricas para os processos; } \\
\text { - Desempenho do processo é imprevisível, os custos da GCS são altos e a } \\
\text { satisfação dos clientes é baixa; } \\
\text { - Estruturas organizacionais não são baseadas em processos horizontais da } \\
\text { cadeia de suprimentos; } \\
\text { - As metas, raramente definidas, na maioria dos casos não são alcançadas e a } \\
\text { cooperação funcional é baixa. }\end{array}$ \\
\hline 2 & Definido & $\begin{array}{l}\text { - Grandes esforços na tentativa de superar as barreiras funcionais; } \\
\text { - Processos básicos de gestão de cadeia de suprimentos são definidos e } \\
\text { documentados, mas a estrutura organizacional não é alterada profundamente } \\
\text { e consequentemente os custos permanecem elevados; } \\
\text { - Metas passam a ser definidas, mas ainda são imprecisas; } \\
\text { - Há uma pequena melhora na satisfação do cliente. }\end{array}$ \\
\hline 3 & Vinculado & $\begin{array}{l}\text { - Redução significativa dos custos da gestão de cadeia de suprimentos; } \\
\text { - Existência de cooperação entre funções intraorganizacionais e equipes } \\
\text { compartilham medidas e objetivos comuns à gestão de cadeia; } \\
\text { - Melhoria expressiva no uso estratégico da gestão de cadeia de suprimentos, } \\
\text { com cooperação e colaboração entre os parceiros; } \\
\text { - Previsibilidade do desempenho se eleva e esforços de melhoria contínua se } \\
\text { concretizam, as metas são alcançadas mais frequentemente; } \\
\text { - Os clientes são incluídos nos esforços de melhoria dos processos resultando } \\
\text { numa melhora da satisfação do cliente. }\end{array}$ \\
\hline 4 & Integrado & $\begin{array}{l}\text { - Estruturas organizacionais e métricas de desempenho baseados nos } \\
\text { princípios da gestão de cadeia de suprimentos; } \\
\text { - Existência de cooperação estratégica entre a empresa, fornecedores e } \\
\text { clientes no nível dos processos; } \\
\text { - Redução drástica nos custos; } \\
\text { - Práticas cooperativas avançadas na gestão de cadeia de suprimentos, tal } \\
\text { como o planejamento colaborativo com clientes e fornecedores; } \\
\text { - Desempenho em processos torna-se muito mais previsível e as metas são } \\
\text { obtidas frequentemente; } \\
\text { - Satisfação do cliente e cooperação entre a rede tornam-se vantagens } \\
\text { competitivas. }\end{array}$ \\
\hline
\end{tabular}




$\begin{array}{ll}\text { NÍVEL } & \text { DESCRIÇÃo } \\ & \text { - Cultura horizontal e colaborativa, com foco decididamente no cliente; } \\ & \text { - Cadeias de suprimentos multi-organizacionais. Competição acontece entre } \\ & \text { cadeias de suprimentos e não apenas entre empresas; } \\ & \text { - Desempenho de processos e a confiabilidade do sistema estendido são } \\ & \text { mensurados. } \\ & \text { - Confiança e interdependência formam a base de sustentação da cadeia de } \\ & \text { suprimentos estendida; } \\ & \text { - Investimentos para melhoria do sistema são compartilhados entre os } \\ & \text { parceiros, assim como os retornos e os riscos. }\end{array}$

Fonte: Elaborado a partir de Lockamy \& McCormack (2004).

Como apresentado, o modelo dos autores se baseia em capabilidade, onde alcançar níveis superiores de maturidade é o mesmo que atingir níveis superiores de capabilidades em processos (Lockamy \& McCormack, 2004).

Nessa perspectiva, é importante ressaltar o conceito de capabilidade, que McCormack et al. (2009) definem como: a) Controle, que é a diferença entre onde se pretendia chegar e onde efetivamente se chegou, e a variação entre eles; b) Previsibilidade, que é medida da variabilidade em alcançar objetivos de custo e desempenho; c) Efetividade, que é o alcance dos resultados almejados e habilidade para se conseguir, potencialmente, resultados mais satisfatórios.

\subsection{6 \\ Modelo de Daozhi et al.}

Daozhi et al. (2006) propuseram um modelo de medição de maturidade aplicado à logística que fundamenta-se em três dimensões: maturidade da gestão, maturidade do ambiente e maturidade dos recursos. Para os autores o modelo proporciona um suporte a cadeia de suprimentos em relação a possibilidade de se gerar melhoria contínua fundamentada na avaliação dos elementos de maturidade que o compõe.

A primeira dimensão abrange a integração da gestão dos processos, gestão de riscos e custos. Já a segunda dimensão, maturidade do ambiente, está relacionada com aspectos de crédito na cadeia, plataforma de comunicação, regulamentação e sinergia de recursos entre os membros componentes da cadeia. Por último, a terceira dimensão, maturidade dos recursos, está relacionada aos recursos que são comuns às outras e aos recursos competitivos, que são responsáveis por gerar vantagem 
competitiva em relação às outras cadeias (Daozhi et al., 2006). A figura 8 ilustra o modelo de Daozhi et al. (2006).

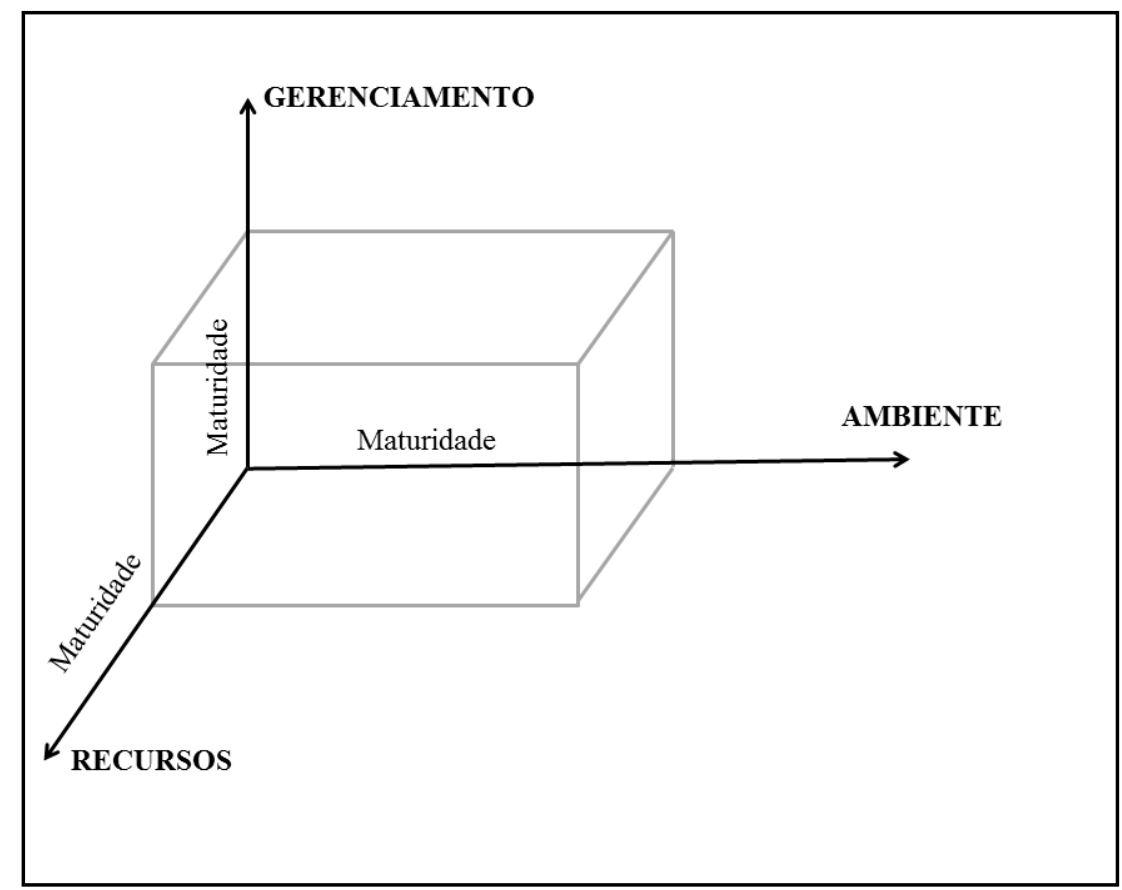

Figura 8: Modelo de Daozhi et al. (2006) e suas três dimensões Fonte: Daozhi et al. (2006).

A partir desta perspectiva tridimensional, Daozhi et al. (2006) elaboraram um modelo com quatro níveis de maturidade, os aspectos característicos desse modelo relacionam-se à sinergia de recursos, à plataforma de comunicação no ambiente da cadeia, à integração na gestão dos processos e ao gerenciamento dos riscos e custos. Os estágios e as características deste referido modelo estão descritos na tabela 9.

Tabela 9: Estágios de Maturidade do Modelo de Daozhi et al. (2006)

\section{ESTÁGIO CARACTERÍSTICAS}

- Inexistência de processos direcionados à gestão de riscos;

1 - Custos elevados e processos não são integrados;

- Inexistência de regulamentação, sistemas de crédito e plataforma comum de comunicação na cadeia de suprimentos.

- Inexistência de sinergia entre os recursos;

- Os custos são reduzidos e os processos são integrados dentro das empresas- foco;

- Alguns recursos são comuns proporcionando a criação de vantagem competitiva dentro da cadeia;

- Inicia-se uma implantação de regulamentações, sistemas de crédito e plataforma comum de comunicação no interior da cadeia;

- Há um sistema de gestão de riscos, mas ainda é ineficaz. 


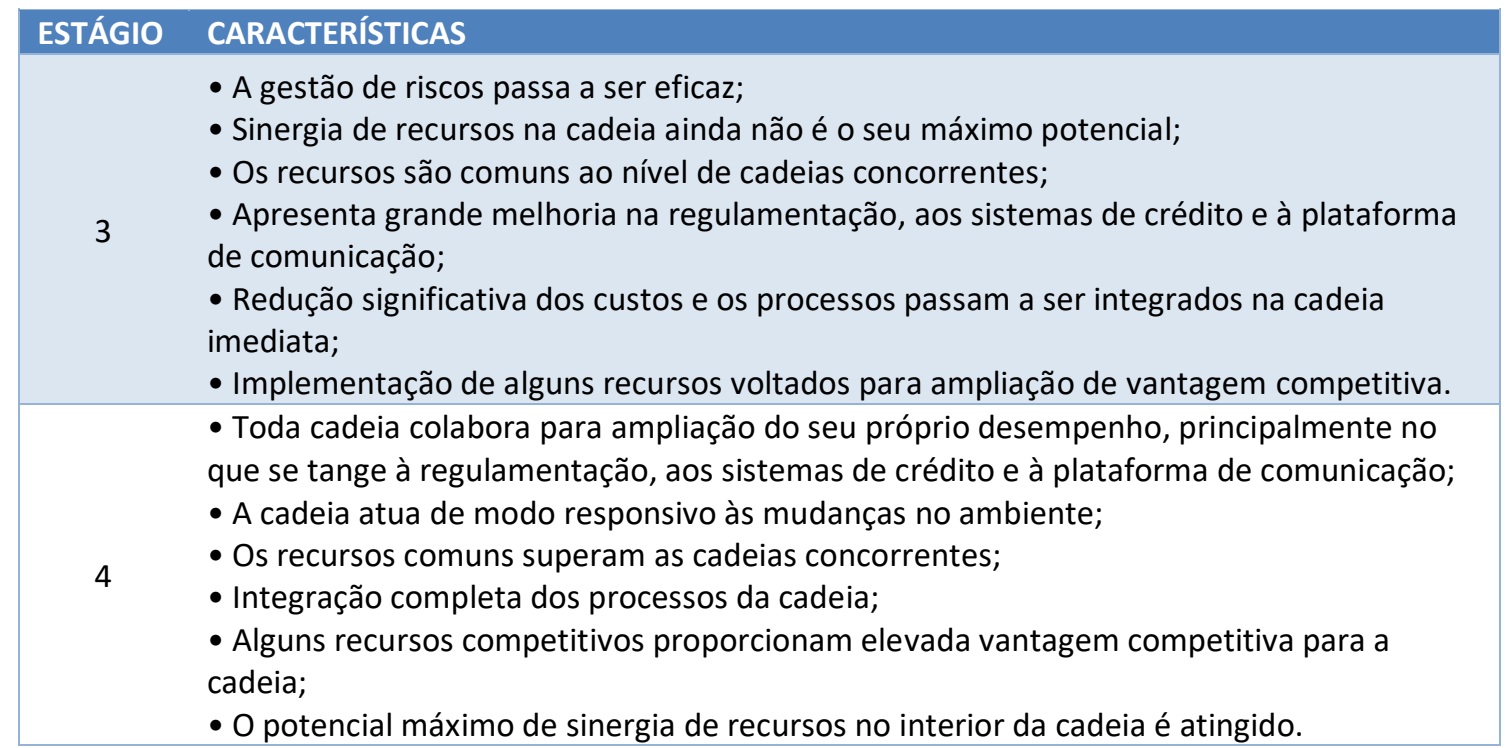

Fonte: Adaptado de Daozhi et al. (2006).

\subsection{7 \\ Modelo do Performance Measurement Group - PMG}

PRTM Management Consultants é uma empresa de consultoria de gestão dos sócios Pittiglio, Robin, Todd \& McGrath. A empresa tem como missão oferecer soluções inovadoras de medição e gestão do desempenho, de forma que seus clientes possam resolver seus desafios de negócios mais críticos de forma simplificada (PMG, 2007).

O PRTM Management Consultants, em conjunto com o Performance Measurement Group (PMG), foi fundado em 1998. Desenvolveram o Supply Chain Maturity Model. O modelo se baseia em métricas do modelo de desempenho SCOR que foram aplicadas em diferentes indústrias e observadas por mais de 5 anos (PMG, 2007).

O modelo de maturidade define quatro estágios da capabilidade operacional para a gestão da cadeia de suprimentos. Os estágios do modelo partem de um cenário com foco funcional para uma situação de colaboração entre os entes da cadeia de suprimentos. Esta progressão ao longo dos níveis de maturidade permite o aumento das competências operacionais da cadeia, gerando um impacto positivo e determinante em seu desempenho (PMG, 2007). 
A figura 9 e a tabela 10 sintetizam as principais características dos níveis do modelo e ilustram a evolução entre os níveis.

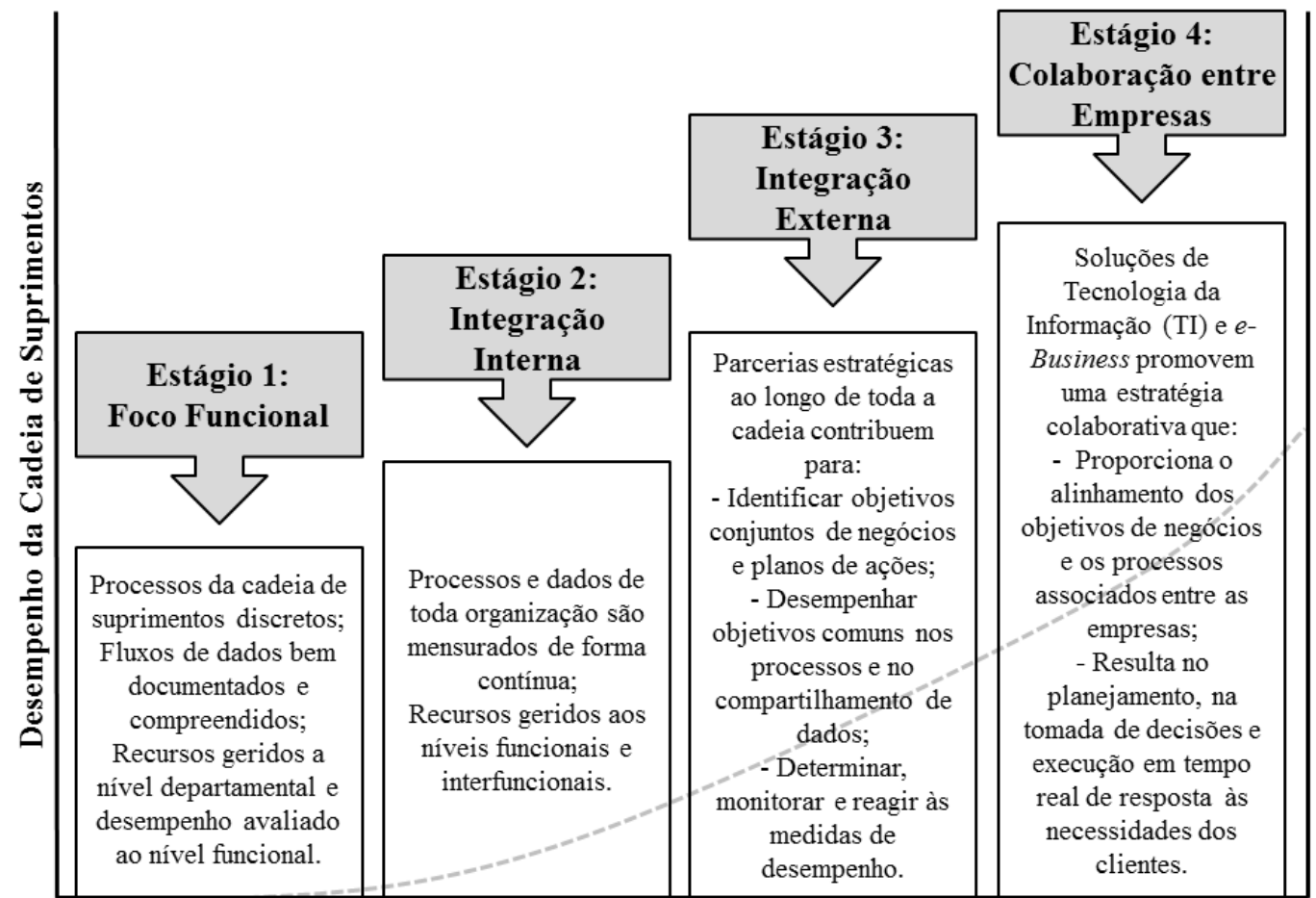

Estágios de Competências Operacionais

Figura 9: Modelo do PMG - Competências e o Desempenho da Cadeia Fonte: PMG (2007)

Tabela 10: Estágios de Maturidade do Modelo de PMG

\begin{tabular}{|c|c|c|}
\hline ESTÁGIO & & CARACTERÍSTICAS \\
\hline 1 & Foco Funcional & $\begin{array}{l}\text { - Departamentos possuem foco funcional e proteção às barreiras } \\
\text { departamentais; } \\
\text { - Foco em custos e performance individual; } \\
\text { - Processos multifuncionais pouco definidos e desestruturados, com baixa } \\
\text { eficiência para a cadeia de suprimentos; } \\
\text { - Os departamentos funcionais das empresas priorizam a melhoria dos seus } \\
\text { processos e o melhor uso de seus recursos. }\end{array}$ \\
\hline 2 & $\begin{array}{l}\text { Integração } \\
\text { Interna }\end{array}$ & $\begin{array}{l}\text { - Há integração interna, mas com divisão de papéis e definição dos processos } \\
\text { multifuncionais; } \\
\text { - Medidas de desempenho definidas; } \\
\text { - Funções individuais contribuem para o desempenho sistêmico; } \\
\text { - Os recursos são distribuídos de forma balanceada; } \\
\text { - Planejamento em suprimentos em função da demanda em alinhamento com } \\
\text { os fornecedores e com a produção. }\end{array}$ \\
\hline 3 & $\begin{array}{l}\text { Integração } \\
\text { Externa }\end{array}$ & $\begin{array}{l}\text { - Existência de integração externa com interface com clientes e fornecedores; } \\
\text { - Identificação de clientes e fornecedores estratégicos; } \\
\text { - Identificação de informações-chaves externas que prestam suporte aos } \\
\text { processos de negócio; } \\
\text { - Utilizados acordos de níveis de serviço em conjunto com a cadeia; } \\
\text { - Práticas de Balanced Scorecard são utilizadas; } \\
\text { - Ações corretivas de controle do desempenho são implementadas. }\end{array}$ \\
\hline
\end{tabular}




\begin{tabular}{|c|l|}
\hline ESTÁGIO & CARACTERÍSTICAS \\
\hline \multirow{4}{*}{$\begin{array}{c}\text { Colaboração } \\
\text { Inter- }\end{array}$} & $\begin{array}{l}\text { - Clientes e fornecedores desenvolvem uma estratégia global; } \\
\text { - Metas comuns de desempenho entre os entes da cadeia; }\end{array}$ \\
& $\begin{array}{c}\text { - Automatização e integração dos processos de negócios com uso de tecnologia } \\
\text { da informação entre os entes da cadeia de suprimentos. }\end{array}$ \\
\hline
\end{tabular}

Fonte: Elaborado a partir de PMG (2007).

\subsection{8 \\ Modelo de Oliveira}

Oliveira (2009) argumenta que os modelos de maturidade disponíveis na literatura possuem um grau elevado de subjetividade, e por isso, defende a criação de alternativas que se fundamentem em uma abordagem quantitativa, incluindo uma análise qualitativa no que tange à construção de sua estrutura.

Com o objetivo de reduzir a subjetividade, o autor desenvolveu um modelo de maturidade, baseado no modelo de Lockamy \& McComark (2004), com apoio de um grupo de pesquisadores de diversos países: EUA, Croácia, Eslovênia, Bélgica e Brasil. A proposta abrangeu a identificação dos pontos de transição entre os estágios de maturidade, baseando-se nos escores individuais das empresas (Oliveira, 2009). O resultado foi a concepção do modelo que ficou conhecido como Supply Chain Process Management Maturity Model (SCPM3), contendo cinco estágios de maturidade, denominados: (1) Fundação; (2) Estrutura; (3) Visão; (4) Integração e (5) Dinâmica.

De acordo com os pontos de transição propostos por Oliveira (2009), as empresas com escore inferior a 203 são classificadas no nível 1 - Fundação, entre 203 e 257, no nível 2 - Estrutura, entre 258 e 303, no nível 3 - Visão, entre 304 e 354, no nível 4 - Integração e, aquelas com escore superior a 354, no nível 5 Dinâmica. A figura 10 ilustra e resume o esquema proposto pelo autor, identificando os pontos de transição entre os estágios, bem como as competências cumulativas e suas relações de precedência. 


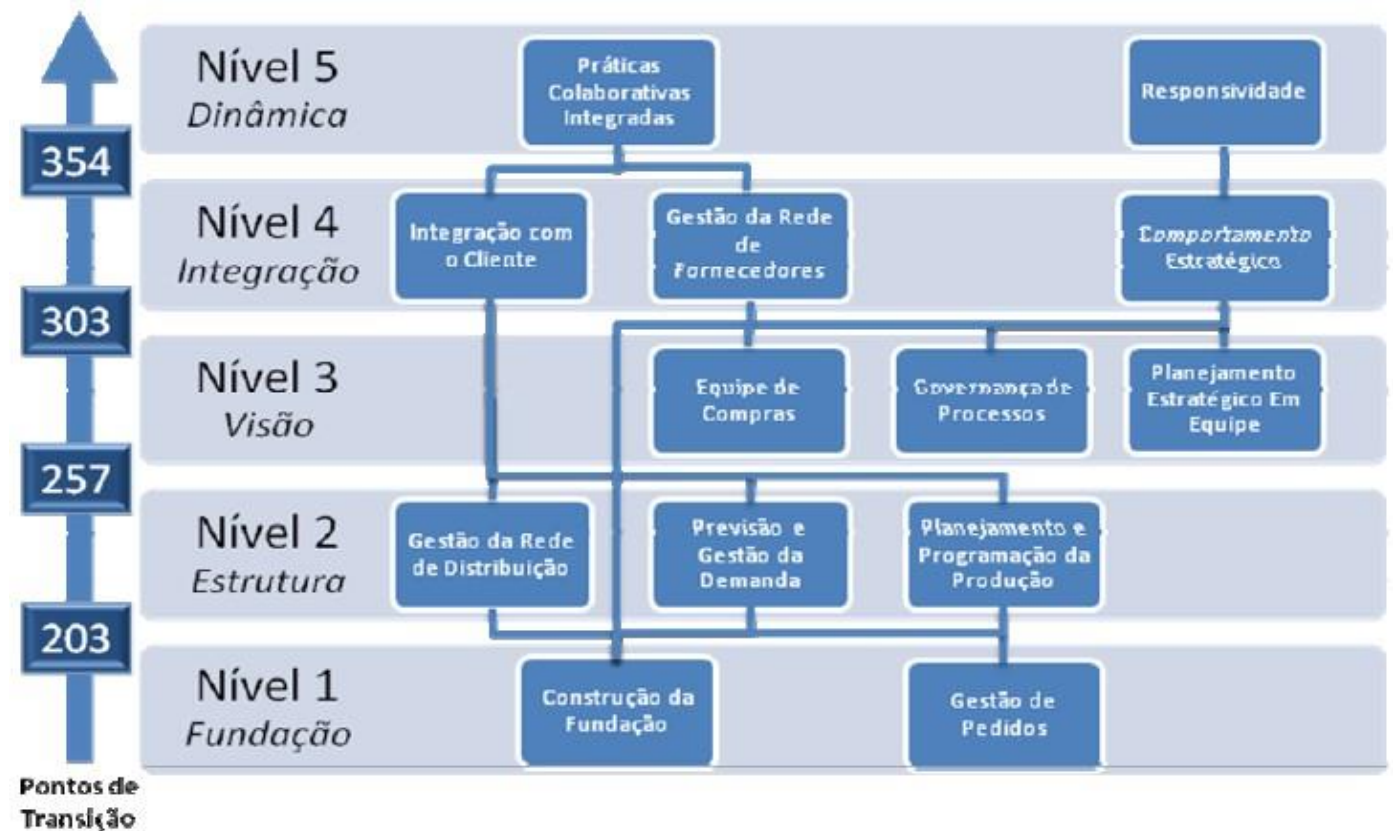

Figura 10: Modelo de Maturidade da Gestão Logística de Oliveira (2009)

Fonte: Oliveira (2009)

Oliveira (2009) define as características de cada nível de maturidade e das empresas neles classificados, conforme sintetizadas na tabela 11.

Tabela 11: Características das Empresas em cada nível de Maturidade

\begin{tabular}{|c|c|c|}
\hline NÍVEL & & CARACTERÍSTICAS \\
\hline Nível 1 & Fundação & $\begin{array}{l}\text { - A implantação de mudanças é ineficiente, lentas, demandam muito esforço e } \\
\text { acarretar desperdício de recursos; } \\
\text { - Presença de insatisfação dos clientes no que tange nível de serviço, uma vez } \\
\text { que não há controle da gestão de pedidos; } \\
\text { - Ausência de integração interna e de métodos de previsão de demanda, } \\
\text { havendo problemas de comunicação entre a área de vendas, produção e } \\
\text { distribuição, fazendo dos processos inflexíveis e não adaptados às necessidades } \\
\text { dos clientes; } \\
\text { - Os sistemas de informação não atendem integralmente os processos na cadeia } \\
\text { de suprimentos e há ausência de documentação e controle dos processos de } \\
\text { colocação de pedidos; } \\
\text { - Ausência de mapeamento de fornecedores estratégicos, gerando incapacidade } \\
\text { de se acordar e cumprir um acordo com níveis de serviço. }\end{array}$ \\
\hline Nível 2 & Estrutura & $\begin{array}{l}\text { - Fluxos de planejamento e programação são documentados, capazes de avaliar } \\
\text { a aderência entre o planejamento, programação da produção e as necessidades } \\
\text { do negócio; } \\
\text { - Inicia-se uma integração entre as áreas da empresa em função do plano de } \\
\text { produção, considerando as restrições de capacidade do sistema de operações da } \\
\text { empresa; } \\
\text { - Os sistemas de informação são mais integrados aos processos da empresa e } \\
\text { práticas de reabastecimento automático na cadeia de suprimentos são adotadas; } \\
\text { - Os processo de previsão e gestão da demanda são implementados e } \\
\text { formalizados. Utilização de métodos estatísticos nas atividades de distribuição e } \\
\text { previsões de demanda, tornando as previsões mais frentes e mais precisas; } \\
\text { - Processos de distribuição são mensurados e controlados e os agentes } \\
\text { econômicos da cadeia são avaliados e recompensados por seus resultados. }\end{array}$ \\
\hline
\end{tabular}




\begin{tabular}{|c|c|c|}
\hline NÍVEL & & CARACTERÍSTICAS \\
\hline Nível 3 & Visão & $\begin{array}{l}\text { - Equipe de compras organizada e estruturada com atuação conjunta com outras } \\
\text { funções da empresa, tais como operação e vendas; } \\
\text { - Os processos de gestão de pedidos, distribuição, planejamento estratégico das } \\
\text { operações, planejamento de demanda, compras e operações possuem um } \\
\text { responsável, conhecido como dono do processo; } \\
\text { - Equipes de planejamento estratégico passam a ser mais integradas, tendo suas } \\
\text { ações documentadas e fazendo uso de ferramentas de análise adequadas; }\end{array}$ \\
\hline Nível 4 & Integração & $\begin{array}{l}\text { - Áreas de vendas, operações e distribuição colaboram nos processos de } \\
\text { planejamento e programação. Neste estágio a demanda é puxada; } \\
\text { - Organização estruturada para absorver adaptações nos processos de forma } \\
\text { suave e integrada, tendo todas as alterações documentadas; } \\
\text { - Medidas de desempenho e controle são implementadas, permitindo a } \\
\text { avaliação do desempenho de fornecedores; } \\
\text { - As informações sobre níveis de estoque, planejamento e programação são } \\
\text { compartilhadas ao longo da cadeia; } \\
\text { - Fornecedores críticos são envolvidos como parceiros da empresa nos } \\
\text { processos; } \\
\text { - Equipe de planejamento estratégico tem a capacidade de definir prioridades } \\
\text { específicas de alocação de recursos para clientes e produtos, uma vez que tem a } \\
\text { visão do resultado individualizado de cada cliente e de cada produto. }\end{array}$ \\
\hline Nível 5 & Dinâmica & $\begin{array}{l}\text { - A empresa atua de modo responsivo às demandas do mercado e há presença } \\
\text { de integração no processo de atendimento de pedidos com os demais processos } \\
\text { da cadeia; } \\
\text { - As áreas de vendas, marketing, distribuição e planejamento são colaborativas } \\
\text { entre si nos processos de atendimento aos pedidos e na preparação de previsões; } \\
\text { - A empresa acompanha os pedidos com os fornecedores e clientes, medindo } \\
\text { sistematicamente o desempenho no atendimento desses pedidos; } \\
\text { - Os tempos de atendimento dos fornecedores são vistos como críticos no } \\
\text { planejamento da produção, de forma que eles são revistos, atualizados e } \\
\text { controlados regularmente. }\end{array}$ \\
\hline
\end{tabular}

Fonte: Elaborado a partir de Oliveira (2009).

\section{4 .9 \\ Modelo de Reyes \& Gianchetti}

Reyes \& Gianchetti (2010) desenvolveram um metamodelo de maturidade para gerenciamento da cadeia de suprimentos, que ficou conhecido como Supply

Chain Capability Maturity Model. O modelo foi concebido e orientado através do método Delphi, com o envolvimento de mais de 80 especialistas.

Metamodelo pode ser definido como um modelo de negócios que altera significativamente a maneira e o ângulo pelos quais se vê e se analisa aspectos da organização. Para engenharia de software, um modelo com mais de quatro camadas será considerado um metamodelo por possuir um alto nível de abstração (Espinoza, 2011).

No estudo, os pesquisadores reuniram múltiplas perspectivas dos processos da cadeia de suprimentos e com os resultados obtidos a partir da eleição dos 
aspectos mais relevantes, estruturaram o modelo. A formulação do metamodelo contou com ajuda de arquiteturas de referência para integração de sistemas empresariais como o Generalized Enterprise Reference Architecture and Methodology (GERAM) que permite descrever a estrutura de uma empresa, sua decomposição em subsistemas, as relações entre os subsistemas e os princípios orientadores para a concepção de cada um deles (Gianchetti, 2010).

A característica principal da abordagem deste modelo é a estrutura de referência de modelagem que estratifica a empresa em múltiplas camadas e níveis de decisão, permitindo assim a visão dos vários processos de uma empresa que podem ser integrados. Para isso, os autores usaram um framework originalmente aplicado na integração de sistemas empresariais para derivação de um modelo de avaliação-integração-desenvolvimento de processos de negócios na cadeia de suprimentos. (Gianchetti, 2010).

Segundo Gianchetti (2010), a utilização da base lógica da arquitetura de referência, GERAM, somados aos conceitos derivados do Total Quality Management, Seis Sigma e Kaizen (melhoria contínua), estágios evolutivos de maturidade CMMI e as métricas SCOR, compuseram o arcabouço metodológico do modelo. Após essa estruturação teórica, os autores aplicaram o método Delphi para concepção de um modelo holístico para a cadeia de suprimentos.

Em virtude do uso de frameworks para projetos de sistemas empresariais no modelo proposto por Reyes \& Gianchetti (2010), a estrutura do modelo engloba três dimensões para avaliação da maturidade: a visão sobre a cadeia de suprimentos; os níveis de decisão ou abstração; e os níveis de maturidade no ciclo de vida. Em virtude dessa proposta tridimensional, o modelo possui uma representação cúbica e a figura 11 ilustra e apresenta a interação dessas três dimensões (Reyes \& Gianchetti, 2010). 


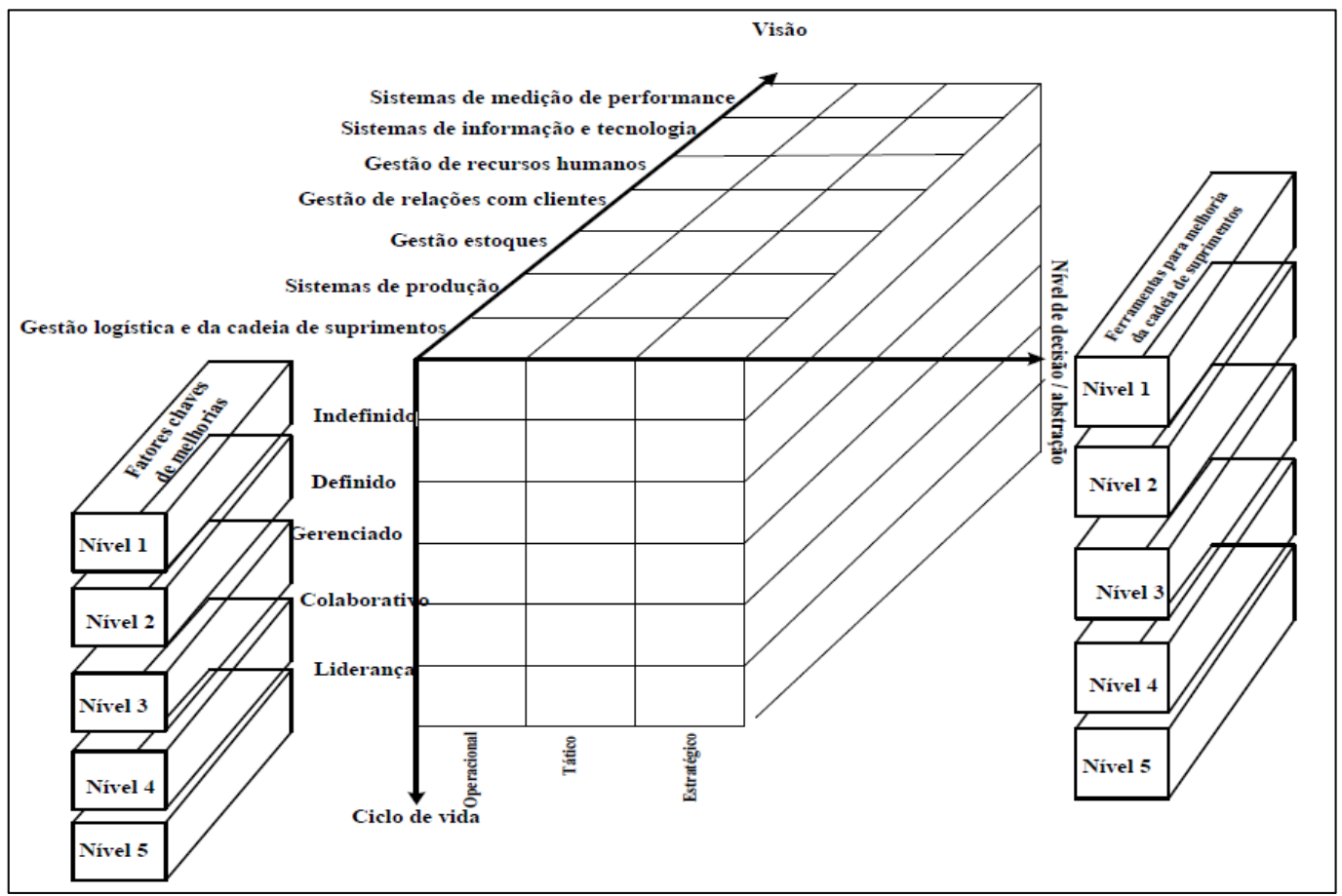

Figura 11: Cubo de representação do modelo de Reyes \& Gianchetti (2010) Fonte: Reyes \& Gianchetti (2010)

Ainda no modelo de Reyes \& Gianchetti (2010) para cada nível de maturidade é definido um fator-chave de melhorias e ferramentas apropriadas, provendo um arcabouço metodológico e ferramental, para que a organização possa usar e migrar para um nível de maturidade superior, sempre objetivando a melhoria contínua. Cada fator-chave descreve as competências que devem ser dominas pelas organizações. Essas visões foram classificadas em Reyes \& Gianchetti (2010) sob sete tipos, sendo elas:

- Gestão Logística e da cadeia de suprimentos - Essa visão inclui processos, funções, atividades e tarefas relacionadas com a integração, colaboração e desenvolvimento de fornecedores. Nesta visão os processos incluem a definição de políticas de seleção e desenvolvimento de fornecedores, implementação de garantia da qualidade no transporte de matérias-primas e materiais, definição de colaboração no nível estratégico com parceiros e a elaboração de acordos comerciais, inclusive internacionais;

- Sistemas de produção - esta visão agrega as funções, processos, atividades e tarefas inerentes à fabricação. Onde estão referidas ações que agregam valor ao produto ou serviço na visão do cliente, como por exemplo: redução de falhas, retrabalho, perdas, documentação e padronização de funções e 
processos, desenvolvimento de projetos para redução do tempo de entrega e execução do planejamento estratégico da produção;

- Gestão de estoques - toda e qualquer ação relativa ao gerenciamento e controle de estoques estão agrupadas nesta visão, e também as atividades relacionadas à gestão e controle de matérias-primas, produtos acabados, trabalho em processo, perdas, peças e reposição;

- Gestão de relacionamento com o cliente - esta visão abrange todas as ações referentes ao cumprimento das expectativas dos clientes. Sendo assim, ações inseridas nesta visão, podem ser citadas: a identificação das necessidades dos clientes, solução de reclamações, fidelização, serviço pósvenda, execução de projetos para aumentar a percepção de valor nos produtos e serviços prestados pela empresa diretamente ao cliente;

- Gestão dos recursos humanos - A visão relaciona todas as ações relativas aos empregados da organização e seu relacionamento com a empresa empregadora e o ambiente de trabalho. Esta visão retrata ações acerca de treinamento, ações de reduções de turnover, desenvolvimento da cultura de trabalho, implementação de projetos para a melhoria das condições de trabalho na organização, desenvolvimento de estratégias de participação e gratificação;

- Gestão de sistemas de informação e tecnologia - esta visão agrega todas as ações vinculadas diretamente aos sistemas de informação e gestão da tecnologia de processos, tanto o que se refere ao seu desenvolvimento, tanto a sua implementação. Algumas das atividades que compõe essa visão são: a implementação de soluções tecnológicas, tais como sistemas ERP, CRM, soluções RFID, sistemas de gestão de armazenagem, automação de equipamentos, documentação, padronização e coleta de dados do processo e projetos de redução de prazos;

- Sistemas de medição de desempenho - essa última visão compreende ações orientadas às medições da performance organizacional em relação à processos. Todas as ações de referentes aos KPI's da empresa estão inseridas nesta visão, tais como: definição de periodicidade da análise do desempenho, comunicação aos funcionários do significado de cada 
indicador de desempenho e forma de cálculo, padronização e divulgação de indicadores da performance.

A tabela 12 apresenta as principais características que definem cada um dos 5 níveis de maturidade proposto pelo modelo de Reyes \& Gianchetti (2010), que são definidos pelos fatores-chave citados e pelos níveis de abstração de cada processo da organização.

Tabela 12: Níveis de maturidade de Reyes \& Gianchetti (2010)

\begin{tabular}{|c|c|c|}
\hline ESTÁGIO & & CARACTERÍSTICAS \\
\hline Nível 1 & Indefinido & $\begin{array}{l}\text { - A empresa não tem documentação ou normalização de seus processos; } \\
\text { - Os processos são ad hoc; } \\
\text { - As atividades não são padronizadas e dependem das pessoas que a } \\
\text { executam; } \\
\text { - Organização caracterizada como reativa; } \\
\text { - Existência de silos funcionais. }\end{array}$ \\
\hline Nível 2 & Definido & $\begin{array}{l}\text { - A empresa define neste nível os processos e procedimentos; } \\
\text { - As áreas de competências são isoladas; } \\
\text { - Há pouco esforço formal para integrar os diversos processos. }\end{array}$ \\
\hline Nível 3 & Gerenciado & $\begin{array}{l}\text { - A empresa define seus procedimentos no nível das atividades operacionais; } \\
\text { - São estabelecidos os indicadores que se deseja medir e acompanhar; } \\
\text { - São definidos processos de gerenciamento; } \\
\text { - Os processos internos e sistemas da empresa são integrados e } \\
\text { coordenados. }\end{array}$ \\
\hline Nível 4 & Colaborativo & $\begin{array}{l}\text { - Processos de colaboração com fornecedores são estabelecidos; } \\
\text { - Maior interação com clientes, parceiros e demais membros da cadeia de } \\
\text { suprimentos em ambiente colaborativo. }\end{array}$ \\
\hline Nível 5 & Liderança & $\begin{array}{l}\text { - Procedimentos para colaborar com os fornecedores e clientes são } \\
\text { definidos; } \\
\text { - São definidas estratégias e estabelecidos os indicadores para mensurar } \\
\text { resultados das práticas colaborativas com clientes e fornecedores; } \\
\text { - Regulam a obtenção de informações que permite alcance da melhoria } \\
\text { contínua. }\end{array}$ \\
\hline
\end{tabular}

Fonte: Adaptado de Reyes \& Gianchetti (2010)

\subsubsection{0 \\ Modelo de Mendes}

Mendes $\operatorname{Jr}$ (2011) afirma que apesar de empresas implementarem ferramentas e processos de previsão para melhorar o planejamento da demanda, essas iniciativas não são suficientes para melhorar a eficiência da cadeia de suprimentos, devido a um descompasso existente entre oferta e demanda. Pensando nisso, Mendes Jr (2011) desenvolveu uma estrutura para apoiar empresas que migram em direção a uma operação de cadeia de suprimentos impulsionada pela demanda.

Mendes $\mathrm{Jr}$ desenvolveu um modelo de maturidade para cadeias de suprimentos orientadas pela demanda (Mendes, Leal e Thomé, 2016). A construção 
contou com um processo participativo, que foi aplicado em uma indústria internacional de bebidas, e teve sua cadeia avaliada em três países: Brasil, Estados Unidos e Uruguai.

No caminho metodológico o estudo realizou uma revisão da literatura, que levou à definição de componentes do modelo de maturidade. Na sequência foi realizada a classificação dos processos da SC, tendo como base o trabalho de Lambert (2008), agrupados em três componentes principais e subdivididos em quinze categorias. Gestão da demanda: previsão estatística, Planejamento de Vendas e Operações (S\&OP), CPFR (Collaborative Planning, Forecasting and Replenishment) e Vendor Managed Inventory (VMI); Fornecimento e Gestão de Operações: aquisições, produção, logística, suporte à alta administração. Gestão do ciclo de vida: Previsão de novos produtos, Abordagem da cadeia de suprimentos para novos produtos, avaliação de risco e Gestão, rastreamento de produtos e visibilidade, Otimização de Portfolio, e Apoio à Gestão para novos produtos.

$\mathrm{Na}$ fase de aplicação, foi utilizada uma técnica multicritério para tomada de decisão, Analytic Hierarchical Process (AHP), que fez uso da escala de Saaty (1980). O método foi utilizado com os executivos da companhia participante com o objetivo de priorizar e classificar as dimensões de maturidade desejadas para avaliação de sua própria cadeia de suprimentos.

O método AHP é uma técnica, composta por quatro passos, que consegue atribuir pontuações (pesos) para alternativas em problemas de decisão multicritério. O método consiste em obter o grau de prioridade, refletindo a importância relativa de cada par de alternativas a serem comparadas. O resultado do método é uma matriz de classificação de prioridades de alternativas para tomada de decisão (Zahedi, 1986; APUD Mendes et al., 2016).

O modelo de maturidade de Mendes et al. (2016) para cadeias de suprimentos orientadas pela demanda (DDSC-MM) possui cinco níveis de maturidade em sua estrutura: 1- Operação básica empurrada, 2- Empurrada optimizada, 3- Híbrido entre empurrada-puxada, 4- Orientada pela demanda avançada e 5- Orientada pela demanda otimizada. Na tabela 13 abaixo é possível observar algumas das principais características deste modelo. 
Tabela 13: Níveis de maturidade do modelo de Mendes Jr. et al. (2016).

\begin{tabular}{|c|c|c|}
\hline ESTÁGIO & & CARACTERÍSTICAS \\
\hline 1 & $\begin{array}{l}\text { Operação } \\
\text { básica } \\
\text { empurrada }\end{array}$ & $\begin{array}{l}\text { - O gerenciamento da demanda é praticamente inexistente e as poucas iniciativas } \\
\text { encontradas são desintegradas ao longo da cadeia. } \\
\text { - Produção e distribuição operam em modo empurrados. } \\
\text { - Os fornecedores são gerenciados em silos, sem uma orientação do cliente ou da alta } \\
\text { administração. } \\
\text { - A gestão do ciclo de vida do produto é incipiente ou inexistente. }\end{array}$ \\
\hline 2 & $\begin{array}{l}\text { Empurrada } \\
\text { optimizada }\end{array}$ & $\begin{array}{l}\text { - A organização ainda funciona de modo empurrado, mas as previsões são mais } \\
\text { assertivas utilizando métodos de S\&OP e iniciativas, ainda imaturas, de CPFR e VMI. } \\
\text { - O fornecimento e as operações estão integradas nas áreas funcionais, com controle } \\
\text { de indicadores-chaves (KPIs). } \\
\text { - Existem políticas formais para distribuição e serviços de clientes e a alta } \\
\text { administração entende a relevância de sistemas de distribuição otimizados. } \\
\text { - Surge a gestão do ciclo de vida do produto com as equipes de novos produtos } \\
\text { formalizadas, mas ainda com baixa integração. } \\
\text { - A previsão de novos produtos é fraca e o gerenciamento de portfólio é incipiente. }\end{array}$ \\
\hline 3 & $\begin{array}{c}\text { Híbrido } \\
\text { entre } \\
\text { empurrada- } \\
\text { puxada }\end{array}$ & $\begin{array}{l}\text { - São introduzidas estratégias de make to order (MTO), estratégia customização de } \\
\text { produção, promoções e tratamento de exceções. } \\
\text { - O uso do S\&OP agora inclui produtos de demanda puxada quanto empurrada. } \\
\text { - CPFR e VMI são estendidos a mais produtos e parceiros, com ferramentas de TI. } \\
\text { - O fornecimento e as operações procuram o alinhamento estratégico com os } \\
\text { principais parceiros da cadeia. } \\
\text { - A alta administração suporta fortemente os sistemas de push-pull híbridos. } \\
\text { - Melhoria da gestão do ciclo de vida do produto com previsões de novos produtos. NP } \\
\text { restrito aos produtos empurrados. } \\
\text { - Previsão de demanda é realizada para produtos puxados. } \\
\text { - Avaliação de risco de novos produtos e gerenciamento de portfólio introduzidos. } \\
\text { - Há suporte de gerenciamento sênior para gestão de portfólio. }\end{array}$ \\
\hline 4 & $\begin{array}{l}\text { Orientada } \\
\text { pela } \\
\text { demanda } \\
\text { avançada }\end{array}$ & $\begin{array}{l}\text { - Vendas puxadas já são mais de } 60 \% \text { do portfólio com maior precisão nas previsões. } \\
\text { - S\&OP é uma atividade de valor agregado, orientada à eventos com cenários 'what-if'. } \\
\text { - As previsões dos clientes estão integradas no CPFR e no VMI. } \\
\text { - O fornecimento e as operações possuem mecanismos de cooperação formal com } \\
\text { fornecedores-chave. } \\
\text { - O lean é ampliado ainda mais, com layouts flexíveis, uso de técnicas de simulação, } \\
\text { rastreamento automático e de distribuição. } \\
\text { - O serviço ao cliente também está vinculado ao CPFR e ao VMI. } \\
\text { - A alta gerência apoia totalmente a abordagem orientada pela demanda. O apoio à } \\
\text { gestão de novos produtos se baseia na cultura de inovação. } \\
\text { - A previsão de novos produtos está restrita às matérias-primas. } \\
\text { - A estratégia da cadeia diferencia produtos funcionais e inovadores. } \\
\text { - O gerenciamento de portfólio é multifuncional. }\end{array}$ \\
\hline 5 & $\begin{array}{l}\text { Orientada } \\
\text { pela } \\
\text { demanda } \\
\text { otimizada }\end{array}$ & $\begin{array}{l}\text { - As vendas puxadas são em torno de } 80 \% \text { do portfólio. } \\
\text { - O marketing e as vendas estão integrados ao longo da cadeia. } \\
\text { - S\&OP é gerenciado com uso de tecnologia avançadas e com comunicação } \\
\text { automatizada, seus eventos são integrados com CPFR e VMI. } \\
\text { - Fornecimento e operações se integram com fornecedores de segundo nível. } \\
\text { - Os KPIs estão vinculados ao nível de serviço e gerenciados em células de serviço ao } \\
\text { cliente especializadas e multifuncionais. } \\
\text { - O suporte de gerenciamento é otimizada e se estende à integração na cadeia de } \\
\text { suprimentos. Existe uma otimização da gestão de portfólio. } \\
\text { - Gestão do ciclo de vida dos produtos se estende para a demanda de novos produtos. } \\
\text { - A cadeia de novos produtos diferencia redes funcionais e inovadoras. }\end{array}$ \\
\hline
\end{tabular}

Fonte: Elaborado a partir de Mendes et al. (2016). 
O modelo também suporta as organizações no desenvolvimento de estratégias para avançar para níveis de maturidade mais elevados. No estudo, as equipes foram capazes de analisar seus resultados relativos nos níveis de maturidade em cada componente e categoria, implementando estratégias para melhoria de seus processos, tornando-se, cada vez mais, uma empresa orientada para a demanda face o ambiente competitivo e seu posicionamento no mercado.

\subsubsection{1}

\section{Outros Modelos}

Mendes, Leal e Thomé (2016) apresentaram o modelo de maturidade para cadeias de suprimento orientadas pela demanda na indústria de bens de consumo, de Mendes, e também reuniram e classificaram alguns modelos de maturidade.

Um dos produtos finais do trabalho foi uma matriz que descreve uma diversidade de modelos identificando seus níveis, tipos e classificadas de acordo com a tipologia proposta por Fraser et al. (2002). Os tipos classificados pelos autores são diversos, incluindo: integração, interoperabilidade organizacional, informatização, estágios de aquisição, integração interna e externa de modelos de planejamento de vendas e operações ( $\& \& O P$ ), cadeia de suprimentos industrial, Planejamento Colaborativo de Previsões e Reabastecimento (CPFR), sustentabilidade, flexibilidade, gerenciamento da cadeia de suprimentos e cadeia de suprimentos orientada para a demanda.

Tendo por base a matriz desenvolvido por Mendes et al. (2016), que foi ampliada por este trabalho, a tabela 14 resume os modelos de maturidade identificados na literatura.

Tabela 14: Modelos de Maturidade em Cadeia de Suprimentos

\begin{tabular}{|llllll|}
\hline Authors & Ano & Focus & Frist Level & Last Level & $\begin{array}{l}\text { \# of } \\
\text { levels }\end{array}$ \\
\hline Stevens & 1989 & SC integration & Baseline & $\begin{array}{l}\text { External } \\
\text { integration }\end{array}$ & 4 \\
\hline $\begin{array}{l}\text { Christopher } \\
\text { Clark and Jones }\end{array}$ & 1997 & SC integration & $\begin{array}{l}\text { Informal or } \\
\text { Basic }\end{array}$ & $\begin{array}{l}\text { External } \\
\text { Integration }\end{array}$ & 4 \\
\hline $\begin{array}{l}\text { Grijpink } \\
\text { Moncrieff and }\end{array}$ & 1999 & SC Organizational & Independent & Unified & 5 \\
\hline $\begin{array}{l}\text { Stonich } \\
\text { Ayers and }\end{array}$ & 2001 & SCM & Informal talks & Common network & 5 \\
\hline $\begin{array}{l}\text { Malmberg } \\
\text { Ayers }\end{array}$ & 2002 & Demand driven SC & Infrastructure & $\begin{array}{l}\text { Cross Enterprise } \\
\text { Strategic }\end{array}$ & 4 \\
\hline
\end{tabular}




\begin{tabular}{|c|c|c|c|c|c|}
\hline Authors & Ano & Focus & Frist Level & Last Level & $\begin{array}{l}\text { \# of } \\
\text { levels }\end{array}$ \\
\hline $\begin{array}{l}\text { Computer } \\
\text { Sciences } \\
\text { Corporation }\end{array}$ & 2003 & SC integration & $\begin{array}{l}\text { Business } \\
\text { integration }\end{array}$ & $\begin{array}{l}\text { Complete network } \\
\text { connectivity }\end{array}$ & 5 \\
\hline $\begin{array}{l}\text { Handfield and } \\
\text { Straight }\end{array}$ & 2004 & Stages of Procurement & Basic & Fully integrated SC & 5 \\
\hline Lapide & 2005 & S\&OP/inter-firm maturity & Marginal & Ideal & 4 \\
\hline $\begin{array}{l}\text { Lockamy and } \\
\text { McCormack }\end{array}$ & 2004 & SCM & Ad-hoc & Extended & 5 \\
\hline IBM & 2005 & SCM / Demand driven SC & Stactic & On-Demand SC & 5 \\
\hline Daozhi et al. & 2006 & $\begin{array}{l}\text { SC Resourse and } \\
\text { Comunication }\end{array}$ & One & Four & 4 \\
\hline McLaren & 2006 & SCM & $\begin{array}{l}\text { Functional } \\
\text { focus }\end{array}$ & $\begin{array}{l}\text { Optimized } \\
\text { network }\end{array}$ & 5 \\
\hline $\begin{array}{l}\text { Ventana } \\
\text { Research }\end{array}$ & 2006 & S\&OP/inter-firm maturity & Tactical & Innovative & 4 \\
\hline $\begin{array}{l}\text { Grimson and } \\
\text { Pyke }\end{array}$ & 2007 & S\&OP/inter-firm maturity & Reactive & Proactive & 4 \\
\hline $\begin{array}{l}\text { Performance } \\
\text { Measurement } \\
\text { Group }\end{array}$ & 2007 & SCM & $\begin{array}{l}\text { Functional } \\
\text { Focus }\end{array}$ & $\begin{array}{l}\text { Interorganizational } \\
\text { Collaboration }\end{array}$ & 4 \\
\hline Ayree et al. & 2008 & SC integration & Optimization & $\begin{array}{l}\text { Co-ordination \& } \\
\text { Synchronisation }\end{array}$ & 3 \\
\hline Garcia & 2008 & SCM & Initial & Leading & 5 \\
\hline Cacere et al. & 2009 & S\&OP/inter-firm maturity & Reactive & Orchestrate & 4 \\
\hline Lahti et al. & 2009 & SCM & $\begin{array}{l}\text { Functional } \\
\text { focus }\end{array}$ & $\begin{array}{l}\text { Cross-enterprise } \\
\text { collaboration }\end{array}$ & 4 \\
\hline Oliveira & 2009 & $\mathrm{SCM}$ & Foundation & Dynamic & 5 \\
\hline Viswanathan & 2009 & S\&OP/inter-firm maturity & Laggards & Best-in-class & 4 \\
\hline Baumann & 2010 & S\&OP/inter-firm maturity & $\begin{array}{l}\text { Demand } \\
\text { Management }\end{array}$ & $\begin{array}{l}\text { Inter Enterprise } \\
\text { IBP }\end{array}$ & 4 \\
\hline $\begin{array}{l}\text { Reyes and } \\
\text { Giachetti }\end{array}$ & 2010 & SCM & Undefined & 5-Leading & 5 \\
\hline Tinker & 2010 & S\&OP/inter-firm maturity & $\begin{array}{l}\text { Lagging } \\
\text { Execution }\end{array}$ & 5- Leading & 5 \\
\hline $\begin{array}{l}\text { Gupta and } \\
\text { Handfield }\end{array}$ & 2011 & SCM & Ad-hoc & 5 - Optimized & 5 \\
\hline VICS & 2010 & SCM/CPFR/S\&OP & Unlinked & Strategic & 4 \\
\hline Hameri et al. & 2013 & Industrial SC & $\begin{array}{l}\text { Initial } \\
\text { Sourcing }\end{array}$ & Lean SCM & 6 \\
\hline Reefke et al. & 2014 & Sustainable SC & $\begin{array}{l}\text { Un-aware \& } \\
\text { non- } \\
\text { compliant }\end{array}$ & $\begin{array}{l}\text { Extended \& } \\
\text { Sustainability } \\
\text { leadership }\end{array}$ & 6 \\
\hline Wagner et al. & 2014 & S\&OP/inter-firm maturity & Undeveloped & Proactive & 6 \\
\hline Fischer et al. & 2016 & SC flexibility & No flexibility & $\begin{array}{l}\text { Paradigmatic } \\
\text { flexibility }\end{array}$ & 5 \\
\hline Mendes et al. & 2016 & Demand driven SC & $\begin{array}{l}\text { Basic Push } \\
\text { Operation }\end{array}$ & $\begin{array}{l}\text { Optimized } \\
\text { demand-driven } \\
\text { (pull) }\end{array}$ & 5 \\
\hline
\end{tabular}

Fonte: Elaborado a partir de Mendes et al. (2016). 
As lacunas identificadas por Paes (2011), apresentadas no capítulo 1 e nas quais se baseiam este trabalho, datam de 2011. Com isso, vale ressaltar que os modelos de maturidade identificados com datas posteriores a ainda não suprem a carência da literatura por modelo amplos e adaptativos, como pode ser observado na tabela 14. O foco dos modelos de maturidade surgidos posteriormente reside em sustentabilidade, S\&OP, flexibilidade, demanda ou possuem foco em empresas industriais.

\section{5 Processo de Desenvolvimento de Modelos de Maturidade}

Observa-se uma crescente preocupação com a sustentação científica na literatura no que tange ao desenvolvimento de novos modelos de maturidade. Mettler (2009) e Becker et al. (2009) desenvolveram diferentes abordagens com o objetivo de nortear o desenvolvimento de novos modelos.

A abordagem de Mettler (2009) sugere 6 etapas para o desenvolvimento de modelos de maturidade e seus estudos contribuíram no sentido de destacar o aspecto não-linear e contínuo do esforço empregado pelas empresas, reforçando a necessidade de se revisitar o modelo continuamente, para que se mantenha atualizado, atendendo às necessidades da organização avaliada.

$\mathrm{Na}$ proposta do autor, inicia-se com a identificação de uma necessidade ou oportunidade, que embasará a definição do escopo do modelo e na sequência o delineamento do modelo, que envolve a definição dos estágios e seu respectivo conteúdo. Importante observar que antes da aplicação do modelo, é necessário avaliar se o delineamento atende à necessidade e escopo definidos. Por fim, o autor sugere uma etapa de acompanhamento do modelo, no sentido de promover sua constante adequação. A figura 12 sintetiza as fases de desenvolvimento e aplicação de modelos de maturidade sugeridos por Mettler (2009). 


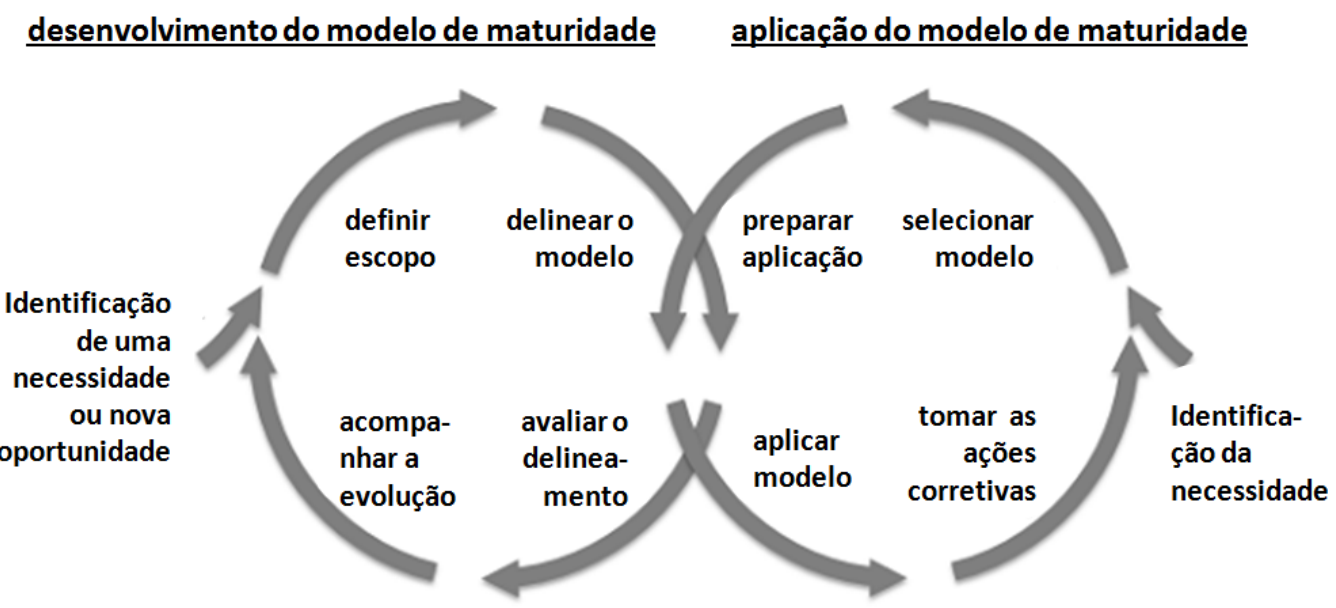

Figura 12: Fases do desenvolvimento e aplicação de modelos de maturidade Fonte: Mettler (2009)

Para Mettler (2009) a iteração entre o delineamento e aplicação garantem a evolução do modelo, reduzem as possibilidades de obsolescência onde a partir da aplicação do modelo, quando podem ser coletadas novas necessidades ou oportunidades e tomada de ações corretivas. $\mathrm{O}$ autor ainda acrescenta parâmetros de decisão relacionados a cada fase do desenvolvimento do modelo de maturidade, a fim de nortear profundamente os novos modelos desenvolvidos a partir de sua metodologia. A figura 13 a seguir apresenta os parâmetros de decisão para o delineamento segundo Mettler (2009). 


\begin{tabular}{|c|c|c|c|c|c|c|c|}
\hline Fase & $\begin{array}{l}\text { Parâmetro de } \\
\text { decisão }\end{array}$ & \multicolumn{6}{|c|}{ Características } \\
\hline \multirow{5}{*}{ 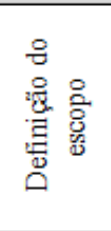 } & Foco & \multicolumn{3}{|c|}{ Generalista } & \multicolumn{3}{|c|}{ Especifico } \\
\hline & $\begin{array}{l}\text { Nivel de análise/ } \\
\text { profundidade }\end{array}$ & $\begin{array}{c}\text { Tomada de decisão } \\
\text { em grupo }\end{array}$ & \multicolumn{2}{|c|}{$\begin{array}{l}\text { Considerações } \\
\text { organizacionais }\end{array}$} & \multicolumn{2}{|c|}{\begin{tabular}{|c|} 
Considerações \\
interorganizacionais
\end{tabular}} & $\begin{array}{l}\text { Considerações } \\
\text { globais e sociais }\end{array}$ \\
\hline & Originali-dade & Emergente & \multicolumn{2}{|c|}{ Regular } & \multicolumn{2}{|c|}{ Disruptivo } & Madura \\
\hline & Público & \multirow{2}{*}{\multicolumn{3}{|c|}{$\begin{array}{r}\text { Orientada para gestão } \\
\text { Aberta }\end{array}$}} & Ira tecnologia & & Ambos \\
\hline & Distribuição & & & & \multicolumn{3}{|c|}{ Exclusiva } \\
\hline \multirow{6}{*}{ 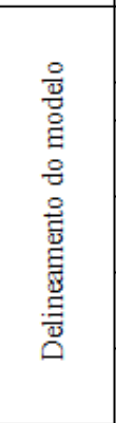 } & $\begin{array}{l}\text { Definição de } \\
\text { maturidade }\end{array}$ & Foco no processo & & co no objeto & Foco nas pe & ssoas & Combinação \\
\hline & Função objetivo & \multicolumn{3}{|c|}{ Unidimensional } & \multicolumn{3}{|c|}{ Multidimensional } \\
\hline & $\begin{array}{l}\text { Processo de } \\
\text { delineamento }\end{array}$ & \multicolumn{2}{|l|}{ Baseado na teoria } & \multicolumn{2}{|c|}{ Baseado na prática } & \multicolumn{2}{|r|}{ Combinação } \\
\hline & \begin{tabular}{|l|}
$\begin{array}{l}\text { Produto do } \\
\text { delineamento }\end{array}$ \\
\end{tabular} & \multicolumn{2}{|c|}{$\begin{array}{l}\text { Descrição textual da } \\
\text { forma }\end{array}$} & \multicolumn{2}{|c|}{$\begin{array}{l}\text { Descrição textual da } \\
\text { forma e da função }\end{array}$} & \multicolumn{2}{|c|}{$\begin{array}{c}\text { Instantiation (Ferramenta } \\
\text { de avaliação) }\end{array}$} \\
\hline & \begin{tabular}{|l|} 
Método de \\
aplicação
\end{tabular} & \multicolumn{2}{|l|}{ Próprio } & \multicolumn{2}{|c|}{ Conduzido por terceiros } & \multicolumn{2}{|c|}{ Profissionais certificados } \\
\hline & Respondentes & Gestão & & Staff & $\begin{array}{r}\text { Parceiros } \\
\text { negócic }\end{array}$ & & Combinação \\
\hline \multirow{3}{*}{ 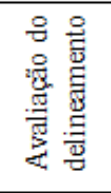 } & $\begin{array}{l}\text { Tópico de } \\
\text { avaliação }\end{array}$ & \multicolumn{2}{|c|}{ Processo do delineamento } & \multicolumn{2}{|c|}{ Produto do delineamento } & \multicolumn{2}{|r|}{ Ambos } \\
\hline & Quando avaliar & Antes da aplicaç & & Após a & aplicação & & Ambos \\
\hline & \begin{tabular}{|l|} 
Método de \\
avaliação
\end{tabular} & \multicolumn{3}{|c|}{ Natural } & \multicolumn{3}{|c|}{ Artificial } \\
\hline \multirow{3}{*}{ 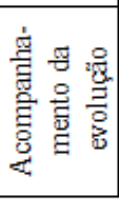 } & $\begin{array}{l}\text { Tópico da } \\
\text { mudança }\end{array}$ & Nenhum & & Forma & Função & & Forma e função \\
\hline & Frequência & \multicolumn{3}{|c|}{ Não recorrente } & \multicolumn{3}{|c|}{ Continua } \\
\hline & $\begin{array}{l}\text { Estrutura da } \\
\text { mudança }\end{array}$ & \multicolumn{3}{|c|}{ Externa/ aberta } & \multicolumn{3}{|c|}{ Interna/ exclusiva } \\
\hline
\end{tabular}

Figura 13: Parâmetros de decisão para o delineamento de modelos de maturidade Fonte: Mettler (2009)

Outra abordagem para o desenvolvimento de modelos de maturidade, também do ano de 2009, é a proposta por Becker et al. (2009), que se baseou na pesquisa desenvolvida por Hevner et al. (2004), onde propuseram sete diretrizes para o desenvolvimento da ciência do campo de desenvolvimento de artefatos, que podem ser constructos, modelos ou métodos. Tendo como conceito de constructo, o conceito teórico ou abstração formada a partir da percepção de determinado fenômeno que seja possível mensurar e avaliar. A partir daí Becker et al. (2009) elaborou oito requisitos para o desenvolvimento de modelos que podem ser observados na tabela 15. (Becker et al., 2009).

Tabela 15: Os 8 requisitos para o desenvolvimento de Modelos de Maturidade

\begin{tabular}{|ll} 
Requisito & Descrição \\
$\begin{array}{l}\text { Definição do } \\
\text { problema }\end{array}$ & $\begin{array}{l}\text { O provável campo de aplicação do modelo de maturidade, bem como as } \\
\text { condições para sua aplicação e os benefícios buscados, precisa ser } \\
\text { determinado antes de seu desenvolvimento. }\end{array}$ \\
\hline $\begin{array}{l}\text { Comparação com } \\
\text { modelos de } \\
\text { maturidade } \\
\text { existentes }\end{array}$ & $\begin{array}{l}\text { A necessidade de desenvolvimento do novo modelo deve ser subsidiado } \\
\text { pela comparação de modelos já existentes. O novo modelo pode ser } \\
\text { também uma melhoria de um já existente. }\end{array}$ \\
\hline
\end{tabular}




\begin{tabular}{|c|c|}
\hline Requisito & Descrição \\
\hline $\begin{array}{l}\text { Procedimento } \\
\text { iterativo }\end{array}$ & $\begin{array}{l}\text { MM devem ser desenvolvidos de forma iterativa, passo a passo, por } \\
\text { exemplo. }\end{array}$ \\
\hline Avaliação & $\begin{array}{l}\text { Todos os princípios e premissas para o desenvolvimento de um modelo de } \\
\text { maturidade, bem como a utilidade, qualidade e eficácia do artefato, devem } \\
\text { ser avaliados frequentemente. }\end{array}$ \\
\hline $\begin{array}{l}\text { Procedimento } \\
\text { multimetodológico }\end{array}$ & $\begin{array}{l}\text { O desenvolvimento de MM utiliza diversos métodos de pesquisa, cujo uso } \\
\text { deve estar bem fundamentado e estreitamente sintonizados. }\end{array}$ \\
\hline $\begin{array}{l}\text { Identificação da } \\
\text { relevância do } \\
\text { problema }\end{array}$ & $\begin{array}{l}\text { A relevância da proposta de solução do problema através do modelo de } \\
\text { maturidade projetado para pesquisadores e usuários precisa ser } \\
\text { demonstrado. }\end{array}$ \\
\hline $\begin{array}{l}\text { Apresentação- } \\
\text { alvo dos } \\
\text { Resultados }\end{array}$ & $\begin{array}{l}\text { A apresentação do modelo de maturidade precisa ser direcionado de } \\
\text { acordo com suas condições de aplicação e as necessidades dos usuários. }\end{array}$ \\
\hline $\begin{array}{l}\text { Documentação } \\
\text { científica }\end{array}$ & $\begin{array}{l}\text { O processo de desenvolvimento do modelo de maturidade necessita ser } \\
\text { documentado em detalhes, considerando cada etapa do processo, as partes } \\
\text { envolvidas, métodos utilizados e os resultados. }\end{array}$ \\
\hline
\end{tabular}

Fonte: Becker et al. (2009)

A partir dos requisitos, como resultado de seus estudos, Becker et al. (2009) criaram uma metodologia para desenvolvimento de artefatos que consistem em 7 passo: (I) definição de problemas e requisitos; (II) análise e comparação com modelos existente; (III) desenvolvimento de estratégias que consiste essencialmente na escolha entre a adoção de modelos existentes ou o desenvolvimento de um novo; (IV) desenvolvimento e validação iterativa; (V) design da transferência e avaliação do modelo; (VI) implementação; e (VII) avaliação modelo em um contexto organizacional (Nord et al., 2016). 


\section{3 \\ Procedimentos Metodológicos}

Este capítulo descreve os procedimentos metodológicos adotados para a construção do modelo de maturidade em cadeia de suprimentos proposto nesta dissertação.

A pesquisa desenvolvida pode ser classificada como aplicada por sua finalidade e de caráter exploratório, tendo em vista a agregação e ampliação de conhecimento sobre a aplicabilidade de modelos de maturidade em cadeias de suprimentos nas empresas. Quanto a sua natureza a pesquisa poderá ser classificada como qualitativa e quantitativa, uma vez que aplicação no mundo real da ferramenta, pode ser lida como uma pesquisa de campo para teste e validação.

Este estudo foi conduzido em quatro fases distintas: Estudos Introdutórios, Pesquisa Bibliográfica, Desenvolvimento e Pesquisa de Campo. Na primeira foi identificada a oportunidade de desenvolvimento do modelo e redigido os capítulos de caráter introdutório. $\mathrm{Na}$ segunda fase do estudo, realizou-se uma extensa pesquisa bibliográfica que serviu de embasamento para a definição de maturidade e eleição dos modelos representativos na medição de maturidade em que se basearam o desenvolvimento do modelo proposto. Na terceira foi realizado o desenvolvimento e ajuste do modelo conceitual proposto, bem como do protótipo de ferramenta desenvolvido. E por último, foi realizada a etapa de pesquisa de campo, que num primeiro instante envolveu a validação do modelo e instrumento e posteriormente a aplicação no mundo real.

A próxima seção apresenta o detalhamento das etapas de desenvolvimento da pesquisa como também as etapas de construção do modelo e do protótipo de ferramenta.

\section{1}

\section{Processo de Desenvolvimento do Modelo de Maturidade}

Como metodologia para o desenvolvimento do modelo de maturidade proposto por esta pesquisa, optou-se por estruturar um híbrido entre as 
metodologias propostas por Mettler (2009) e Becker et al. (2009), concatenando etapas propostas com referência nos autores.

As fases foram subdivididas em etapas, objetivando abranger a pesquisa como um todo. A figura 14 abaixo, sintetiza as etapas planejadas como caminho metodológico para o alcance do objetivo da pesquisa, bem como a relação de ligação e precedência entre as atividades propostas.

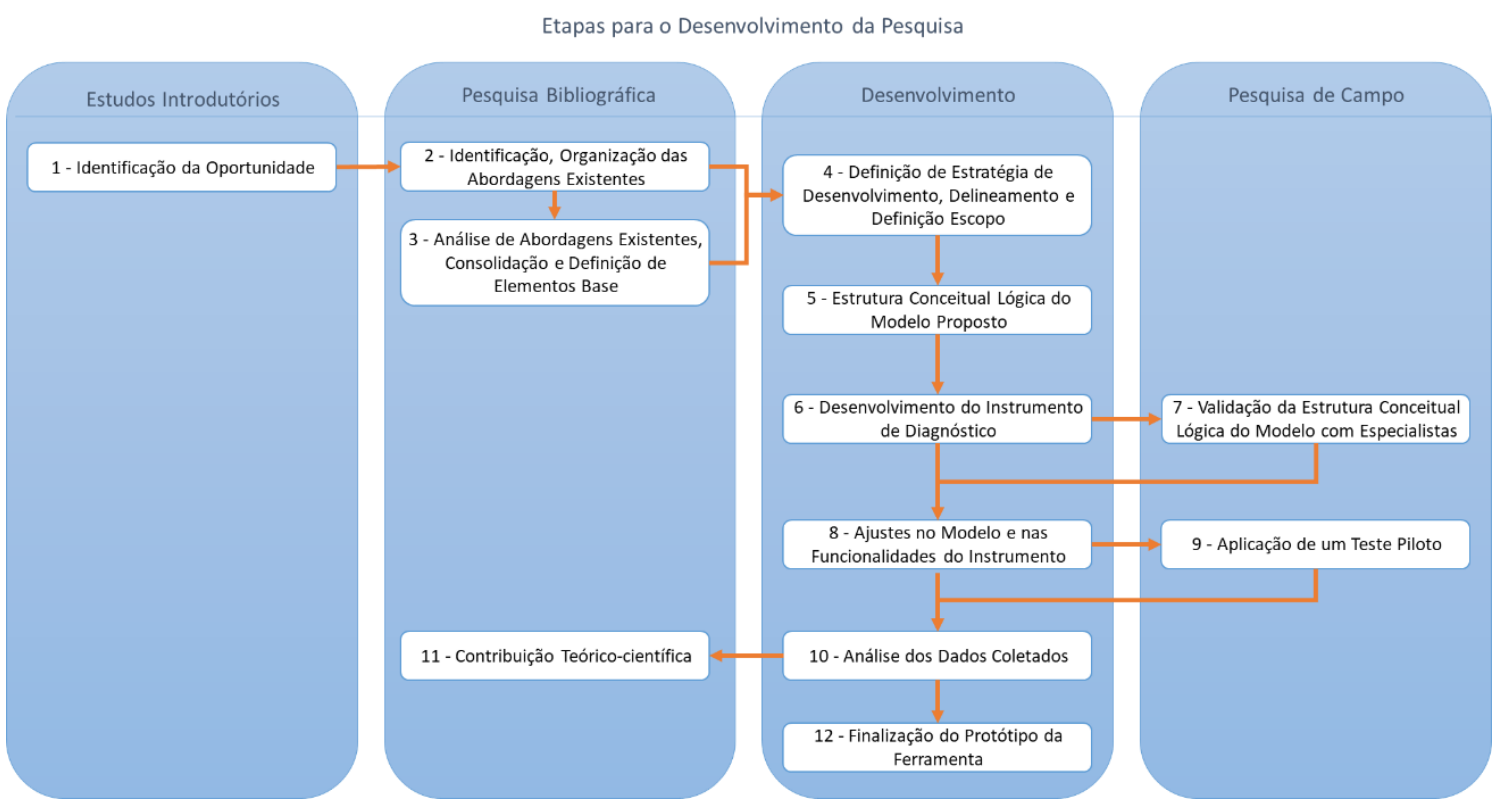

Figura 14: Etapas para o Desenvolvimento da Pesquisa Fonte: Elaborado por este trabalho

A etapa 1 se assemelha a primeira etapa da metodologia de Mettler (2009), quando o autor sugere a apresentação de uma oportunidade ou a identificação de uma necessidade que embase o desenvolvimento do modelo. As etapas 2 e 3 inspiraram-se no passo 1 de Becker et al. (2009) onde são definidos problemas e requisitos e no passo 2 de Becker et al. (2009) onde são analisados e comparados os modelos existentes.

$\mathrm{Na}$ fase de desenvolvimento, a etapa 4 teve origem nos critérios da segunda etapa de Mettler (2009), onde se sugere a definição do escopo e no passo 3 de Becker et al. (2009) que propõe o desenvolvimento de estratégias que consistem essencialmente na escolha entre a adoção de um modelo pré-existente ou no desenvolvimento de um novo. A etapa 5 alinha-se com a etapa 3 de Mettler (2009) onde o modelo é delineado. A etapa 6 está em congruência com o passo 5 de Becker et al. (2009) no que tange ao desenvolvimento do instrumento de pesquisa. 
A etapa 7, da fase de pesquisa de campo, possui aspectos inerentes a quarta etapa de Mettler (2009) e aos passos 4 e 5 Becker et al. (2009), onde ocorrem a avaliação do delineamento, validação e avaliação do modelo. A etapa 9 se inspira no último passo de Becker et al. (2009) onde se sugere o teste do modelo em um contexto organizacional. Importante salientar que esta pesquisa se propõe a validar tanto o modelo quanto o instrumento, mas por uma limitação de recursos e tempo, não fará uma validação iterativa com diversas rodadas como sugerido por Becker et al. (2009). Esta fase é recomendada para pesquisas futuras a partir do produto final do modelo proposto.

Por fim, A etapa 11 de contribuição teórica é o resultado natural do processo da pesquisa científica. As etapas 8, 10 e 12 são etapas internas de ajustes que derivam da etapa de validação do modelo e que é sugerida pelos dois autores.

\section{2}

\section{Detalhamento do Desenvolvimento da Pesquisa}

As subseções que seguem ampliam as informações dos grupos de etapas da metodologia.

\subsection{1}

\section{Estudos Introdutórios}

Conforme apresentado nas seções introdutórias, inúmeros estudos se predispõem a estudar o desenvolvimento de modelos de maturidade, porém a imensa maioria são incompletos no que se refere a totalidade da cadeia de suprimentos e a abrangência de setores da economia.

A academia reconhece a necessidade de criação de modelos que avaliem a gestão da cadeia de suprimentos, mas também contribuam para evolução das capabilidades das empresas e possuam instrumentos sistemáticos de aplicação associados. Estudos também apontam a carência por modelos adaptativos, que atendam as mais diversas indústrias (Paes, 2011; Lockamy \& McCormack, 2004; Netland e Alfnes, 2011).

Esta fase do trabalho ajudou a identificar os principais estudos na literatura voltados para maturidade em cadeias de suprimentos e a identificar lacunas e oportunidades deste campo de estudo. 
Em resposta, este trabalho se predispôs a construir um modelo de maturidade que mensura os aspectos inerentes à cadeia de suprimentos, bem como seus processos gerenciais, desenvolvido para ser acessível e capaz de ser adaptado atendendo os diversos setores da economia.

\subsection{2}

\section{Pesquisa Bibliográfica}

Nesta etapa foram realizados estudo exploratório e as análises que permitiram a consolidação e definição dos elementos conceituais teóricos de base. Em seguida, foi realizado o recorte bibliográfico para aprofundamento nos modelos de maturidade: foram pesquisadas as palavras-chaves "supply chain maturity model" na plataforma Google Acadêmico. Os resultados foram ordenados por maior incidência em número de citações, para se garantir estudar os modelos mais relevantes. A partir da classificação, foram considerados os 50 primeiros resultados, sendo descartados trabalhos que não produziram efetivamente um modelo de maturidade ou que somente faziam aplicação de outros modelos existentes e também foram descartados trabalhos que realizavam apenas uma revisão da literatura, sem proposta de novo modelos de maturidade.

Importante salientar que este referencial bibliográfico começou a ser construído em 2016. Os resultados das etapas pertencentes a esta fase da pesquisa, estão na seção 2 e 4.1, onde dados foram consolidados, chegando a eleição dos elementos de base a serem utilizados no modelo proposto por esta dissertação.

\subsection{3}

\section{Desenvolvimento}

A etapa pode ser considerada a etapa central deste trabalho, pois, refere-se ao trabalho de criação do modelo, abrangendo desde a definição da estratégia até sua finalização. Como já mencionado, este trabalho traçou o desenvolvimento de um modelo genérico e para esta etapa optou-se por defini-lo a partir da grade de classificação proposta por Mettler (2009), conforme tabela 16, onde a classificação do modelo proposto é indicada nas células sombreadas em cinza. 
Tabela 16: Definição das características do modelo da pesquisa segundo classificação de Mettler (2009)

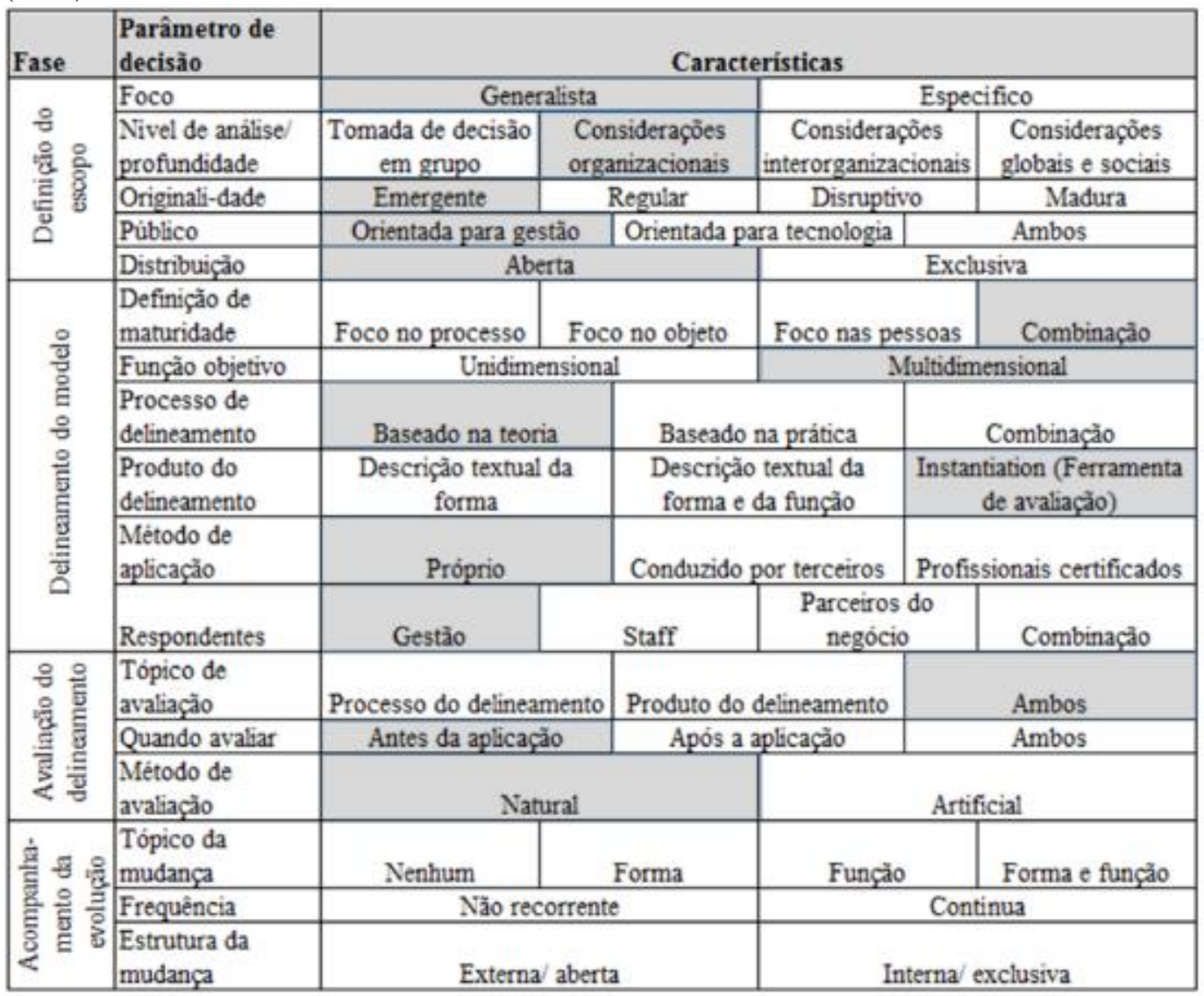

Fonte: Adaptado de Mettler (2009)

Sendo assim, o modelo desenvolvido se classifica com relação a definição do escopo, com foco generalista, um nível de profundidade com considerações organizacionais, de originalidade emergente, em relação ao público está orientado para gestão e de distribuição aberta.

Em relação ao delineamento do modelo, como definição de maturidade considerou-se como premissa uma combinação entre foco no processo e foco no objeto. Tendo em vista que função objetivo é a forma com que as variáveis do modelo se organizam numa equação matemática, com o objetivo de otimizar os resultados (minimização ou maximização), a função para este modelo é multidimensional de maximização, uma vez que o nível de maturidade da organização estará em função das diversas variáveis distribuídas nas seis dimensões de maturidade e partindo do pressuposto que todas as organizações empenham esforços para maximizar seus resultados. $\mathrm{O}$ processo de delineamento se baseia na teoria e o produto de delineamento é uma ferramenta de avaliação onde o método de aplicação é próprio e os respondentes são membros da gestão. 
Já para a avaliação de delineamento, tem-se como tópico de avaliação o produto do delineamento, ou seja, o próprio modelo juntamente com a ferramenta. Uma vez que para Mettler (2009), a avaliação de delineamento por método natural ocorre quando se utiliza da aplicação no mundo real, pode-se assim classificar o método de avaliação deste modelo como sendo natural. Por uma restrição de tempo e recursos, esta pesquisa não se predispõe a acompanhar a evolução do modelo no horizonte temporal na organização em que será aplicado, esta fase está sugerida para pesquisas futuras.

O modelo de maturidade desenvolvido por este trabalho se baseia nos modelos de Reyes \& Gianchetti (2010) e no modelo de Lockamy \& McCormack (2004), a opção por estes modelos e a análise dos modelos apresentados no referencial teórico estão detalhadas no capítulo 4.

A estrutura conceitual se deu a partir da análise e da exploração dos conceitos gerais dos modelos de base, sendo identificados os atributos da maturidade utilizados pelos autores. Esta identificação foi feita de forma dedutiva, a partir do entendimento da estrutura esquemática de cada modelo. Foram identificadas as práticas defendidas e como forma de organização, criou-se subdivisões chamadas de dimensões, onde nas mesmas se agrupam as práticas com características semelhantes.

Foi necessário, para isso, identificar os atributos e características apresentadas pelos modelos, identificando e eliminando sobreposições, através de um trabalho de depuração de redundâncias. Vale ressaltar que foram localizadas poucas sobreposições, uma vez que, como posto, os modelos possuíam focos distintos na avaliação da cadeia de suprimentos. Com base nas dimensões finais, desenhou-se as características esperadas pelas organizações maduras, também com base nos modelos de origem. Em seguida, foi estruturada a composição de estágios, que deu origem ao que efetivamente precisava ser medido pelo modelo.

Importante salientar que o resultado obtido e a seguir apresentado no capítulo 4 é apenas uma proposição a partir dos modelos base e que precisa ter sua estabilidade observada ao longo do tempo, no que se refere a estrutura do modelo, no desenho de suas dimensões, agrupamento de seus atributos e hierarquização dos níveis de maturidade

Em relação à tipificação do modelo, é classificado como híbrido, pois agrega o modelo conceitual e uma ferramenta associada, corroborando com a carência 
identificada pela pesquisa realizada por Paes (2011) que indica grande concentração de grades de maturidade como mecanismo de avaliação e apenas $17,86 \%$ dos modelos utilizam questionários Likert como forma de aplicação. Conforme tabela 17, nenhum modelo híbrido foi localizado no recorte de horizonte temporal proposto pela pesquisa de Paes (2011).

Tabela 17: Análise de modelos de maturidade SCM conforme formas de aplicação

\begin{tabular}{|ccc|}
\hline Formas de Aplicação & Quantidade & $\%$ \\
\hline Grade de maturidade & 16 & $57,14 \%$ \\
\hline Não disponível / outros & 6 & $21,43 \%$ \\
\hline Questionário Likert & 5 & $17,86 \%$ \\
\hline Modelo estruturado CMMI & 1 & $3,57 \%$ \\
\hline Modelo hibrido/escala Likert & 0 & $0,00 \%$ \\
\hline Total de modelos analisados & 28 & $100 \%$ \\
\hline
\end{tabular}

Fonte: Paes (2011)

O desenvolvimento do instrumento atende a duas partes essenciais de um modelo de maturidade, o diagnóstico e a análise. Esta etapa contemplou a elaboração de um instrumento de pesquisa, onde foram realizadas análises dos instrumentos dos modelos base e o cruzamento das dimensões preconizada por Reyes \& Gianchetti (2010) e Lockamy \& McCormack (2004). Novamente foi realizado um esforço de eliminação de redundância, uniformização e estratificação. Esta forma de organizar os resultados permitirá que as empresas obtenham a avaliação apenas de uma dimensão de suas cadeias de suprimentos, se assim desejarem.

Como contribuição para o instrumento também foram formuladas questões da função retorno, uma vez que, a área de processo return do SCOR não era abordada na época da concepção do estudo de Lockamy \& McCormack (2004) e somente foi introduzida após a versão 5 do SCOR.

Para construção da ferramenta, esta pesquisa utilizou como linguagem de programação o Visual Basic (VBA), versão 14.0 e o Excel com interface.

$\mathrm{O}$ ajuste no modelo e nas funcionalidades do instrumento, também considerada etapa do desenvolvimento (vide figura 14), é um produto da etapa de validação com os especialistas na pesquisa de campo. Todas as respostas emitidas pelos entrevistados, que contivessem indicações desde sugestões até reprovação, geraram reavaliação do modelo, tanto na avaliação ampla das características gerais e análise da consistência, quanto na avaliação de requisitos específicos. Por fim, 
todas as considerações relevantes foram adicionadas ao modelo final a seguir apresentado.

Após a etapa de aplicação no mundo real em ambiente organizacional, foram realizadas análises dos dados coletados, partindo do geral para o específico, ou seja, gerada a maturidade geral da companhia e observando de forma específica cada atributo, permitindo identificação do que possa ser potencializado, de acordo com a estratégia empresarial. Esta etapa também gerou inputs para atualização da ferramenta.

\subsection{4}

\section{Pesquisa de Campo}

Esta macro etapa engloba tanto os esforços metodológicos para validação do modelo com especialistas, quanto para a aplicação no mundo real.

A etapa de validação descreve os procedimentos metodológicos utilizados para validar a estrutura conceitual lógica do modelo proposto e o protótipo da ferramenta, com objetivo de obter um maior embasamento para a sua estrutura.

Foram conduzidas entrevistas individuais semiestruturadas, com o seguinte roteiro: na abertura os especialistas eram contextualizados brevemente sobre os objetivos, resultados esperados e limites de pesquisa; em seguida eram apresentando-lhes a versão do modelo e a ferramenta; e por fim, eram apresentadas as perguntas a serem respondidas na plataforma Survey Monkey. Os indivíduos que fizeram parte da pesquisa e os resultados obtidos com os mesmo na etapa de validação serão apresentadas na seção 4.4.1.

O roteiro de entrevistas foi estruturado de forma que o pesquisado tivesse que opinar em relação ao modelo e a ferramenta em duas esferas: (i) avaliação ampla das características gerais e a análise da consistência, (ii) a avaliação de requisitos específicos, de acordo com critérios embasados na literatura.

Garcia (2009) sugere em seu trabalho critérios para avaliação de constructos e esta pesquisa seguiu os critérios propostos pelo autor. A primeira parte da avaliação, sobre análise de características gerais e análise da consistência, foram questionados acerca dos seguintes critérios: (i) vantagens da sua aplicação; (ii) oportunidades de melhoria; e (iii) alcance de objetivos. Em relação a análise de requisitos específicos, os critérios: (i) interface - observando se a estrutura gráfica do modelo eram compreensíveis e amigáveis aos olhos do usuário; (ii) conteúdo - 
avaliando a aderência e relevância do conteúdo frente às necessidades da avaliação e melhoria da cadeia de suprimentos; (iii) encadeamento lógico - examinando se a sequência de preenchimento do formulário e de leitura do modelo eram inteligíveis e amigável ao usuário; (iv) viabilidade - identificando a capacidade do modelo de fato poder ser utilizado nas organizações; e (v) aceitabilidade - mensurando o possível nível de aceitação do modelo por profissionais de gestão em cadeia de suprimentos.

Após a apresentação, os entrevistados foram convidados a avaliar em uma escala de 0 - Discordo Plenamente a 5 - Concordo Plenamente cada critério na plataforma Survey Monkey, segundo o roteiro que pode ser visto na tabela 18.

Tabela 18: Roteiro para Validação da Estrutura do Modelo e Instrumento de Pesquisa

\begin{tabular}{|c|c|c|}
\hline \multicolumn{3}{|r|}{ Validação da Estrutura Conceitual Lógica } \\
\hline & & Avaliação Geral e a Análise da Consistência \\
\hline $\mathrm{i}$ & $\begin{array}{l}\text { Vantagens de } \\
\text { aplicação }\end{array}$ & Quais as vantagens que identificou no modelo? \\
\hline ii & $\begin{array}{l}\text { Oportunidades de } \\
\text { Melhoria }\end{array}$ & Quais oportunidades de melhoria identificou no modelo? \\
\hline iii & $\begin{array}{l}\text { Alcance de } \\
\text { Objetivos }\end{array}$ & $\begin{array}{l}\text { Sabendo que este modelo foi elaborado com objetivo de medir o nível } \\
\text { de maturidade em cadeias de suprimentos, considera que este modelo } \\
\text { atingiu seu objetivo? }\end{array}$ \\
\hline \multicolumn{3}{|r|}{ Avaliação de Requisitos Específicos } \\
\hline $\mathrm{i}$ & Interface & $\begin{array}{l}\text { Interface - Considero que a estrutura gráfica do modelo é } \\
\text { compreensível e amigável aos olhos do usuário. }\end{array}$ \\
\hline ii & Conteúdo & $\begin{array}{l}\text { Conteúdo - Considero que o conteúdo do modelo é relevante frente às } \\
\text { necessidades da avaliação da maturidade de uma cadeia de } \\
\text { suprimentos. }\end{array}$ \\
\hline iii & $\begin{array}{l}\text { Encadeamento } \\
\text { lógico }\end{array}$ & $\begin{array}{l}\text { Encadeamento Lógico - Acredito que a sequência de preenchimento do } \\
\text { formulário e de leitura do modelo sejam inteligíveis e amigável aos } \\
\text { usuários. }\end{array}$ \\
\hline iv & Viabilidade & $\begin{array}{l}\text { Viabilidade - Na minha opinião, o modelo seja é capaz de ser utilizado } \\
\text { de fato nas organizações. }\end{array}$ \\
\hline v & Aceitabilidade & $\begin{array}{l}\text { Aceitabilidade - Acredito que haverá boa aceitação do modelo por } \\
\text { parte de profissionais de gestão em cadeia de suprimentos. }\end{array}$ \\
\hline
\end{tabular}

Fonte: Elaborado por este trabalho

$\mathrm{Na}$ sequência, foi realizada uma análise das respostas emitidas, buscando associá-las com cinco critérios (5) aprovação; (4) sugestão; (3) neutralidade; (2) incerteza e (1) reprovação. Todas as sugestões de alteração dos especialistas foram acatadas, gerando alterações na ferramenta. 
Em relação aos sujeitos da pesquisa, o processo de amostragem foi realizado de forma não-probabilística intencional, considerando a proximidade com pesquisadores e profissionais participantes, obedecendo dois critérios: possuir mais de 10 anos de experiência no setor de atuação e formação mínima de pós-graduação stricto sensu. Na tabela 19, a seguir, apresenta-se os sujeitos e suas características a partir dos critérios observados.

Tabela 19: Amostra dos entrevistados para validação do modelo

\begin{tabular}{|ccccc|} 
Especialista & $\begin{array}{c}\text { Anos de } \\
\text { experiência }\end{array}$ & Cargo na empresa & Segmento & Formação \\
\hline 1 & 10 & Professor / Especialista & Transportes & $\begin{array}{c}\text { Pós- } \\
\text { doutorado }\end{array}$ \\
\hline 2 & 11 & Professor / Analista de Sistemas & Academia / TI & $\begin{array}{c}\text { Pós- } \\
\text { doutorado }\end{array}$ \\
\hline 3 & 15 & $\begin{array}{c}\text { Gerente Geral de Planejamento } \\
\text { Logístico }\end{array}$ & Telecomunicações & Mestrado \\
\hline 4 & 13 & Professor / Pesquisador & Academia & Pós- \\
\hline
\end{tabular}

Fonte: Elaborado por este trabalho

Após a validação com os especialistas, a versão do modelo foi aplicada em ambiente organizacional. Foram selecionadas duas empresas, com o critério que fosse de grande porte com informações históricas capazes de demonstrar a existência de uma gestão logística estruturada e que fosse aberta e acessível à pesquisa acadêmica.

A escolha da empresa para esta etapa também se deu de forma nãoprobabilística intencional e por isso entende-se a fragilidade do método, onde a organização escolhida pode não ser representativa do conjunto de empresas de seu segmento. 


\section{4 \\ Resultados da Pesquisa}

\section{1 Escolha dos Modelos de Maturidade}

Para avançar na investigação da problemática de pesquisa e preencher a lacuna referente à deficiência de pesquisas sobre modelos de maturidade standard aplicados à gestão de cadeia de suprimentos, que se proponha a atender todos os mercados e que possam estar mais acessíveis às empresas, foram escolhidos os modelos: de Reyes \& Gianchetti (2010) e o modelo de Lockamy \& McCormack (2004) para servirem de base para estruturação do modelo de maturidade aqui proposto.

\subsection{1}

\section{Análise dos Modelos de Maturidade}

Com objetivo de atender as premissas assumidas por este trabalho, a escolha dos modelos base priorizou modelos que complementarmente fossem baseados no conceito de capabilidade de processos, dispor de métricas precisas de mensuração de dimensões e baseados em modelos de referência que conferissem robustez aos constructos.

O modelo de Stevens (1989) é centrado na integração das funções de uma cadeia de suprimentos e tem menor ênfase nos processos de gestão. Quanto aos seus elementos característicos, ressaltam-se o nível de estoques, as fronteiras organizacionais, o foco estratégico, as ineficiências ao longo da cadeia, o compartilhamento de informações entre os membros componentes e a cooperação com fornecedores e clientes.

Como observado, o modelo de Christopher (1997) não se estrutura no conceito de capabilidade de processos, apesar de sugerir estágios evolutivos, mas pressupõe a evolução da atuação logística e do grau de integração entre áreas funcionais e de seus processos que sustentar as atividades de negócios na cadeia de suprimentos. O modelo concebe que a organização é madura, quando atinge o 
estágio de organização de processos em uma logística integrada, avaliando o resultado desta integração no nível de serviço e custo total.

Entretanto, o modelo não sugere métricas que mensurem com precisão e eficiência o grau de integração da empresa. Esta lacuna é preenchida em outros modelos, como o CMMI, sendo assim o modelo se enquadra mais como uma sistematização da evolução da integração nas empresas ou ainda como um mapa de melhorias do que como um modelo de maturidade.

Já o modelo de Ayers \& Malmberg (2002) foca nas competências operacionais e menos nos processos de gestão e está relacionado com o nível de integração na cadeia. Para os autores, o desenvolvimento dessas competências operacionais é necessário para a evolução entre estágios de maturidade na gestão da cadeia de suprimentos. No que tange aos seus elementos característicos, destacam-se as competências em gestão de projetos, otimização e integração da estrutura organizacional, a disponibilidade de informações ao longo da cadeia, a parceria e o compartilhamento de ganhos.

Retomando o modelo do Computer Sciences Corporation Framework - CSC apresentado no referencial teórico, Poirier et. al. (2009) esclarecem que a cultura organizacional nas empresas, pode ser o grande obstáculo no progresso de suas ações em direção a níveis superiores de excelência. Empresas permanecem com ideias de centralização da inovação por receio de que ajuda externa signifique ineficiência interna e compartilhamento de informações internas seja perigoso em virtude da concorrência existente entre os mercados. Os autores apontam algumas estratégias para que as empresas vençam as barreiras, alcançando níveis mais evoluídos de maturidade e acrescentam que as empresas só podem expandir seus limites de eficiência quando sua gestão, em especial nas áreas vinculadas à área de operações, resolva romper com essas premissas e restrições impostas por sua cultura interna. Mas o modelo é limitado uma vez que apenas mede a integração da cadeia e o impacto em processos, relacionamento com fornecedores e fluxo de informação.

Uma crítica a este modelo é que desde o nível 1 os autores já sugerem certo nível de integração com uso de modelos de referências, sendo assim, o modelo não abrange empresas com níveis realmente baixos de maturidade.

O modelo de Lockamy \& McCormack (2004) sustenta que uma organização deve orientar suas estratégias e esforços a uniformidade e horizontalidade dos 
processos da cadeia de suprimentos, em oposição à rigidez funcional hierárquica das empresas, com ênfase na satisfação do cliente para o desenvolvendo da maturidade na organização.

O modelo de Lockamy \& McCormack (2004) engloba características relacionadas à estrutura e medição dos processos, à satisfação do cliente, à cooperação, ao planejamento colaborativo, ao compartilhamento de ganhos e aos custos da cadeia. Tal modelo é o mais completo dentre os identificados na pesquisa bibliográfica com foco em processo gerencias, e, em virtude disso, ele foi um dos modelos adotados para servir como base para o desenvolvimento do modelo de medição de maturidade em cadeias de suprimentos, proposto por esta dissertação.

O modelo é o primeiro, dentre os avaliados, que dispõe de métricas precisas de mensuração, permitindo extrapolação. O constructo se destaca, pois, parte da importante referência para processos de negócio em modelo de maturidade (BPOMM) e do guia de referência em operações de cadeia de suprimentos (SCOR) e se baseia em capabilidades de processos, que definem: controle, previsibilidade, efetividade. Ou seja, o modelo não apenas mede a existência de determinado processo, mas investiga se o mesmo é planejado, controlado e efetivo.

O modelo de Daozhi et al. (2006) propõe uma avaliação ampliada, uma vez que não abrange apenas a avaliação de processos, mas das competências e atividades que tangem uma cadeia de suprimentos. Trata-se de um modelo tridimensional, que inclui: maturidade da gestão, maturidade do ambiente e maturidade dos recursos, onde a aferição do estágio de maturidade em que uma empresa se encontra, mede o impacto em riscos e custos, regulamentações, comunicação e sinergia dos recursos entre a cadeia.

O Supply Chain Maturity Model do Performance Measurement Group (2007) enfatiza a evolução de um nível funcional para um nível de colaboração, passando pelos estágios intermediários de integração interna e externa. Seus elementos característicos focam, dentre outros aspectos, nos processos, nos fluxos de informações, nas parcerias entre os membros da cadeia e na gestão de recursos.

O modelo é vantajoso pela simplicidade de aplicação, e se destaca por ter em sua trajetória de desenvolvimento as melhores práticas que a PRTM e PMG captaram do meio industrial e empresarial e ainda conta com padrão de linguagem simples aliado ao SCOR. O modelo se demostra efetivo para avaliação e desenvolvimento da capabilidade em operações ao longo da cadeia de suprimentos 
(PMG, 2007). Entretanto, o modelo se predispõe a medir apenas o nível de integração da cadeia.

O modelo proposto por Oliveira (2009) é bastante robusto e propõe a avaliação processos na gestão de cadeia de suprimentos a partir de uma abordagem quantitativa e qualitativa. Entretanto, o modelo se limita em avaliar apenas os processos organizacionais e não se baseia em desenvolvimento de capabilidade e funções, como outros modelos aqui apresentados.

Dentre as inovações desse modelo, se destacam a dinâmica de precedência entre as competências da gestão da cadeia de suprimentos e a identificação dos pontos chaves de transição entre os níveis de maturidade evolutivos (OLIVEIRA, 2009). Mas uma lacuna do modelo é que apesar de ajudar os gestores a perceber o estágio atual de desenvolvimento da gestão logística das empresas e a identificar as competências que faltam para se atingir estágios de maturidade maior, o modelo é complexo em sua aplicação e pouco acessível às organizações.

O modelo de Reyes \& Gianchetti (2010) se destaca dentre os modelos apresentados por ser um metamodelo que se predispõe a englobar todos os aspectos tangíveis que envolvem uma cadeia sob a concepção de processos de negócios.

A tomada de decisões sobre melhorias na cadeia de suprimentos, sem adequada análise interdisciplinar pode levar a decisões desastrosas, resultando em desperdício de tempo, dinheiro e posição de mercado. Por estas razões, há a necessidade de orientações de modelos baseados nas melhores práticas (Reyes \& Gianchetti, 2010).

Netland e Alfnes (2011) corroboram com um argumento em que uma vertente mais holística é necessária para estudos e aplicações em cadeias de suprimentos, uma vez que as cadeias de suprimentos possuem também uma dimensão interdisciplinar complexa inerente. Este argumento reforça a importância da existência de modelos de base prática como de Reyes \& Gianchetti (2010), um dos escolhidos para a elaboração do constructo proposto neste trabalho.

O modelo de Reyes \& Gianchetti (2010) é o maior em termos de número de dimensões avaliadas na cadeia de suprimentos. O constructo é o primeiro que traz, de maneira clara e abrangente, a avaliação do sistema de controle de desempenho da organização. Também é o único, dentre os avaliados, que tem uma dimensão dedicada a avaliar a maturidade dos recursos humanos e está entre os primeiros modelos que agregam a perspectiva do cliente (além do modelo de Mendes, 2011), 
não apenas sinalizando a satisfação do mesmo como consequência dos processos organizacionais, mas questionando o papel do cliente e sua participação nos processos produtivos.

Dos que tratam acerca de tecnologia, Reyes \& Gianchetti (2010) demonstraram ser o mais amplo. Isso se deu pela robustez do guia de referência para arquiteturas e integração de sistemas empresariais, o GERAM, utilizado pelos autores, permitindo descrever a estrutura de uma empresa e sua decomposição em subsistemas. Além disso é o primeiro modelo dentre os avaliados que buscou identificar a maturidade da empresa estratificada pelo nível de decisão (gerencial, tático e operacional), buscando um entendimento integral dos fenômenos da cadeia.

Entretanto, o modelo não possui um instrumento de fácil aplicação, comparando com outros modelos e é menos robusto em medir implantação de processos gerenciais, uma vez que não utiliza o conceito ampliado de capabilidades que mede os processos na perspectiva do controle, previsibilidade e efetividade. Além disso, em princípio o modelo foi desenvolvido para ser aplicado no setor industrial.

O modelo DDSC-MM de Mendes (Mendes, 2011; Mendes et al., 2016) destaca-se por medir o quão orientada uma organização está para a demanda, mas não se predisponde a ser um modelo cumulativo e seu framework não se destina a ser uma solução standard e fixa, que sirva aos diversos setores da economia em seus mais variados momentos no ciclo de vida. Os autores assumem que existe uma dificuldade de sua generalização para diferentes contextos e que o modelo necessita ser adaptado a cada aplicação. Mendes (2011) conclui seu trabalho indicando que o modelo precisa ser reformulado para empresas que não possuem um processo de fabricação, como empresas de serviços e varejo.

Vale ressaltar que esta dissertação de mestrado, em reposta a oportunidade de pesquisa detalhada na seção 1.1, tem por premissa estruturar um modelo de maturidade que tenha por enforque no gerenciamento da cadeia de suprimentos. Paes (2011) em sua pesquisa concluiu que o foco principal da maior parte dos modelos de maturidade avalia apenas as atividades logísticas básicas, indicando oportunidade para surgimento de modelos de maturidade que foque no gerenciamento da cadeia de suprimentos de forma ampliada.

A escolha foi feita levando-se em consideração o caráter interdisciplinar do modelo de Reyes \& Gianchetti (2010), que abrange uma avaliação de múltiplos 
perspectivas, onde suas dimensões conseguem ir além de outras propostas de avaliação. Ainda acrescenta-se o fato de que o modelo possui uma capacidade de avaliação holística, aproximando-se da representação real do caráter interdisciplinar da gestão da cadeia de suprimentos, obtendo uma medida a partir da avaliação de cada uma das dimensões.

Já a escolha do modelo de Lockamy \& McCormack (2004) se deu, por ser o mais completo no âmbito de avaliação de processos. Apesar de esta esfera ser abordada no modelo de Reyes \& Gianchetti (2010), Lockamy \& McCormack (2004) conseguiram ser mais detalhados e possuir um foco assertivo em processos gerenciais, e sendo assim, este foi o segundo adotado como base para o desenvolvimento do modelo de maturidade desta dissertação.

As duas mais valiosas contribuições do modelo de Lockamy \& McCormack (2004), como modelo base, são a sua robustez na proposta de avaliação dos processos, alinhados com a referência do BPO para gerenciamento de processos em SCM e a perspectiva do SCOR, focando nas áreas de processos chave Plan, Source, Make e Delivery. A dimensão de Return não estava presente no modelo original e é uma contribuição desta dissertação de mestrado.

Sumarizando as principais características e a análise dos modelos de maturidade acima apresentados, segue a tabela 20.

Tabela 20: Amostra dos entrevistados para validação do modelo

\begin{tabular}{|c|c|c|c|c|}
\hline Stevens (1989) & Christopher (1997) & $\begin{array}{l}\text { Ayers \&Malmberg } \\
\text { (2002) }\end{array}$ & CSC (2003) & $\begin{array}{c}\text { Lockamy \& } \\
\text { McCormack (2004) }\end{array}$ \\
\hline $\begin{array}{c}04 \text { estágios } \\
\text { (1) linha base } \\
\text { (4) integração } \\
\text { externa } \\
\text { Mede nível de } \\
\text { integração, está } \\
\text { centrado na } \\
\text { integração da SC e } \\
\text { com menor ênfase } \\
\text { nos processos de } \\
\text { gestão. }\end{array}$ & $\begin{array}{c}\text { 04 estágios } \\
\text { (1)Informal } \\
\text { (4)Externa } \\
\text { Focado nas } \\
\text { atividades } \\
\text { logísticas. } \\
\text { Não se estrutura } \\
\text { em capabilidade. } \\
\text { Avalia resultado da } \\
\text { integração de SC } \\
\text { no nível de serviço } \\
\text { e custo total. } \\
\text { Não sugere } \\
\text { métricas com } \\
\text { precisão. }\end{array}$ & $\begin{array}{c}05 \text { estágios } \\
\text { (1)Disfuncional } \\
\text { (5)Contribuição } \\
\text { Estratégica } \\
\text { Base em SCM } \\
\text { Foco nas } \\
\text { competências } \\
\text { operacionais e } \\
\text { menos nos } \\
\text { processos de } \\
\text { gestão e nível de } \\
\text { integração na } \\
\text { cadeia. }\end{array}$ & $\begin{array}{c}05 \text { estágios } \\
\text { (1)Integração } \\
\text { (05) Completa } \\
\text { Conectividade } \\
\text { Baseia-se em } \\
\text { função logística } \\
\text { Entende que a } \\
\text { Cultura } \\
\text { Organizacional } \\
\text { pode ser um } \\
\text { entrave para o } \\
\text { desenvolvimento } \\
\text { organizacional. }\end{array}$ & $\begin{array}{c}05 \text { níveis } \\
\text { (01)Ad Hoc } \\
\text { (05)Estendido } \\
\text { Com base no } \\
\text { BPOMM e SCOR. } \\
\text { Mais completo em } \\
\text { processo } \\
\text { gerencias, com } \\
\text { métricas precisas e } \\
\text { abordagem } \\
\text { quantitativa. } \\
\text { Baseia-se em } \\
\text { Capabilidade, com } \\
\text { a perspectiva de } \\
\text { controle, } \\
\text { previsibilidade e } \\
\text { efetividade. }\end{array}$ \\
\hline
\end{tabular}




\begin{tabular}{|c|c|c|c|c|}
\hline $\begin{array}{c}\text { Daozhi et al. } \\
(2006)\end{array}$ & PMG (2007) & Oliveira (2009) & $\begin{array}{l}\text { Reyes \& Gianchetti } \\
(2010)\end{array}$ & $\begin{array}{l}\text { Mendes et } \\
\text { al.(2016) }\end{array}$ \\
\hline $\begin{array}{c}04 \text { níveis } \\
\text { (1)Inexistência de } \\
\text { Processos } \\
\text { (04) Colaboração e } \\
\text { Sinergia } \\
\text { Modelo possui } 03 \\
\text { dimensões: gestão, } \\
\text { ambiente e } \\
\text { recursos. } \\
\text { Avalia processos, } \\
\text { competências e } \\
\text { atividades de SC. }\end{array}$ & $\begin{array}{l}04 \text { estágios } \\
\text { (1)Foco Funcional } \\
\text { (4)Estratégia } \\
\text { Colaborativa } \\
\text { Base no SCOR e no } \\
\text { conceito de } \\
\text { capabilidade } \\
\text { Operacional. } \\
\text { Mede a integração } \\
\text { da cadeia. }\end{array}$ & $\begin{array}{l}05 \text { estágios } \\
\text { (1)Fundação } \\
\text { (4)Dinâmica } \\
\text { Abordagem } \\
\text { quantitativa e } \\
\text { qualitativa. } \\
\text { Limitado à } \\
\text { processos } \\
\text { organizacionais e } \\
\text { sem instrumento } \\
\text { acessível. }\end{array}$ & $\begin{array}{l}7 \text { Visões e } 5 \text { níveis } \\
\text { (1)Indefinido } \\
\text { (5)Liderança } \\
\text { Baseado em } \\
\text { experimentação e } \\
\text { no GERAM, CMMI } \\
\text { e SCOR. } \\
\text { Análise } \\
\text { interdisciplinar e } \\
\text { com maior número } \\
\text { de dimensões. } \\
\text { Mais amplo nas } \\
\text { dimensões de TI, } \\
\text { RH e Clientes. }\end{array}$ & $\begin{array}{c}05 \text { níveis } \\
\text { (1)Básica } \\
\text { Empurrada } \\
\text { (5)Orientada pela } \\
\text { Demanda } \\
03 \text { Componentes } \\
15 \text { categorias } \\
\text { Destaca-se em } \\
\text { DDSC. } \\
\text { Framework não } \\
\text { standard e fixo. } \\
\text { Dificuldade de } \\
\text { generalização. }\end{array}$ \\
\hline
\end{tabular}

Fonte: Elaborado por este trabalho

A escolha também se deu pelo fato de os dois modelos de maturidade terem sido revelados como os mais relevantes dentre os modelos de maturidade do recorte teórico com foco em gestão de cadeia de suprimentos. Em um trabalho desenvolvido por Tramarico et al. (2015) foi realizado um estudo detalhado, com o uso do software CitNetExplorer para análise de dados, sobre modelos de maturidade mais citados em artigos acadêmicos na referida área de conhecimento. O resultado da pesquisa identificou que os principais autores citados, são Lockamy \& McCormack (2004) e que deram origem a uma rede de citação, seguido de Reyes e outros autores, como pode ser observado na figura 15. A visualização apresenta os trabalhos mais frequentes baseado na relevância.

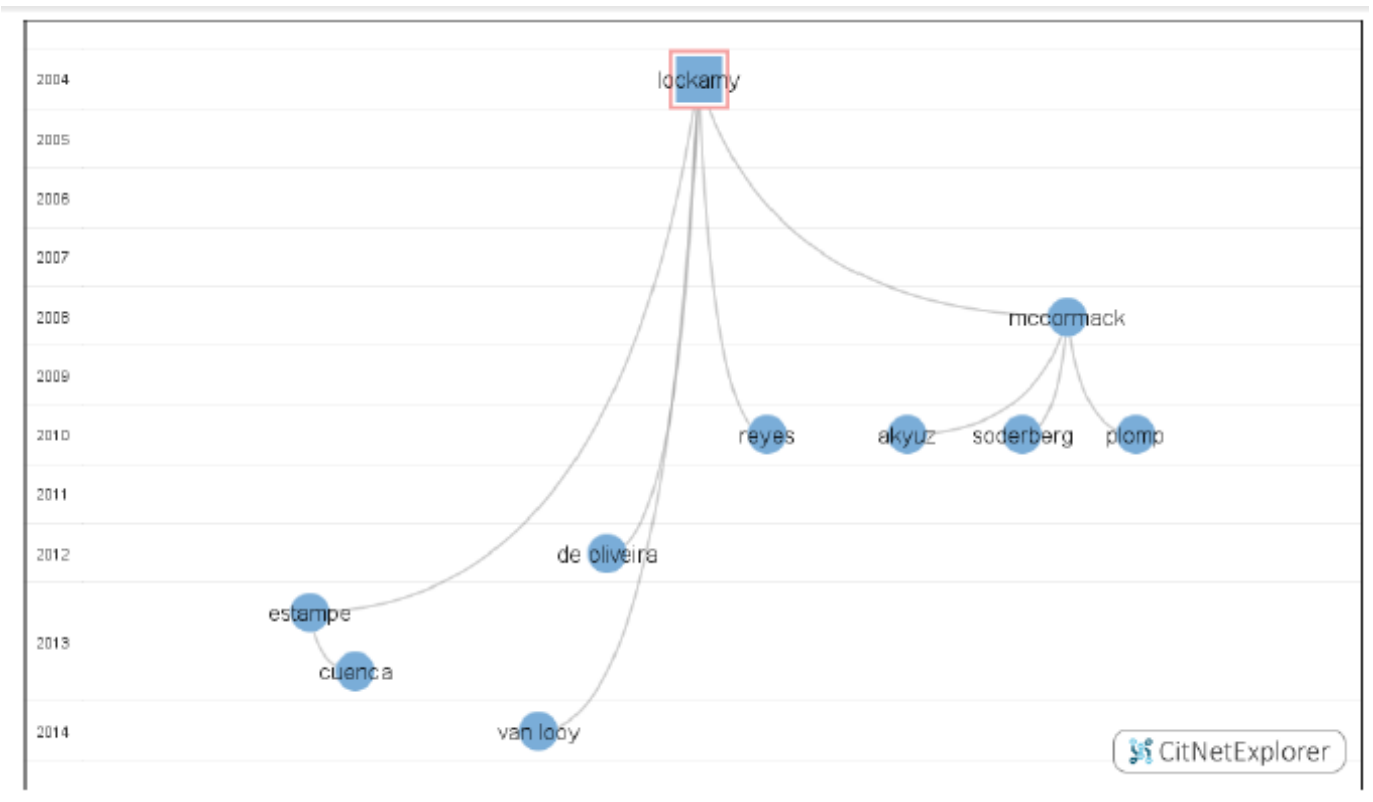

Figura 15: Autores mais citados em modelos de maturidade em cadeias de suprimentos Fonte: Tramarico et al. (2015) 
Para elaboração de um método de apoio à aplicação do constructo foram observados também os modelos do CMMI pelo SEI (2001), o Project Management Maturity Model desenvolvido por Harold Kerzner (2003) e o Supply Chain Maturity Assessment Test proposto por Netland e Alfnes (2008). Esta operacionalização do modelo está detalhada na seção 4.3.

\section{2}

\section{Modelo de Maturidade Proposto}

O modelo de maturidade proposto nesta dissertação tem como atribuição medir o grau de maturidade da cadeia de suprimentos de uma organização. O modelo se predispõe a gerar resultados compatíveis e comparáveis, isto é, será possível realizar análises de benchmarking, aferindo qual organização é a mais madura, em comparação com outras. Da forma análoga, a empresa poderá comparar-se a si própria no decorrer do tempo, acompanhando seu desenvolvimento e evolução.

Nesta seção, serão apresentadas cada particularidade do modelo, bem como o instrumento de diagnóstico e o método de cálculo dos níveis de maturidade. Por fim, serão apresentados os dados coletados na etapa de validação com os especialistas e expostos os resultados da aplicação em ambiente organizacional.

\subsection{1}

\section{Visão Conceitual e Padrão Representativo}

O modelo de maturidade é composto por suas dimensões, atributos e seus respectivos níveis de maturidade, determinado pelas práticas adotadas pela organização que está sendo avaliada. Também faz parte do modelo de maturidade a ferramenta de medição, com a qual são coletadas as informações pertinentes para o cálculo da maturidade.

A visão geral da estrutura é sustentada pelo conceito de que as dimensões do modelo se materializam pela derivação de seus atributos, que nada mais são que a execução das melhores práticas em cadeias de suprimentos, componho assim os níveis de maturidade, ou seja, certo grau de maturidade se caracterizará com o grau de desenvolvimento das práticas existentes em determinada cadeia de suprimentos. 
Sustenta-se que os gestores da cadeia de suprimento devam priorizar o máximo desempenho, para isso, identificando as dimensões de aplicação estratégicas e assim, estabelecer planos de melhoria orientados à implantação das práticas relacionadas àquela dimensão, que alinhada com as empresas pertencentes a mesma cadeia, gerará vantagem competitiva sustentável no longo prazo.

Tendo por base a análise do estado da arte dos modelos que basearam esta pesquisa, definiu-se por padrão representativo um modelo cúbico, representando a união das 6 dimensões de aplicação a serem avaliadas. A figura 16 apresenta a representação gráfica da estrutura do modelo desenvolvido.

O modelo pode ser melhor observado a partir da expansão do modelo cúbico, seu padrão representativo, onde se extrapola a visão das 6 dimensões do modelo. Nesta ampliação de entendimento, é possível observar que cada dimensão está representada por uma pirâmide de base quadrada de igual proporção onde no cubo fechado, pode-se apenas observar suas faces.

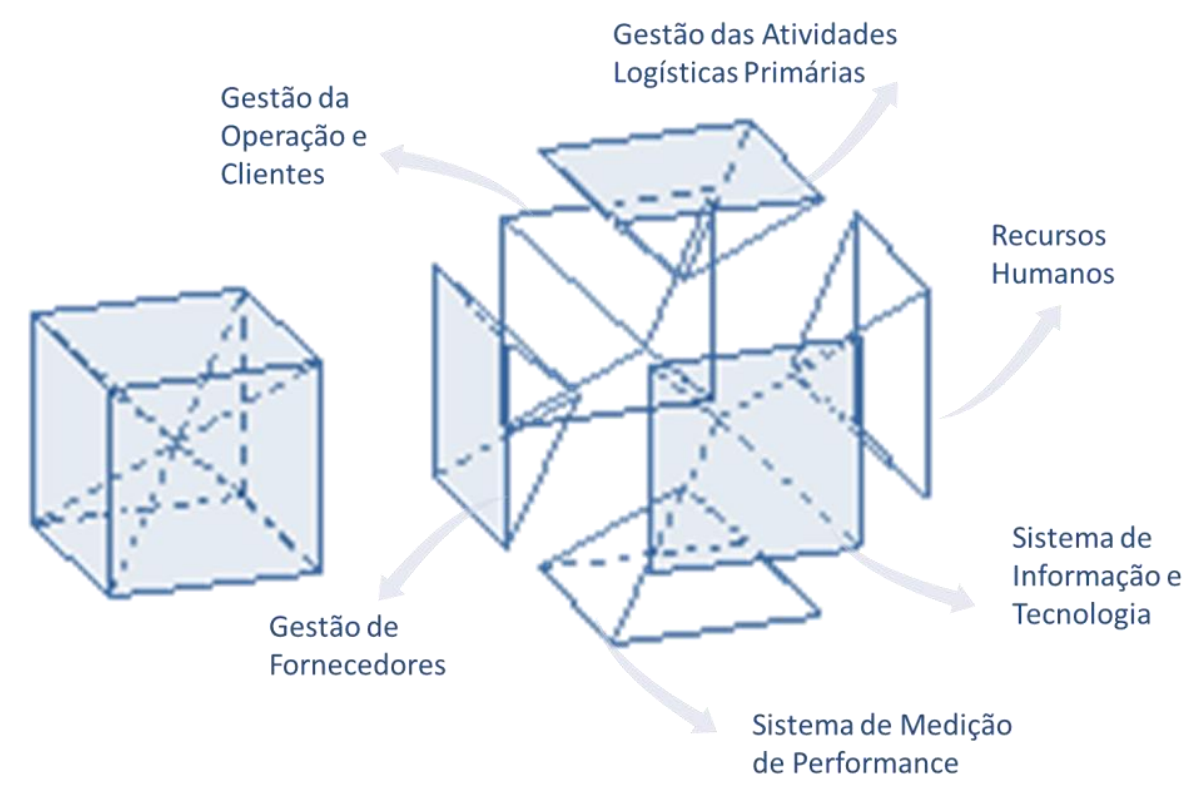

Figura 16: Dimensões de aplicação do modelo em 3D Fonte: Elaborado por este trabalho

As dimensões do modelo derivaram das dimensões apresentadas pelo modelo de Reyes \& Gianchetti (2010), onde os mesmos foram reavaliados e sintetizados. Cada dimensão ganhou a perspectiva da avaliação dos processos, herdados do modelo de Lockamy \& McCormack (2004), com fundamentação no SCOR e alinhados aos preceitos da abordagem BPO (Business Process Orientation), uma vez que o modelo base deriva desta abordagem. 
Para melhor compreender do modelo, é necessária a compreensão de três relações: (i) a relação entre as dimensões de desempenho e as estratégias da empresa; (ii) a relação entre as práticas, representadas pelos atributos no modelo, e os níveis de maturidade das dimensões de aplicação; e (iii) a relação entre o grau de importância estratégica da dimensão e seus respectivos níveis de maturidade.

A primeira estabelece um relacionamento entre as dimensões de desempenho e o desenvolvimento de estratégia que visem o melhor desempenho logístico. A segunda está associada ao grau de execução de práticas que se relaciona diretamente com o nível de desempenho nas dimensões de aplicação. A terceira visa fornecer indícios para a tomada de decisão no sentido de identificar e priorizar as dimensões de aplicação que precisam estar no foco do desenvolvimento de práticas organizacionais.

As dimensões representadas por cada uma destas pirâmides são: Gestão de Fornecedores - que trata dos aspectos relativos à garantia da qualidade no fornecimento de matérias-primas e materiais; Gestão da Operação e Clientes abrange às questões relativas a gestão da produção e qualidade dos serviços destinados aos clientes; Gestão das Atividades Logísticas Primárias - que abrange todas ações relativas à gestão de transportes, estoques, armazenagem e pedido; Recursos Humanos - faz referência aos funcionários envolvidos nos processos produtivos e serviços logísticos; Sistema de Informação e Tecnologia - refere-se às ações vinculadas aos sistemas de informação e gestão tecnológica dos processos logísticos; e Sistema de Medição de Performance - compreende ações de medição de desempenho logístico e da estrutura da organização. As dimensões serão mais detalhadas nas sessões a seguir.

Ainda com o objetivo de aprofundar o entendimento sobre o modelo, uma outra perspectiva de representação do modelo, se dá em formato $2 \mathrm{D}$ e pode ser vista abaixo na figura 17. Esta representação lembra a forma de um radar e ajuda a perceber como as dimensões de aplicação estão interligadas entre si, e por sua vez, individual e coletivamente geram os índices de maturidade que caracterizaram o nível de maturidade da organização. Antecipadamente, a representação do modelo nos permite observar que todas as dimensões do modelo de maturidade podem ser medidas separadamente e como as mesmas se relacionam com os níveis de maturidade global. 


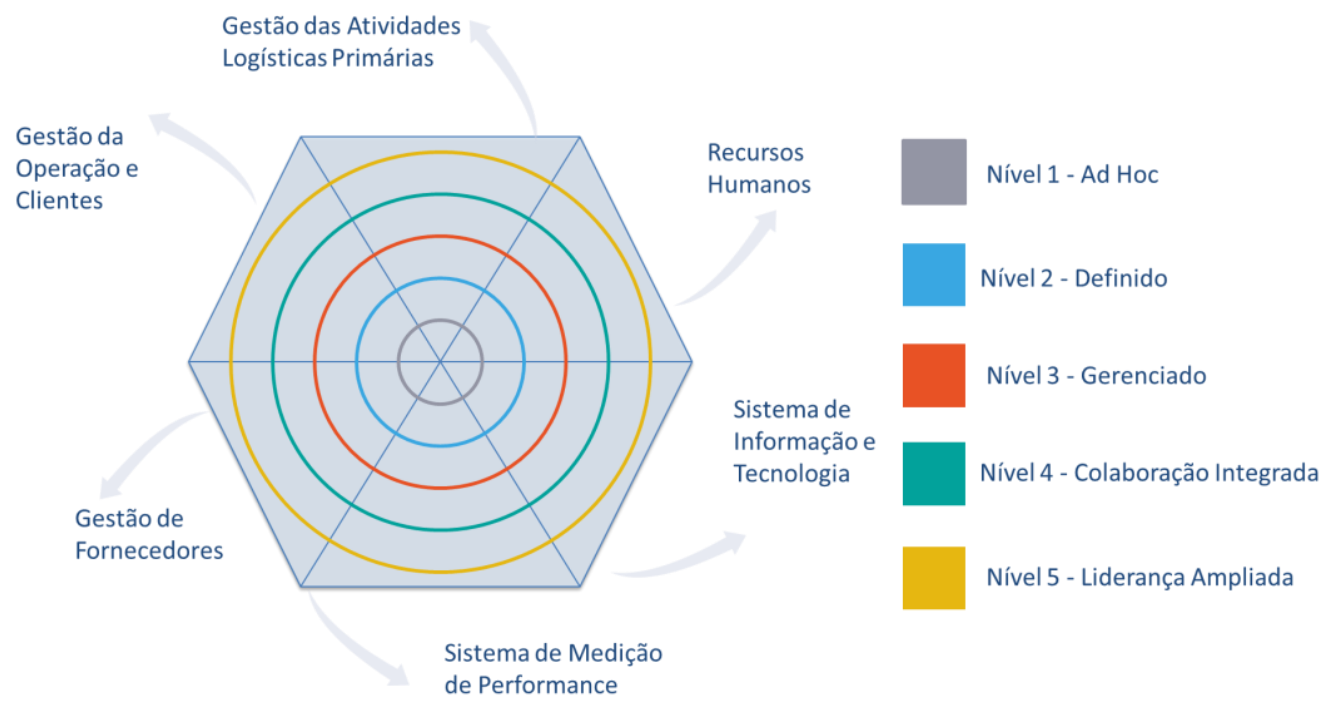

Figura 17: Dimensões de aplicação do modelo em 2D

Fonte: Elaborado por este trabalho

\subsection{2}

\section{Dimensões do Modelo}

As dimensões do modelo de maturidade descrevem as competências dentro da cadeia de suprimentos que uma empresa deve desenvolver e dominar, objetivando alcançar melhores resultados para a empresa. As dimensões são pensadas para haver uma mínima sobreposição de conceitos entre as dimensões.

No merge realizado por essa pesquisa, entre os modelos base foram necessárias adaptações com objetivo de padroniza-lo e transformá-lo em um constructo standard. Uma vez que, o modelo de Lockamy \& McCormack (2004) acrescenta com seu foco em processos gerenciais ao modelo de Reyes \& Gianchetti (2010), concebido orginalmente como base em empresas do setor industrial, conferindo maior generalidade ao modelo.

Cada dimensão, representada aqui por uma pirâmide de base quadrada, pode vista separadamente uma da outra. Sendo assim, os níveis de maturidade podem ser observados, analisados e medidos em cada uma das perspectivas separadamente, conforme ilustrado na figura 18. 


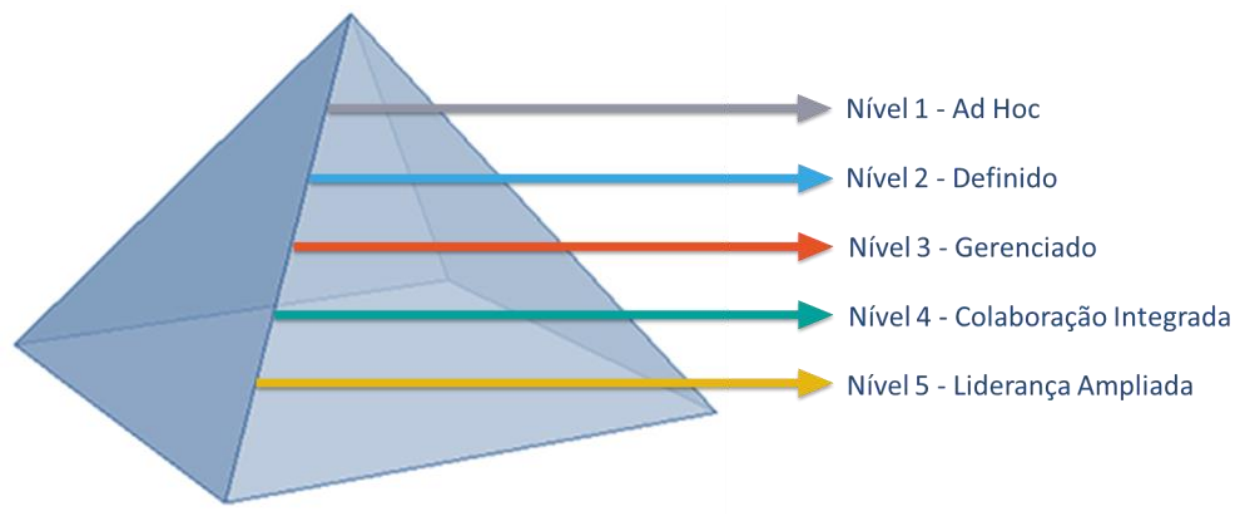

Figura 18: Aplicação do SCOR no modelo de referência Fonte: Elaborado por este trabalho

Na sequência, são apresentadas as dimensões do modelo, especificando o que está sendo mensurado em cada uma delas.

\section{a) Gestão de Fornecedores}

A dimensão Gestão de Fornecedores trata as funções, processos, atividades e tarefas relacionadas à integração, relacionamento, colaboração e desenvolvimento de fornecedores de matérias-primas e materiais na cadeia de suprimentos, segundo apresentado na Tabela 21 .

A dimensão inclui também as políticas, processos e procedimentos relacionados a: definição, seleção e desenvolvimento de fornecedores; definição e implementação de estratégias de colaboração, compartilhamento de informações, riscos, custos e benefícios entre clientes e fornecedores; implementação de garantia de qualidade no transporte e entrega de materiais; e acordos comerciais de colaboração.

Tabela 21: Práticas avaliadas relativas à dimensão Gestão de Fornecedores.

\begin{tabular}{|c|c|c|c|}
\hline Dimensão & \multicolumn{2}{|c|}{ Práticas Avaliadas } & Referências \\
\hline $\begin{array}{l}\text { Gestão de } \\
\text { Fornecedores }\end{array}$ & $\begin{array}{l}0 \\
0 \\
0 \\
0 \\
0 \\
0 \\
0 \\
0 \\
0 \\
0\end{array}$ & $\begin{array}{l}\text { Padronização e documentação da gestão de fornecedores; } \\
\text { Projetos de melhorias de operações de fornecimento; } \\
\text { Gerenciamento do desempenho de fornecedores; } \\
\text { Planejamento e controle da produção dos fornecedores; } \\
\text { Medição e análise de desempenho do nível de serviço e } \\
\text { Service Levels Agreements (SLA); } \\
\text { Políticas de contratação e seleção de novos parceiros; } \\
\text { Gerenciamento das operações integradas; } \\
\text { Análise estatística da logística de fornecimento; } \\
\text { Integração estratégica, desenvolvimento e gerenciamento } \\
\text { colaborativo com a rede de fornecimento; } \\
\text { Logística reversa; e } \\
\text { Colaboração no desenvolvimento de novos produtos. }\end{array}$ & $\begin{array}{l}\text { Pires (2009); Ballou } \\
\text { (2006); Reyes \& } \\
\text { Gianchetti (2010); } \\
\text { (McCormack, } \\
\text { 2001); (Bowersox, } \\
\text { et. al.,2010); } \\
\text { (Lambert e } \\
\text { Knemeyer, 2008); } \\
\text { Simchi-levi et. al., } \\
\text { 2003); (Poirier e } \\
\text { Quinn, 2004). }\end{array}$ \\
\hline
\end{tabular}

Fonte: Elaborado por este trabalho 


\section{b) Gestão da Operação e Clientes}

A Dimensão relativa à Gestão da Operação e Clientes abrange as funções, processos, atividades e tarefas relacionadas à transformação do produto ou serviço, bem como todas as ações para garantir a qualidade do serviço prestado na perspectiva do cliente. Esta dimensão está indicada na Tabela 22.

Esta dimensão inclui a questões relativas a Gestão da Produção e as ações de referência que agregam valor ao produto ou serviço, tais como: redução de defeitos, sucata e retrabalhos; padronização; otimização da logística interna; busca na redução do tempo de espera; e implementação de estratégias de planejamento de produção. A dimensão abrange também implementação de projetos em conjunto com clientes para aumentar a percepção de valor nos produtos e serviços fornecidos, buscando o atendimento das expectativas e a colaboração entre a empresa e seus clientes.

Tabela 22: Práticas avaliadas relativas à dimensão Gestão da Operação e Clientes

\begin{tabular}{|c|c|c|c|}
\hline Dimensão & \multicolumn{2}{|c|}{ Práticas Avaliadas } & Referências \\
\hline $\begin{array}{l}\text { Gestão da } \\
\text { Operação e } \\
\text { Clientes }\end{array}$ & $\begin{array}{l}0 \\
0 \\
0 \\
0 \\
0 \\
0 \\
0 \\
0 \\
0 \\
0 \\
0 \\
0\end{array}$ & $\begin{array}{l}\text { Documentação padronizada e projetos de melhorias na } \\
\text { gestão da operação; } \\
\text { Melhores práticas de programação e controle da } \\
\text { produção; } \\
\text { Gestão dos custos de produção; } \\
\text { Planejamento estratégico e análise estatística dos dados } \\
\text { de produção; } \\
\text { Gestão da qualidade, manutenção e custos; } \\
\text { Processos para descarte de material; } \\
\text { Métodos de análise quantitativa da demanda; } \\
\text { Integração interfuncional entre os departamentos; } \\
\text { Práticas avançadas de gestão dos serviços logísticos, } \\
\text { que garantam flexibilidade e agilidade; } \\
\text { Customização e inovação do portfólio de serviço; } \\
\text { Gestão da qualidade, manutenção e melhoria contínua; } \\
\text { Gerenciamento da demanda, colaboração e gestão dos } \\
\text { processos de negócios dos clientes. }\end{array}$ & $\begin{array}{l}\text { Novaes (2007); } \\
\text { Pires (2009) } \\
\text { Gianchetti (2010); } \\
\text { Ballou (2006); } \\
\text { (McCormack, } \\
\text { 2001); (Bowersox, } \\
\text { et. al.,2010); } \\
\text { (Lambert e } \\
\text { Knemeyer, 2008) } \\
\text { Simchi-levi et. al., } \\
\text { 2003); (Poirier et. } \\
\text { al. 2009). }\end{array}$ \\
\hline
\end{tabular}

Fonte: Elaborado por este trabalho

Importante salientar que no modelo de Reyes \& Gianchetti (2010), as dimensões relativas à Gestão da Produção e Gerenciamento dos Clientes eram apresentadas em separado, porém os autores já previam certa sobreposição entre as mesmas, visto que em seu instrumento de pesquisas as questões para avaliar essas duas dimensões aparecem unificadas e a grande maioria das ações voltadas para 
geração de valor de um produto e aumento da satisfação do cliente se dá na produção ou nas funções agregadas à operação. Sendo assim, o modelo de maturidade, fruto desta pesquisa, unificou as duas dimensões nomeando-a como Gestão da Operação e Clientes.

\section{c) Gestão das Atividades Logísticas Primárias}

A Dimensão Gestão das Atividades Logísticas Primárias aparece na Tabela 23 e abrange todas as ações relativas à gestão de transportes, estoques, armazenagem e processamento de pedido; logo, todas as ações referentes a localização e controle de inventários de matérias-primas, produtos acabados, produtos em processo de fabricação, material para descarte e material de logística reversa, entre outros. Esta dimensão enfatiza a integração para aumento da produção, performance e otimização, buscando o melhor balanceamento entre demanda e capabilidades operacionais.

Tabela 23: Práticas avaliadas relativas à dimensão Gestão das Atividades Logísticas Primárias

\begin{tabular}{|c|c|c|c|}
\hline \multirow[b]{2}{*}{$\begin{array}{l}\text { Dimensão } \\
\text { Gestão das } \\
\text { Atividades } \\
\text { Logísticas } \\
\text { Primárias }\end{array}$} & \multicolumn{2}{|c|}{ Práticas Avaliadas } & Referências \\
\hline & $\begin{array}{l}0 \\
0\end{array}$ & $\begin{array}{l}\text { Processos padronizados e projetos de melhorias das } \\
\text { atividades básicas; } \\
\text { Mensuração da performance e análise estatísticas dos } \\
\text { resultados; } \\
\text { Gerenciamento dos processos logísticos físicos e } \\
\text { administrativos; } \\
\text { Integração tecnológica e comunicação; } \\
\text { Desenvolvimento de estratégias e aplicação de métodos } \\
\text { de otimização da operação; } \\
\text { Desenvolvimento de projetos, compartilhamento de } \\
\text { responsabilidades e resultados com parceiros na cadeia; } \\
\text { Envolvimento de centros de pesquisa e consultorias } \\
\text { para uso de métodos avançados de gestão; } \\
\text { Operações multimodais e alianças logísticas; } \\
\text { Método de reposição automática, tal como Vendor } \\
\text { Managed Inventory (VMI); } \\
\text { Atividades de Logística Reversa; e } \\
\text { Planos de contingências e Projetos de serviços físicos e } \\
\text { gerenciais no curto prazo para o cliente; }\end{array}$ & $\begin{array}{l}\text { Pires (2009); } \\
\text { Bowersox e Closs } \\
\text { (2010); Novaes } \\
\text { (2007); Lambert } \\
\text { (2008); Ballou } \\
\text { (2006); } \\
\text { (McCormack, } \\
\text { 2001); (Lambert e } \\
\text { Knemeyer, 2008) } \\
\text { Simchi-levi et. al., } \\
\text { 2003); (Poirier e } \\
\text { Quinn, 2004). }\end{array}$ \\
\hline
\end{tabular}

Fonte: Elaborado por este trabalho

\section{d) Recursos Humanos}

A dimensão relativa aos Recursos Humanos engloba as ações referentes aos funcionários da organização envolvidos nos processos produtivos e serviços 
logísticos, assumindo que este agente tem um papel chave para o aumento da qualidade das entregas da organização, impactando em todas as funções na cadeia. Estão incluídas nesta dimensão ações referentes à treinamento, cultura organizacional, motivação, condições de trabalho, remuneração, entre outros, conforme indicado na Tabela 24.

Tabela 24: Práticas avaliadas relativas à dimensão Recursos Humanos

\begin{tabular}{|c|c|c|c|}
\hline Dimensão & \multicolumn{2}{|c|}{ Práticas Avaliadas } & Referências \\
\hline $\begin{array}{l}\text { Recursos } \\
\text { Humanos }\end{array}$ & $\begin{array}{l}0 \\
0 \\
0 \\
0 \\
0 \\
0 \\
0 \\
0 \\
0\end{array}$ & $\begin{array}{l}\text { Processos padronizados e projetos de solução dos problemas } \\
\text { relativos aos recursos humanos; } \\
\text { Programas de recrutamento, seleção, treinamento e avaliação da } \\
\text { performance; } \\
\text { Gestão de pessoas e Gestão do capital intelectual; } \\
\text { Programas de motivação e retenção de profissional; } \\
\text { Programas de formação e qualificação profissional; } \\
\text { Avaliação da Produtividade e Performance; } \\
\text { Gestão de perdas por turnover e empowerment dos funcionários; } \\
\text { Comunicação e colaboração com o RH dos parceiros; e } \\
\text { Estratégias de gestão de Recursos Humanos alinhadas com as } \\
\text { metas organizacionais. }\end{array}$ & $\begin{array}{l}\text { Chiavenato } \\
\text { (2010); Pires } \\
\text { (2009); } \\
\text { Chopra e Meindl } \\
\text { (2011); } \\
\text { (McCormack, } \\
\text { 2001); } \\
\text { (Bowersox, et. } \\
\text { al.,2010); } \\
\text { (Lambert e } \\
\text { Knemeyer, } \\
\text { 2008); Simchi- } \\
\text { levi, Kaminsky e } \\
\text { Simchi-levi, } \\
\text { 2003). }\end{array}$ \\
\hline
\end{tabular}

Fonte: Elaborado por este trabalho

\section{e) Sistema de Informação e Tecnologia}

A dimensão de Sistema de Informação e Tecnologia compreende ações vinculadas à implementação e manutenção de sistemas de informação, bem como, a gestão tecnológica dos processos logísticos. Ações incluídas nesta dimensão podem ser citadas, como a implementação de soluções tecnológicas que auxiliam os processos produtivos e a gestão logística, tais como sistemas de ERP, soluções de RFID, VMI informatizadas, entre outros. Esta dimensão também abrange os equipamentos da empresa, sendo avaliadas ações relativas à automatização, padronização de processo, alimentação/utilização estratégica de base de dados (BI) e implementação de projetos de otimização dos sistemas de informação. Esta dimensão é indicada na Tabela 25. 
Tabela 25: Práticas avaliadas relativas à dimensão Sistema de Informação e Tecnologia

\begin{tabular}{|c|c|c|c|}
\hline Dimensão & \multicolumn{2}{|c|}{ Práticas Avaliadas } & Referências \\
\hline $\begin{array}{l}\text { Sistema de } \\
\text { Informação e } \\
\text { Tecnologia }\end{array}$ & $\begin{array}{l}0 \\
0 \\
0 \\
0 \\
0 \\
0\end{array}$ & $\begin{array}{l}\text { Sistemas de TI implantados, com capacidade analítica de apoio } \\
\text { à decisão; } \\
\text { Sistema de TI integrando todo o sistema produtivo e outras } \\
\text { funções da empresa; } \\
\text { Sistemas integrados de controle da produção de serviços } \\
\text { (Manufacturing Execution System); } \\
\text { Compartilhamento de informações de fornecedores e cliente } \\
\text { on-line e real time; } \\
\text { Gerenciamento do relacionamento com clientes (CRM); } \\
\text { Gestão da informação e do conhecimento; } \\
\text { Tecnologias de Radio-Frequency Identification (RFID); } \\
\text { Planejamento de Recursos da Empresa (ERP); } \\
\text { Sistemas de Intercambio de dados por meio eletrônico (EDI); e } \\
\text { Sistemas de TI para conduzir negócios em plataforma de } \\
\text { mercados eletrônicos. }\end{array}$ & $\begin{array}{l}\text { Pires (2009); } \\
\text { Chopra e } \\
\text { Meindl (2011); } \\
\text { Bowersox, } \\
\text { Closs e Cooper } \\
\text { (2010); Novaes } \\
\text { (2007); } \\
\text { (McCormack, } \\
\text { 2001); } \\
\text { (Lambert e } \\
\text { Knemeyer, } \\
\text { 2008); Simchi- } \\
\text { levi, Kaminsky } \\
\text { e Simchi-levi, } \\
\text { 2003); (Poirier } \\
\text { e Quinn, 2003). }\end{array}$ \\
\hline
\end{tabular}

Fonte: Elaborado por este trabalho

\section{f) Sistema de Medição de Performance}

A dimensão Sistema de Medição de Performance engloba ações de medição do desempenho organizacional em várias esferas da empresa, mas principalmente em relação aos aspectos inerente à cadeia, conforme indicado na Tabela 26.

Aqui são avaliados os esforços de medição de desempenho em função da operação, custos, estratégias, processos, funções e funcionários, entre outros. A dimensão compreende ações de referência para definição de KPIs, frequência de medição, cálculo dos indicadores de desempenho, padronização da utilização, apresentação dos indicadores de performance e comunicação.

Tabela 26: Práticas avaliadas relativas à dimensão Sistema de Medição de Performance

\begin{tabular}{|c|c|c|c|}
\hline Dimensão & \multicolumn{2}{|c|}{ Práticas Avaliadas } & Referências \\
\hline $\begin{array}{l}\text { Sistema de } \\
\text { Medição de } \\
\text { Performance }\end{array}$ & $\begin{array}{l}0 \\
0 \\
0 \\
0\end{array}$ & $\begin{array}{l}\text { Sistemas de medição de performance implantados e } \\
\text { documentados; } \\
\text { Sistemas de medição de performance apoiando à } \\
\text { tomada de decisões; } \\
\text { Credibilidade e simetria das informações; } \\
\text { Avaliação de benchmarking funcional da empresa e } \\
\text { entre divisões da organização; } \\
\text { Indicadores Estratégicos, Operacionais, de Qualidade, } \\
\text { de Custos bem definido e documentado e com } \\
\text { acompanhamento periódico estabelecido; } \\
\text { Avaliação da integração interna e externa; e } \\
\text { Monitoramento dos objetivos estratégicos das metas } \\
\text { de desempenho gerenciais; }\end{array}$ & $\begin{array}{l}\text { Pires (2009); Novaes } \\
\text { 2007; Chopra e Meindl } \\
\text { (2011); Bowersox, Closs } \\
\text { e Cooper (2010); } \\
\text { Gianchetti (2010); } \\
\text { Christopher (2011); } \\
\text { Lambert (2008); } \\
\text { (McCormack, 2001); } \\
\text { (Lambert e Knemeyer, } \\
\text { 2008); Simchi-levi, } \\
\text { Kaminsky e Simchi-levi, } \\
\text { 2003); (Poirier e Quinn, } \\
\text { 2003). }\end{array}$ \\
\hline
\end{tabular}

Fonte: Elaborado por este trabalho 


\subsection{3}

\section{Os Atributos de Maturidade nas Dimensões do Modelo}

Dentre as conceituações para palavra atributo em Larousse (2007) estão: característica que definem e diferencia um elemento do outro em uma classe, ou ainda, elementos que definem a estrutura de uma classe também conhecidos como variáveis. Para o modelo um atributo é um agrupamento de práticas que o caracteriza reunidas por matéria e na ferramenta serão entendidas como campos que permitirão a estratificação dos resultados.

A partir da especificação das dimensões do construto, originam-se os atributos que constituem o modelo de maturidade, que nasceram a partir da aglutinação das práticas. Esses foram novamente derivados dos modelos base e entende-se como premissa que foram validadas nestas pesquisas anteriores.

Os atributos do modelo são fatores essenciais contidos nos domínios de gestão de uma cadeia de suprimentos e se apresentam como um conjunto de práticas que são avaliadas pelo modelo e agrupadas por matéria e distribuídos nos diferentes níveis de maturidade.

Na tabela 27 é apresentada a Matriz "Dimensões X Atributos do Modelo de Maturidade", onde é possível observar as relações existentes entre os indicadores selecionados para cada dimensão do construto. Por exemplo, a dimensão "Sistema de Medição de Performance”, é composta por quatro atributos (A23 a A26).

Tabela 27: Matriz "Dimensões X Atributos do modelo de maturidade"

\begin{tabular}{|c|ll}
\hline \multicolumn{1}{|c|}{ DIMENSÃO } & & \multicolumn{1}{c}{ ATRIBUTOS } \\
\hline \multirow{3}{*}{ Gestão de Fornecedores } & A1 & Fornecimento de Matéria-prima \\
& A2 & Controle de Fornecedores \\
\hline \multirow{3}{*}{ Gestão da Operação e Clientes } & A3 & Colaboração e desenvolvimento entre parceiros \\
& A4 & Desenvolvimento de Novos Produtos \\
& A5 & Gerenciamento da Produção \\
& A6 & Planejamento Estratégico \\
& A8 & Gerenciamento de Clientes \\
& A9 & Controle do Nível de Serviço \\
\hline Gestão das Atividades Logísticas & A10 & Gerenciamento da Demanda \\
\hline Primárias & A11 & Gerenciamento de Estoque \\
& A13 & Gerenciamento de Transporte \\
& A14 & Gerenciamento de Armazenagem \\
& &
\end{tabular}




\begin{tabular}{|c|ll}
\hline \multicolumn{1}{|c|}{ DIMENSÃO } & \multicolumn{1}{c}{ ATRIBUTOS } \\
\hline \multirow{2}{*}{ Recursos Humanos } & A15 & Administração de Pessoal \\
& A16 & Recrutamento e Seleção \\
\hline Sistema de Informação e & A17 & Treinamento, Motivação e Retenção \\
\hline Tecnologia & A18 & Produtividade, Avaliação e Performance \\
\hline Aistema de Medição de & A20 & Sistemas de Integração Interna \\
\hline Performance & A21 & Sistemas de Integração Externa \\
\hline & A22 & Gestão da Informação e do Conhecimento \\
\hline & A23 & Indicadores de Qualidade \\
\hline & A25 & Indicadores Operacionais \\
\hline
\end{tabular}

Fonte: Elaborado por este trabalho

A dimensão Gestão de Fornecedores agrega os seguintes atributos: A1Fornecimento de Matéria-prima: que avalia as práticas relacionadas aos processos do fluxo de matéria prima, desde sua qualidade, controle, até a solução de problemas relativos ao fornecimento. A2-Controle de Fornecedores: que observa práticas relativas ao controle nível de serviço, contratos e parcerias. A3Colaboração e Desenvolvimento entre Parceiros: avalia as práticas de compartilhamento de informações e recursos, modelo de seleção, contratação, certificação e desenvolvimento de parceiros estratégicos. A4-Desenvolvimento de Novos Produtos: que avalia a comunicação, os estudos e projetos desenvolvidos para novos produtos com parceiros.

A dimensão Gestão da Operação e Clientes, é a maior das dimensões agregando 6 atributos: A5-Gerenciamento da Produção: que avalia práticas relativas à produção como planejamento, programação e melhores práticas de controle da produção; engloba também avaliação das práticas relativas à gestão de cliente, como gestão do portfólio dos serviços, fluxo reverso de material e a existência de facilitadores para os clientes na operação. A6-Planejamento Estratégico: questiona acerca das práticas estratégicas para operação, medições da eficiência do planejamento, formalização do planejamento estratégico, integração de outras áreas e projetos com clientes e parceiros. A7-Gerenciamento de Clientes: avalia existência de práticas voltadas para gestão do cliente, como gestão de integração, práticas de customização e prioridades por cliente, capacidade de gerenciar os processos de negócios logísticos dos clientes, parcerias e cultura colaborativa. A8-Gerenciamento de Custos: inclui a avaliação de políticas, projetos 
e estratégias de minimização de custos e o controle dos custos segmentados por cliente e por produto. A9-Controle do Nível de Serviço: verifica o grau de implementação e controle da qualidade, gestão da manutenção, controle do nível de serviço por cliente, gestão da qualidade e presença de modelos quantitativos de controle e análise. A10-Gerenciamento da Demanda: analisa a existência na organização de métodos quantitativos de previsão e estudo de sazonalidade, envolvimento de outros departamentos, clientes, fornecedores e do mercado e a capacidade de flexibilidade e rapidez frente às necessidades da demanda.

Na dimensão Gestão das Atividades Logísticas Primárias encontram-se os atributos: A11-Gerenciamento de Estoque: que observa as melhores práticas de controle de estoque, sistema de reposição automática e existência de planos de contingência. A12-Gerenciamento de Transporte: avalia a otimização da localização, roteirização, aceleração e despacho, consolidação de cargas, lote econômico e tempos de reabastecimento, integração multimodal, alianças logísticas e planos de contingência. A13-Gerenciamento de Armazenagem: observa as melhores práticas de programação, manuseio, acondicionamento de materiais, a existência de processos documentados, projetos de melhoria e parcerias no que tange ao armazenamento. A14-Gerenciamento e Processamento de Pedidos: avalia a existência de ferramenta que otimizem processamento do pedido, comunicação, aceleração, práticas de Just in Time (JIT), serviços físicos e gerenciais oferecidos a partir do canal de distribuição e acompanhamento da logística reversa.

Para a dimensão Recursos Humanos estão distribuídos os atributos: A15Administração de Pessoal: que mensura a capacidade resolutiva de problemas relativos a recursos humanos, observa as práticas de comunicação, dimensionamento de equipe, gerenciamento dos funcionários, alinhamento com as estratégias e implementação de projetos de melhoria na referida área. A16Recrutamento e Seleção: engloba as práticas de políticas de terceirização, processos de recrutamento e seleção de pessoal, seleção de jovens talentos, recrutamento interno e foco em pessoas. Já o A17-Treinamento, Motivação e Retenção: engloba a existência de programa formal voltado para formação, aumento motivacional e manutenção do funcionário, práticas como empowerment, integração e intercâmbio entre funcionários das diversas áreas. Por fim, A18-Produtividade, Avaliação e Performance: avalia papeis, responsabilidades a performance dos recursos, observa 
a existência de uma estrutura hierárquica mais horizontalizada, capacidade de controle do turnover e gestão do conhecimento e do capital intelectual.

A dimensão Sistema de Informação e Tecnologia engloba os seguintes atributos: A19-Sistemas de Integração Interna: que questiona acerca da existência de departamento e sistema de TI implementados e que apoiem a tomada de decisão, integrado com outras áreas e funções da empresa, existência de sistemas integrados de controle da produção, RFID para controle automático e rastreabilidade de produtos, sistemas operacionais de planejamento de recursos ERP, plataforma de compartilhamento de dados EDI interna, integração dos departamentos nas atividades logísticas. A20-Sistemas de Integração Externa: observa se as informações sobre o fornecedor e as condições de fornecimento estão disponíveis em sistemas online, a existência de plataforma de CRM, B2B, B2C, EDI com fornecedores e sistema de controle da logística reversa. Já o A21-Sistemas de Apoio à Decisão avalia: ferramentas analíticas de planejamento e apoio à decisão, ferramentas operacionais de apoio às decisões de produção, previsão e produção disponíveis on-line e real time. A22-Gestão da Informação e do Conhecimento: observa a precisão e disponibilidade das informações dos sistemas logísticos e de gestão do conhecimento, e analisa se a organização entende a informação como fator crítico de sucesso que potencializa os resultados financeiros da cadeia.

Por último, a dimensão Sistema de Medição de Performance se constitui dos seguintes atributos: A23-Indicadores de Qualidade: observa os processos e sistemas de medição de performance, indicadores de qualidade dos produtos e serviços prestados, satisfação do consumidor e benchmarking funcional. A24-Indicadores Operacionais: avalia a existência de KPI's bem definidos e controlados, programa de melhoria continua da performance operacional, indicadores de produtividade das atividades logísticas básicas, segurança operacional, retorno de materiais, desempenho operacional dos parceiros e acompanhamento do processo global de distribuição e suas integrações. A25-Indicadores de Custos Financeiros: avalia se existe monitoria periódica dos indicadores de custos de produção e serviços, indicadores de custos de transportes, armazenagem/manuseio e estocagem, custos indiretos, o grau de aderência dos indicadores atrelados aos objetivos estratégicos financeiros. A26-Indicadores Estratégicos: monitora as metas de desempenho gerenciais, verifica se o sistema de medição de desempenho está vinculado as recompensas e penalidades, observa o controle dos indicadores relativos aos 
objetivos estratégicos e operacionais, indicadores relativos a aprendizagem e crescimento organizacional, avaliação de benchmarking competitivo e indicadores de desempenho das práticas colaborativas no nível estratégico.

\subsection{4 \\ Especificação dos Níveis de Maturidade}

Os padrões definidos como previsíveis para cada nível de maturidade no sentido de caracterizá-los em seus estágios de desenvolvimento, seguiu as diretrizes propostas pelo modelo proposto e demarca a gradação evolutiva em relação a: processos e padronização; integração organizacional; sistematização e desenvolvimento de parcerias; utilização de sistemas de TI e comunicação; integração e flexibilidade da cadeia.

Todas as dimensões do modelo de maturidade poderão ser medidas separadamente e que todas as dimensões se relacionam com os níveis de maturidade, ou seja, é possível que uma organização tenha grau um em uma dimensão e grau cinco em outra distinta, por exemplo. Importante salientar que esta é uma simplificação teórica para facilitar a avaliação estratificada das organizações, sabe-se que na prática há uma correlação entre as dimensões de maturidade, mas que este modelo não se propôs a investigar. Detalhes sobre o cálculo do escore do modelo serão apresentados na seção 4.2.5.

Considerando os conteúdos de base conceitual apresentados, tendo os modelos de Reyes \& Gianchetti (2010) e de Lockamy \& McCormack (2004), os níveis de maturidade, para efeitos deste estudo, correspondem ao indicado na Tabela 28.

Tabela 28: Níveis de Maturidade

- Práticas de SCM são desestruturadas, ausência de documentação e inexistência de boas práticas.

- Baixo nível de integração funcional e externa. Nenhuma colaboração com parceiros e clientes.

- Estratégias para cadeia indefinida.

Nível 1 - Ad

- Baixíssimo grau de flexibilidade. Baixo nível de satisfação dos clientes.

Hoc

- Pouca ou nenhuma medição de performance com desempenho imprevisível.

- Gestão dos custos é ineficiente.

- Poucos iniciativas de resolução dos problemas de fornecimento.

- Baixa taxa de utilização de sistemas de informação, sem capacidade de apoiar as decisões.

- Pouca estrutura na gestão de pessoas.

- Foco da organização está na detecção de problemas. 
- Processos básicos de SCM definidos e medidos, mas com grau de ineficiência.

- Início do desenvolvimento de estratégias para a cadeia.

- Comunicação periódica com os fornecedores para alinhamento no nível de serviço.

- RH estruturado com programas de recrutamento e seleção implementados.

- Grau médio de Integração funcional e baixo grau de integração externa.

Nível 2 - • Existência de medição de performance, mas de poucos KPI's.

Definido $\quad$ O desempenho pouco mais previsível, mas ineficiências mantém os custos altos.

- Há esforço para superar a perspectiva funcional e atingir os objetivos estratégicos.

- Comunicação periódicas com clientes, mas grau baixo de flexibilidade e satisfação dos clientes.

- Baixa taxa de utilização de SI e dificuldade nas análises de dados para apoio às decisões.

- Organização não possui práticas de gestão do conhecimento.

- Foco da empresa está na análise de problemas.

- O sistema de SCM estruturado e eficiente com adoção de boas práticas.

- Capacidade de controlar grande número de indicadores de performance.

- Parcerias estratégicas com fornecedores e alinhamento organizacional.

- A cooperação internas e compartilhamento de recursos e informações na SC.

- O desempenho é previsível e os objetivos são frequentemente atingidos.

- Os esforços de melhoria focados na eliminação da causa raiz do problema.

Nível 3 - $\quad$ - São desenvolvidas estratégias de redução dos custos ao longo da cadeia.

Gerenciado - $\mathrm{O}$ uso de SI é ampliado, gerando inteligência no apoio às decisões.

- Projetos em conjunto com fornecedores para desenvolvê-los e integrá-los.

- Políticas estabelecidas terceirização de serviços.

- Algum grau de flexibilidade, com iniciativas de integração com os clientes, gerando satisfação.

- RH possui programas de produtividade e avaliação de performance.

- Foco está no controle de problemas.

- Integração e cooperação com clientes e fornecedores no nível estratégicos.

- Planejamento colaborativo institucionalizado entre os departamentos.

- Controle dos indicadores de performance de seus parceiros e fornecedores.

- Práticas avançadas de gestão de SC, como: custo mínimo, VMI, RFID e etc.

- O desempenho é previsível e confiável.

Nível 4 - - $\quad$ Satisfação dos clientes e elevado espírito de cooperação.

Colaboração

- Gestão e compartilhamento da informação com clientes e parceiros.

Integrada

- Processos consolidado de certificação e desenvolvimento de fornecedores.

- Desenvolvimento de parcerias estratégicas de longo prazo na cadeia.

- Uso de tecnologias avançadas, automação e análises complexas em tempo real.

- Empresa possui grau elevado de flexibilidade.

- RH com programas motivacionais, de treinamento e retenção implementados.

- Foco em melhoria contínua.

- Processos liderados pela empresa e disseminados na SC com sistema de gestão comum.

- Colaboração entre os entes da cadeia estendida é sólida, com uso de práticas avançadas de gestão com confiança, transferência e responsabilidade.

Nível 5 - Cultura horizontal, adaptativa, colaborativa e focada no cliente.

Liderança - Os investimentos, os retornos e os riscos são partilhados pela SC.

- Sl integrados na cadeia estendida com iniciativas de gestão do conhecimento.

- Projetos em conjunto com fornecedores no desenvolvimento de novos produtos.

- Benchmarking sobre os processos de colaboração e seleção de fornecedores.

- RH com foco no desenvolvimento humano, gerando vantagens competitivas.

- Foco da empresa na Integração interempresarial e no cliente.

Fonte: Elaborado por este trabalho 
As figuras 19 e 20 representam a caracterização dos níveis de maturidade e são utilizadas como guia geral para compreensão dos estágios de desenvolvimentos do modelo em termos conceituais.

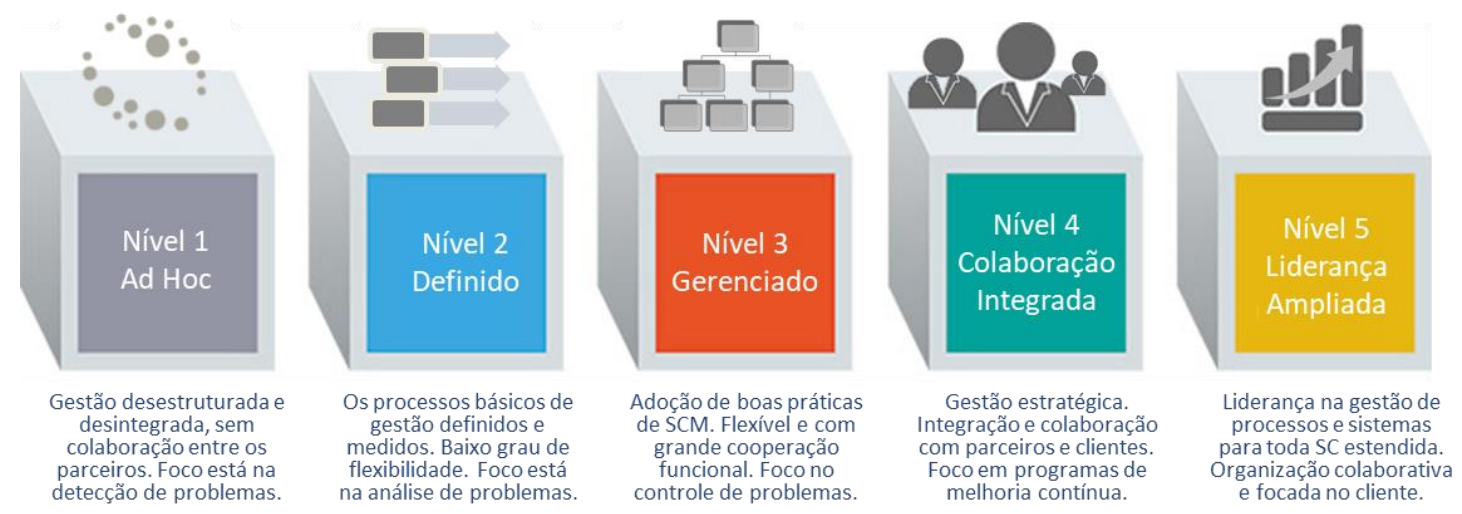

Figura 19: Níveis de maturidade do modelo Fonte: Elaborado por este trabalho

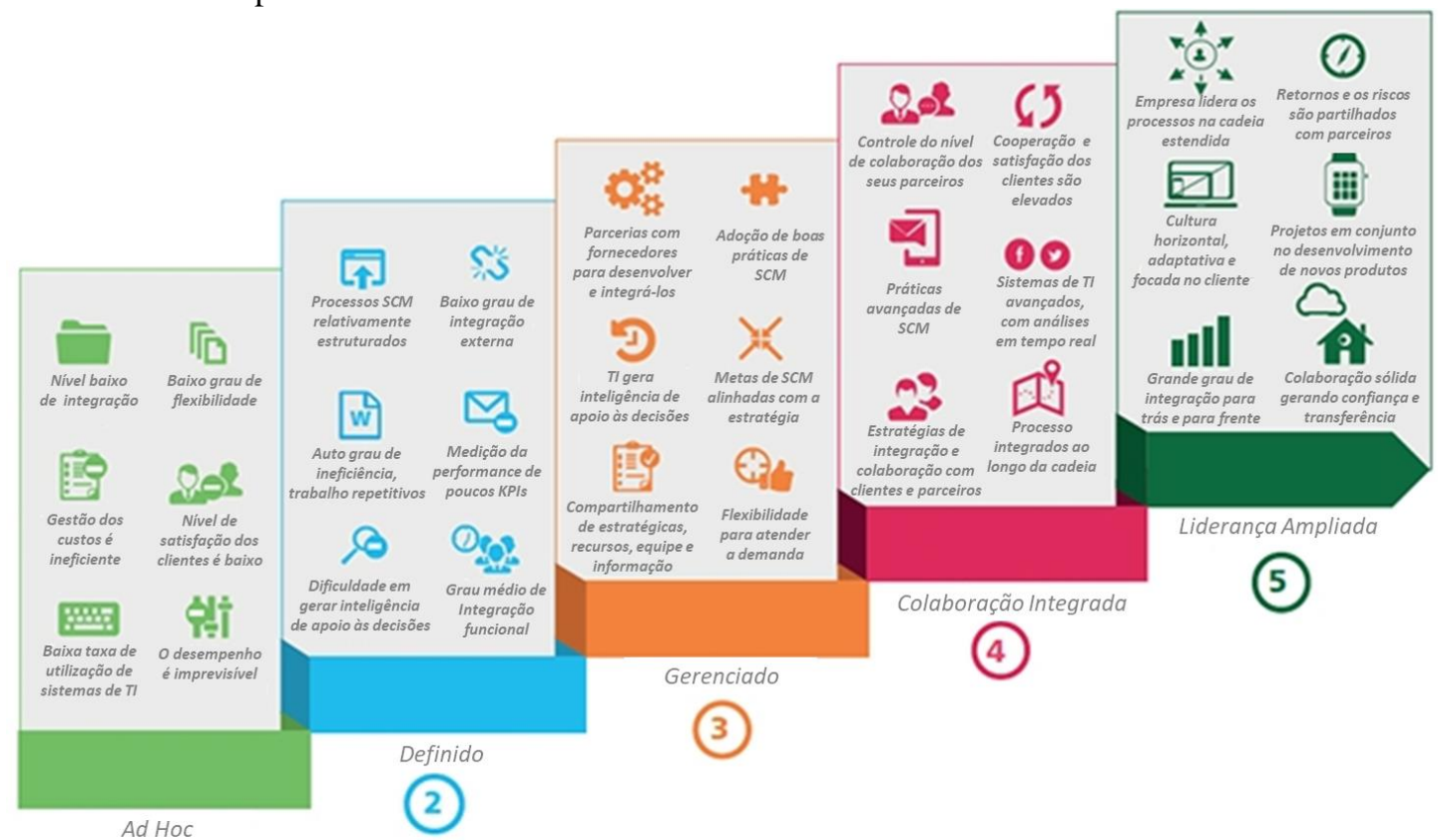

(1)

Figura 20: Principais características dos níveis de maturidade do modelo Fonte: Elaborado por este trabalho

\subsection{5}

\section{Determinando o Nível de Maturidade}

\section{a) Tipificação do Modelo}

Segundo Fraser, et al. (2002), os meios pelos quais os modelos de maturidade utilizam para definir o grau de maturidade de uma dimensão é conhecido como 
forma de aplicação, que são tipificados em: Grade de Maturidade; Modelos Estruturados; Modelos Híbridos e Escalas Likert.

O modelo gerado por esta pesquisa pode ser classificado como um Modelo Híbrido, que combina um modelo de referência estruturado, possuindo definição de práticas por nível de maturidade e uma ferramenta em escala Likert agregada ao constructo. Nesse caso de tipificação, o instrumento de pesquisa agrega questionamentos em termos das práticas executadas pela empresa, onde é solicitado ao respondente sua manifestação considerando critérios específicos em uma escala de 1 a n que expresse seu grau de implantação daquela referida prática. Conforme já mencionado, são raros os modelos de maturidade nesta tipificação na literatura.

\section{b) Cálculo do Escore}

Para melhor compreensão do cálculo do escore, é importante ter em vista a codificação utilizada para fins de notação. As dimensões receberam a codificação de D1, D2, D3, D4, D5 E D6; cada código representativo de uma dimensão. As questões do questionário também estão numeradas em ordem crescente, desta forma pode-se localizar qualquer questão a partir de seu código, por exemplo, o código D4.91, seria a nonagésima primeira questão do questionário e que faz parte da dimensão Recursos Humanos.

Outro fator importante, é que a determinação do nível da maturidade de cada dimensão é realizada considerando o grau de execução das práticas, medida a partir de uma escala de likert, com valores compreendidos entre 1 e 5, considerando critérios específicos para cada prática. A escolha por esta escala permite capturar não somente a existência, mas principalmente o grau de adesão por parte da organização e de outros integrantes na cadeia ampliada.

A obtenção do escore global de maturidade de uma empresa neste modelo, segue o mesmo critério de pontuação proposta pelo modelo de Lockamy \& McCormack (2004), embora o modelo original tenha optado por escala de 4 pontos e o modelo de Reyes \& Gianchetti (2010) apresenta perguntas do tipo "sim ou não", enquanto esse modelo optou por seguir uma padronização de escala likert, mais comumente aceita dentro do meio acadêmico por seus inúmeros benefícios, com 5 pontos. 
Os escores aqui são obtidos por meio de uma média aritmética das pontuações correspondente a escala Likert atribuída a cada questão pelo respondente. Os escores atribuídos às práticas avaliadas se reúnem em uma média, para cada uma das 6 dimensões, formando um padrão de médias não constantes, com escores variando entre 1 e 5 .

A ferramenta, parte importante do modelo e que será melhor detalhada na seção 4.3.1, é o instrumento que permite a avaliação das empresas. Este instrumento reúne as 153 questões divididas nas seis dimensões e referem-se às práticas onde o grau de aderência observado enquadrará a empresa em um dos 5 níveis de maturidade do modelo. As práticas a serem avaliadas via ferramenta pelo respondente poderão ser compreendidas entre 1 e 5 , representando o grau de implantação da prática avaliada, onde cada número representa: 1 - nãoimplementado; 2 - em fase de estudos para implementação; 3 - parcialmente implementado; 4 - implementado sem acompanhamento; 5 - implementado com acompanhamento periódico dos resultados.

Sendo o número de questões variável entre as dimensões do modelo, é possível que sejam gerados escores fracionados para dimensões distintas. Este modelo optou por manter este escore fracionado e utilizar a teoria do ponto-chave de transição para determinação do nível de maturidade, detalhado na próxima seção.

A equação 1 abaixo explicita a forma do cálculo do escore. A pontuação atingida em cada dimensão do modelo é calculada através do somatório simples da nota atribuída em questão relativa, onde o respondente indicará o grau de aderência, variando de 1, que indica "NÃO-IMPLEMENTADO" a 5, indicado "IMPLEMENTADO COM ACOMPANHAMENTO PERIÓDICO DOS RESULTADOS" em cada grupo de questões relacionado às dimensões D1, D2, D3, D4, D5 e D6. Esse somatório é dividido pelo número de questões de cada uma das seis dimensões.

$$
\text { Escore }=\frac{\sum_{j=1}^{m i} A_{i j}}{m i} ; \quad i=1, \ldots n ; \quad j=1, \ldots n
$$

Onde:

A $\rightarrow$ Somatório da pontuação obtida nas questões dos atributos avaliados;

$\mathrm{m} \rightarrow$ número de questões $\mathrm{n}$ dos atributos $\mathrm{A}$ avaliados. 
$\mathrm{i} \rightarrow$ número de dimensões i $(\mathrm{i}=1,2, \ldots 6)$.

$\mathrm{j} \rightarrow$ número de questões $\mathrm{j}(\mathrm{j}=1,2, \ldots \mathrm{n})$.

O escore obtido por uma organização é um grau aferido que dá condições a empresa para acompanhar sua evolução ao longo do tempo, ou até mesmo, servir de base para realização de um benchmarking externo. Ressaltando que o escore obtido não será a base para calcular a mudança de nível da organização, para isso será utilizado o ponto-chave de transição, apresentado a seguir.

\section{c) Ponto-Chave de Transição}

Objetivando incorporar aos modelos de maturidade de natureza descritiva maior praticidade e clareza, alguns estudos relevantes desenvolveram o conceito de turning points, ou pontos-chave de transição (McCORMACK et al., 2009), que englobam um conjunto variado de práticas, apontado os elementos-chave no alcance de níveis superiores de maturidade.

Os pontos-chave de transição também podem ser definidos como um pico de transição para uma expansão ou recessão, como uma alteração brusca no comportamento dos processos de negócio. Apesar de representar um fenômeno complexo, os pontos-chave de transição beneficiam as organizações uma vez que auxiliam na canalização de seus esforços de priorização e investimentos na gestão de seus processos. McCormack et. al. (2009) elucidam que é esperado um crescimento na utilização de pontos de transição para modelos de maturidade, por parte de pesquisadores e de profissionais, como uma ferramenta importante para o planejamento e implementação de ações de melhoria na gestão de cadeias de suprimentos.

Nesta pesquisa, para a identificação de pontos-chave de transição (turning points) foram analisados três modelos de maturidade, o desenvolvido por McCormack, Johnson e Walker (2003), o de Hammer (2007) e o de Oliveira (2009), com objetivo de delinear uma metodologia para balizar a mudança de nível de maturidade. Conforme já salientado, o escore obtido pelas empresas por meio da ferramenta será apenas um número pelo qual a organização poderá realizar análises comparativas, acompanhando sua evolução no longo prazo. Para marcar a mudança 
de nível, o modelo de maturidade proposto fará uso dos pontos-chave de transição a partir da avaliação do que chamamos de nota global.

Para definição do ponto-chave de transição, soma-se os escores individuais máximos obtidos em cada questão por nível, variando na escala de cinco pontos, de 1 (nível ad hoc) até 5 (nível Liderança Ampliada), são agrupadas por somatório aos atributos do modelo e em seguida agrupados às seis dimensões de maturidade ponderados pelos níveis de maturidade.

Os centroides são os pontos máximos obtidos por uma organização em determinado nível. Por exemplo, uma vez que a ferramenta possui no total 153 perguntas, se em todas as perguntar uma determinada empresa obtiver 1, ela terá 153 pontos de nota global, se ela obtiver em tudo 2, terá 306 pontos e assim sucessivamente. Para mudança de nível de maturidade a empresa precisa atingir no mínimo a mediana entre dois centroides, neste nosso exemplo, 229,5 para mudar do nível 1 para o nível 2 de maturidade. A tabela 29 abaixo ilustra os pontos-chaves de transição por nível de maturidade.

Tabela 29: Pontos-chave de transição do modelo.

\begin{tabular}{|c|c|c|c|}
\hline \multicolumn{2}{|r|}{$\begin{array}{l}\text { Níveis de } \\
\text { maturidade }\end{array}$} & Centroides - Nota Global Máxima por Nível & $\begin{array}{l}\text { Ponto-chave de } \\
\text { transição }\end{array}$ \\
\hline 1 & Ad Hoc & $\begin{array}{c}{[D 1(25)+D 2(34)+D 3(23)+D 4(24)+D 5(22)+} \\
D 6(25)] \times 1 \text { ponto }=153 \text { pontos }\end{array}$ & $\leq 229,5$ \\
\hline 2 & Definido & $\begin{array}{c}{[D 1(25)+D 2(34)+D 3(23)+D 4(24)+D 5(22)+} \\
D 6(25)] \times 2 \text { ponto = } 306 \text { pontos }\end{array}$ & $>229,5 \leq 382,5$ \\
\hline 3 & Gerenciado & $\begin{array}{c}{[D 1(25)+D 2(34)+D 3(23)+D 4(24)+D 5(22)+} \\
D 6(25)] \times 3 \text { ponto }=459 \text { pontos }\end{array}$ & $>382,5 \leq 535,5$ \\
\hline 4 & $\begin{array}{l}\text { Colaboração } \\
\text { Integrada }\end{array}$ & $\begin{array}{c}{[D 1(25)+D 2(34)+D 3(23)+D 4(24)+D 5(22)+} \\
D 6(25)] \times 4 \text { ponto }=612 \text { pontos }\end{array}$ & $>535,5 \leq 688,5$ \\
\hline 5 & $\begin{array}{l}\text { Liderança } \\
\text { Ampliada }\end{array}$ & $\begin{array}{c}{[D 1(25)+D 2(34)+D 3(23)+D 4(24)+D 5(22)+} \\
D 6(25)] \times 5 \text { ponto }=765 \text { pontos }\end{array}$ & $>688,5$ \\
\hline
\end{tabular}

Fonte: Elaborado por este trabalho

Para ajudar a elucidar melhor o conceito dos postos-chave de transição, a figura 21 abaixo apresenta uma forma de operacionalização da escala, marcando os pontos de transição e os centroides máximos por nível, onde fica claro que a empresa precisa atingir uma pontuação maior que a mediana, entre dois níveis para se enquadrar no limite superior. Na ferramenta esse processo é transparente ao usuário, todo cálculo para determinação de sua nota global e enquadramento no nível de maturidade referido, fica restrito ao programador e o respondente não terá acesso, apenas o escore e o nível de maturidade final serão exibidos. 


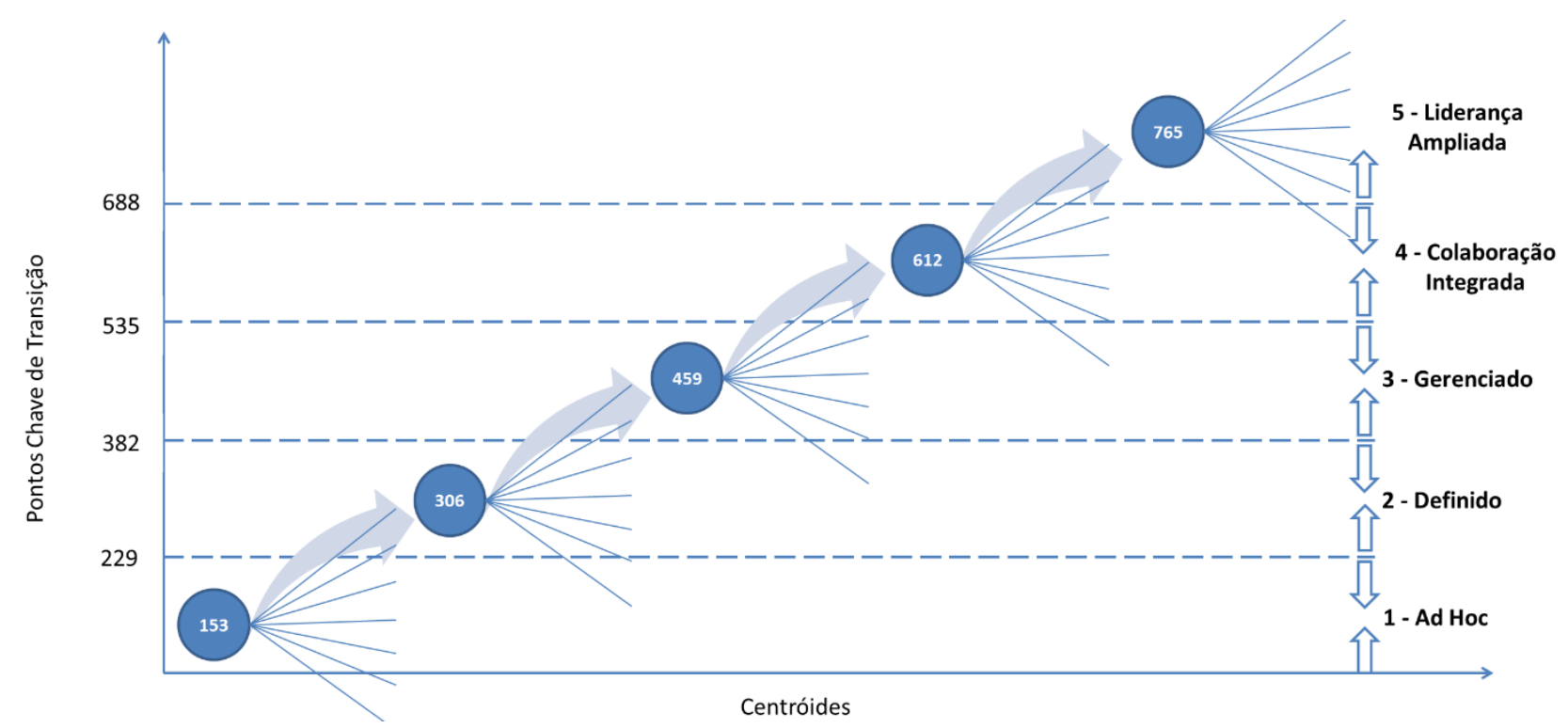

Figura 21: Pontos-chave de transição baseado nos centroides Fonte: Elaborado por este trabalho

A nota global por empresa é uma pontuação que será comparada com os pontos-chave de transição para efetivo enquadramento do nível de maturidade da empresa, determinada na equação 2 abaixo. Para isso, as notas individuas atribuídas a cada prática avaliada são somadas em cada atributo e esses, por sua vez, somados dentro de suas dimensões, considerando que todos os pontos entre um centroide e outro são pontos possíveis. Logo, a organização que obtiver uma nota global menor ou igual à mediana entre dois centroides se classificará no limite inferior de maturidade dentre os dois; e a empresa que, por sua vez, apresentar uma nota global maior que a mediana se classificará no limite superior dentre esses níveis.

Determinando a Nota Global, tem-se que:

$$
N G=\sum_{i=1}^{n} \sum_{j=1}^{m i} A_{i j}
$$

Onde:

$\mathrm{A} \rightarrow$ Somatório da pontuação obtida nas questões do atributo avaliado;

i $\rightarrow$ número de dimensões i $(i=1,2, \ldots 6)$.

$\mathrm{j} \rightarrow$ número de questões $\mathrm{j}(\mathrm{j}=1,2, \ldots \mathrm{n})$.

Algoritmo para determinação do Nível de Maturidade:

$\mathrm{i}=0$ 
Repita $\mathrm{i}<=\mathrm{i}+1$ até limite de $\mathrm{i}$

$$
\begin{aligned}
& \text { Para } i=1 \rightarrow N G \leq C_{i} ; \Rightarrow N=i \\
& \text { Para } i>1 \rightarrow \operatorname{Se}\left(N G \leq C_{i} \quad \Lambda \quad N G>P C_{i-1}\right) \Rightarrow N=i \text {; } \\
& \text { Se não } \Rightarrow N=i-1 ; \quad i=1, \ldots n \text {; } \\
& \cdots P C_{i}=\frac{C_{i}+C_{i+1}}{2}
\end{aligned}
$$

Onde:

NG $\rightarrow$ Nota Global aferida;

$\mathrm{C} \rightarrow$ Centroide do nível de maturidade;

$\mathrm{PC} \rightarrow$ Ponto-chave de transição;

$\mathrm{N} \rightarrow$ Nível de Maturidade;

$\mathrm{i} \rightarrow$ número de dimensões i $(\mathrm{i}=1,2, \ldots 6)$.

\section{3 \\ Operacionalização do Modelo}

\subsection{1 \\ A Ferramenta}

A ferramenta é parte integrante do modelo de maturidade. O questionário nela contido possui 153 perguntas em uma escala do tipo Likert de 5 pontos, segmentadas em vinte e seis conjuntos de questões, onde cada conjunto se refere a um atributo do modelo e os atributos por sua vez, estão agrupados nas dimensões do constructo. Este arranjo foi inspirado na organização das questões da ferramenta de avaliação usada pelo modelo CMMI (SEI, 2001).

A seguir é feito o detalhamento das funcionalidades da ferramenta.

\subsubsection{1}

\section{Funcionalidades da Ferramenta}

A ferramenta possui 5 funções principais, que podem ser facilmente identificadas a partir da visualização da tela inicial da aplicação, demostrada pela figura 22. 


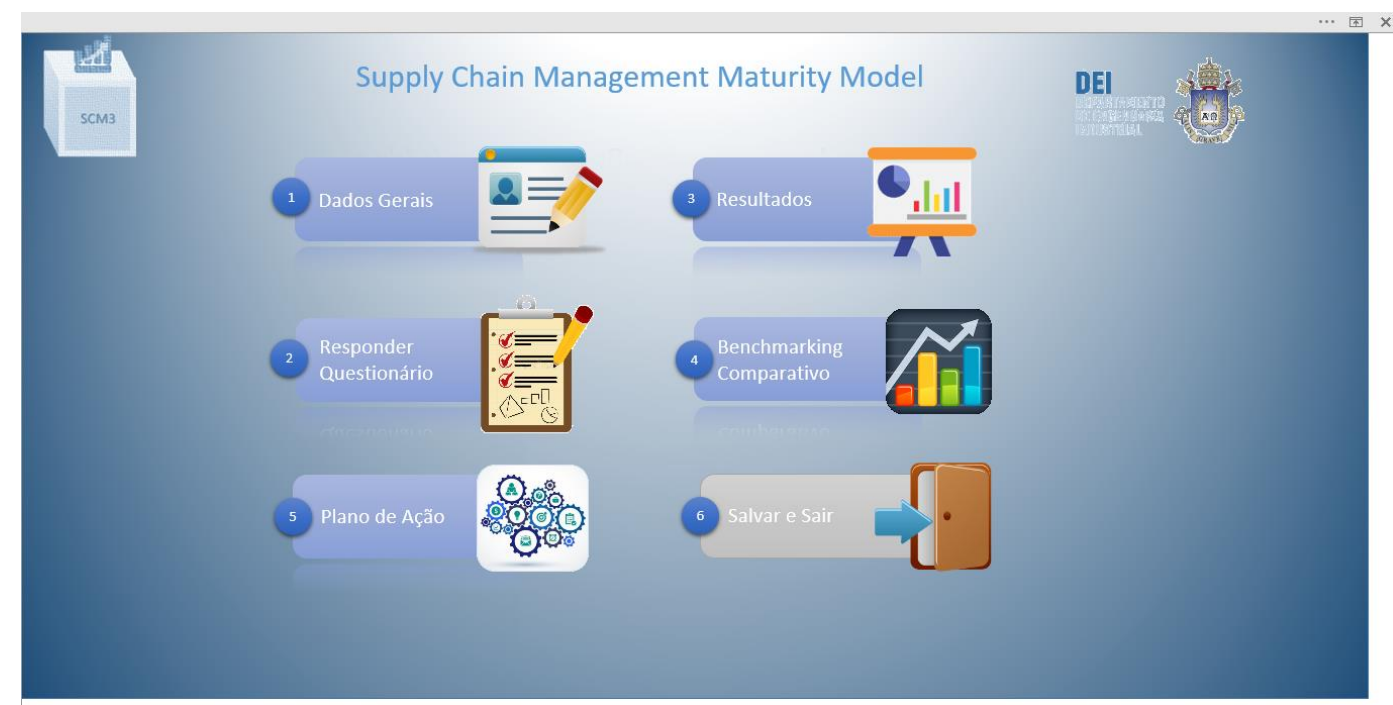

Figura 22: Tela Inicial da Ferramenta Fonte: Elaborado por este trabalho

A primeira delas é a função de captura de dados gerais que, por sua vez, serão fundamentais para caracterização da empresa, segmentação dos dados e servirão de base para as análises de benchmarking. Aqui o respondente insere informações de dados pessoais e dados da empresa, tais como: nome, cargo, posição na organização, indústria de atuação, anos no setor, nome da empresa, localização, classificação por receita, entre outros. Na figura 23, a tela de captura de dados gerais pode ser vista na íntegra.

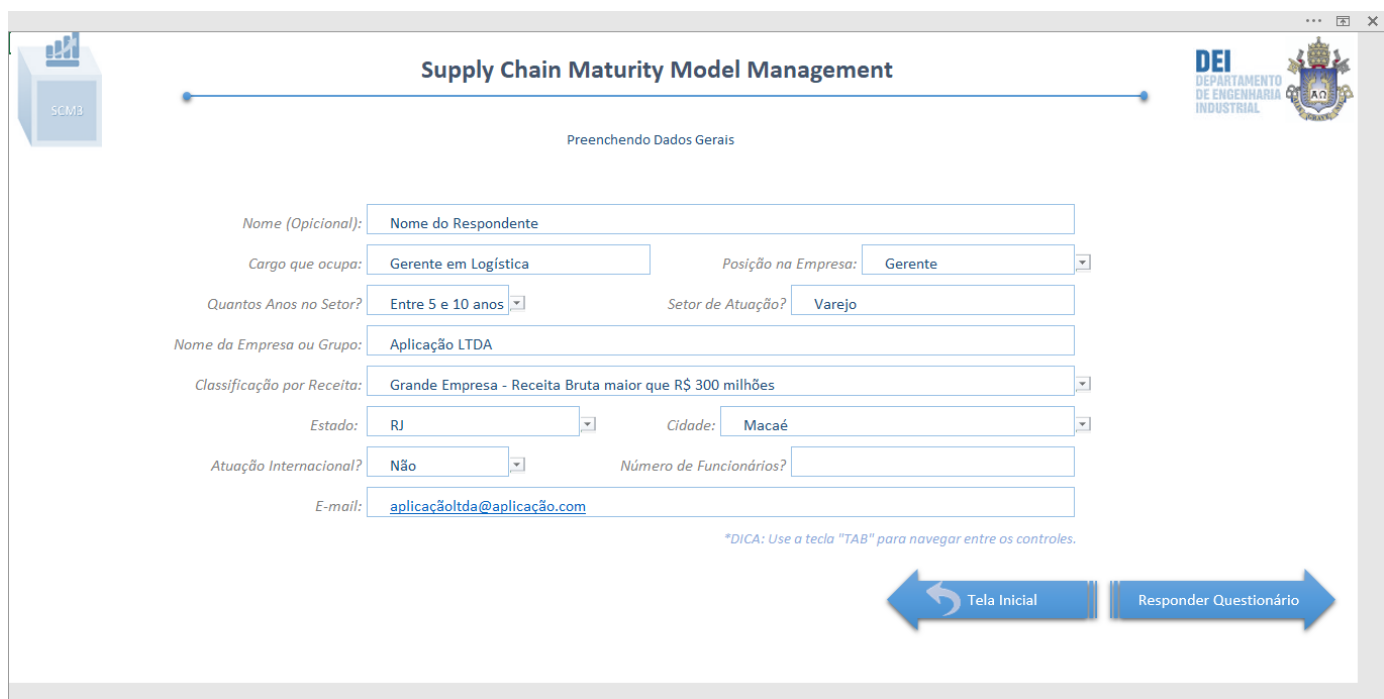

Figura 23: Tela Inicial de Dados Gerais

Fonte: Elaborado por este trabalho

A segunda funcionalidade é o coração da aplicação, com a função de capturar a avaliação dos atributos por meio de uma coleção de 153 perguntas. Cada dimensão 
ao ser avaliada, traz inicialmente uma tela de abertura própria, objetivando situar e explicar para o respondente qual o conteúdo que será avaliado, em linhas gerais. $\mathrm{Na}$ tela abaixo, figura 24 , está apenas um exemplo de tela de abertura, a ferramenta traz uma tela similar no início de cada dimensão a ser avaliada.

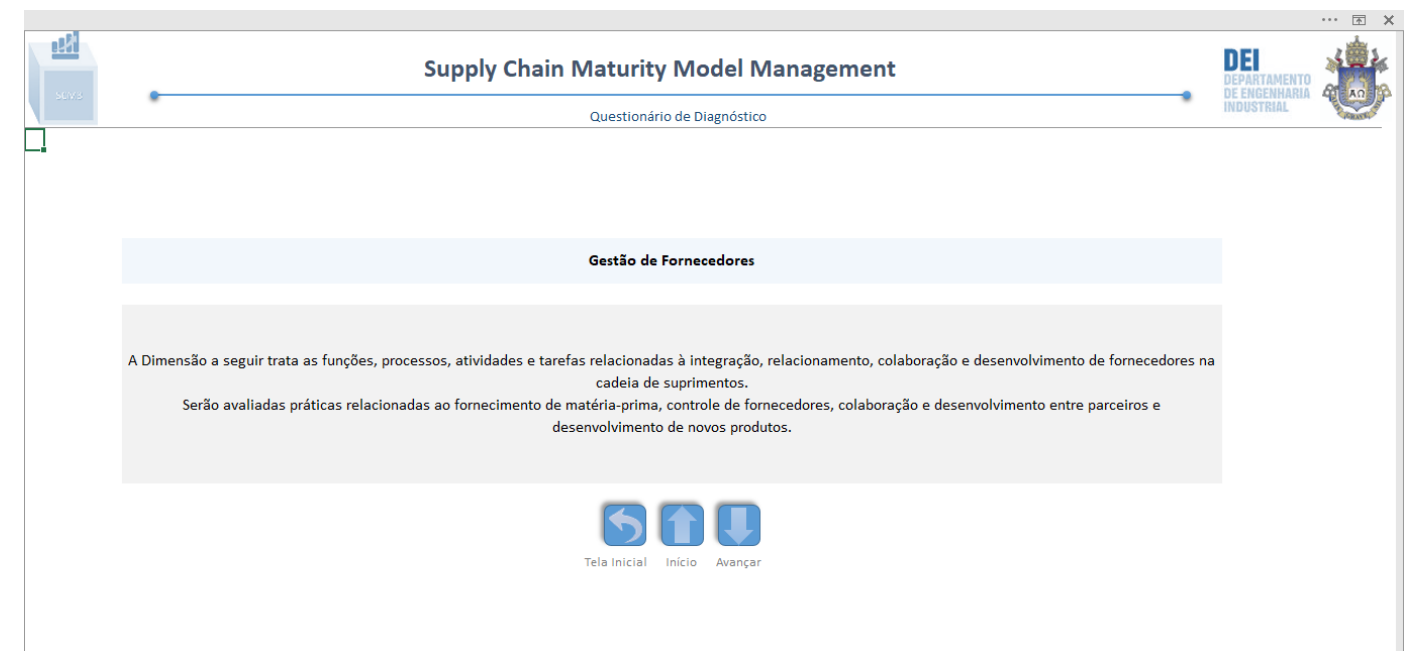

Figura 24: Tela de Abertura da Dimensão Fornecedores Fonte: Elaborado por este trabalho

Em seguida a tela representada na figura 25 exemplifica a interface de captura das questões que tornam tangíveis os atributos avaliados. Cada pergunta tem um conjunto de botões-opção em um combobox associado, que admite apenas uma resposta por pergunta.

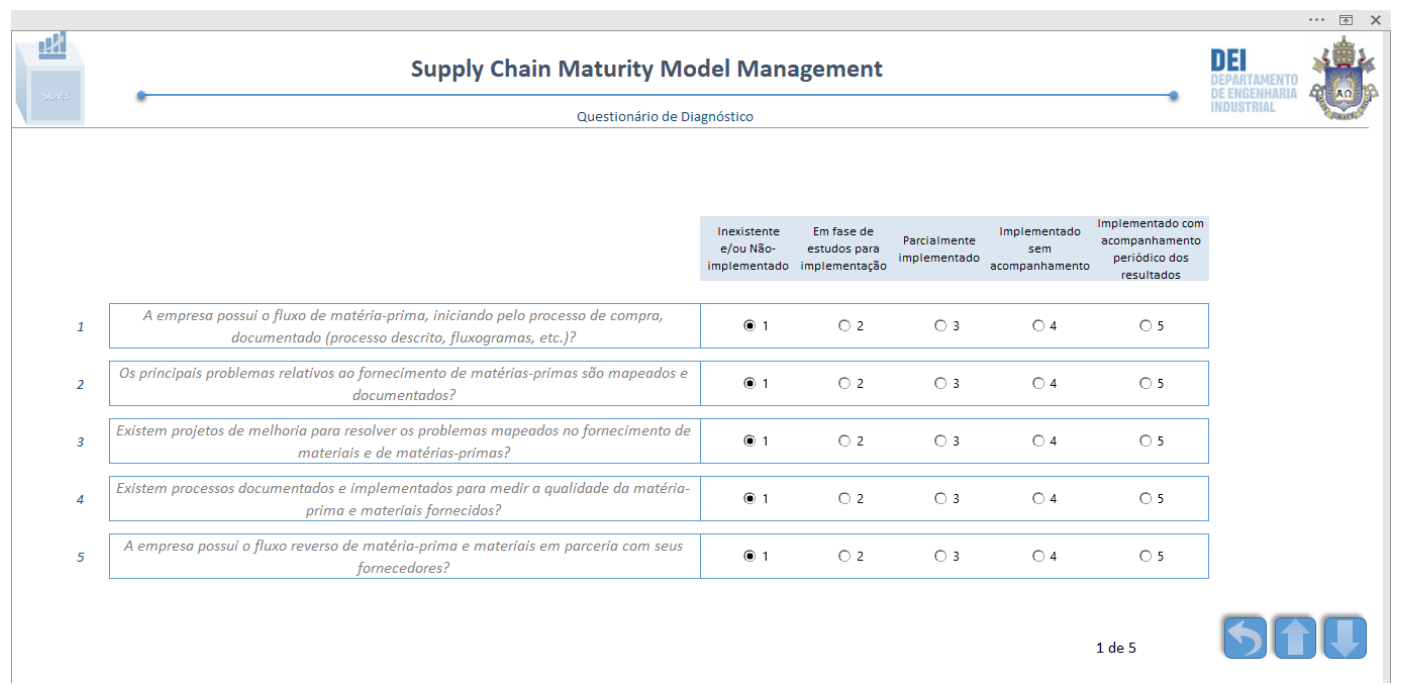

Figura 25: Tela 1 de Avaliação da Dimensão Fornecedores

Fonte: Elaborado por este trabalho 
A seguir são demonstradas as funções de relatórios primários gerados automaticamente pela ferramenta.

\subsubsection{2}

\section{Relatório de Resultados Primários}

A ferramenta conta com várias formas de apresentação dos resultados, os quais visam demonstrar os graus de maturidade aferidos após as práticas avaliadas. Uma série de gráficos auxiliam nesta análise, que são suporte para o delineamento e priorização das ações a serem implantadas.

Importante salientar que, para fins de demonstração, foi realizado um preenchimento aleatórios nas telas de avaliação a fim de gerar resultados hipotéticos para auxiliar a visualização da funcionalidade de geração de relatórios.

Na primeira tela de resultados, a organização terá antecipadamente uma visão geral de seu nível de maturidade. Tanto o escore, quanto o nível de maturidade, terão sido calculados de forma automatizada pela ferramenta e exibidos nesta seção. Esse cálculo é transparente ao usuário, ou seja, não visível na camada de interface da ferramenta. Os dados são exibidos, bem como as principais características de empresas que se enquadrem nesse referido nível e uma imagem posicionando o grau de maturidade de forma ilustrativa. Na figura 26 a primeira tela de resultados pode ser exibida.

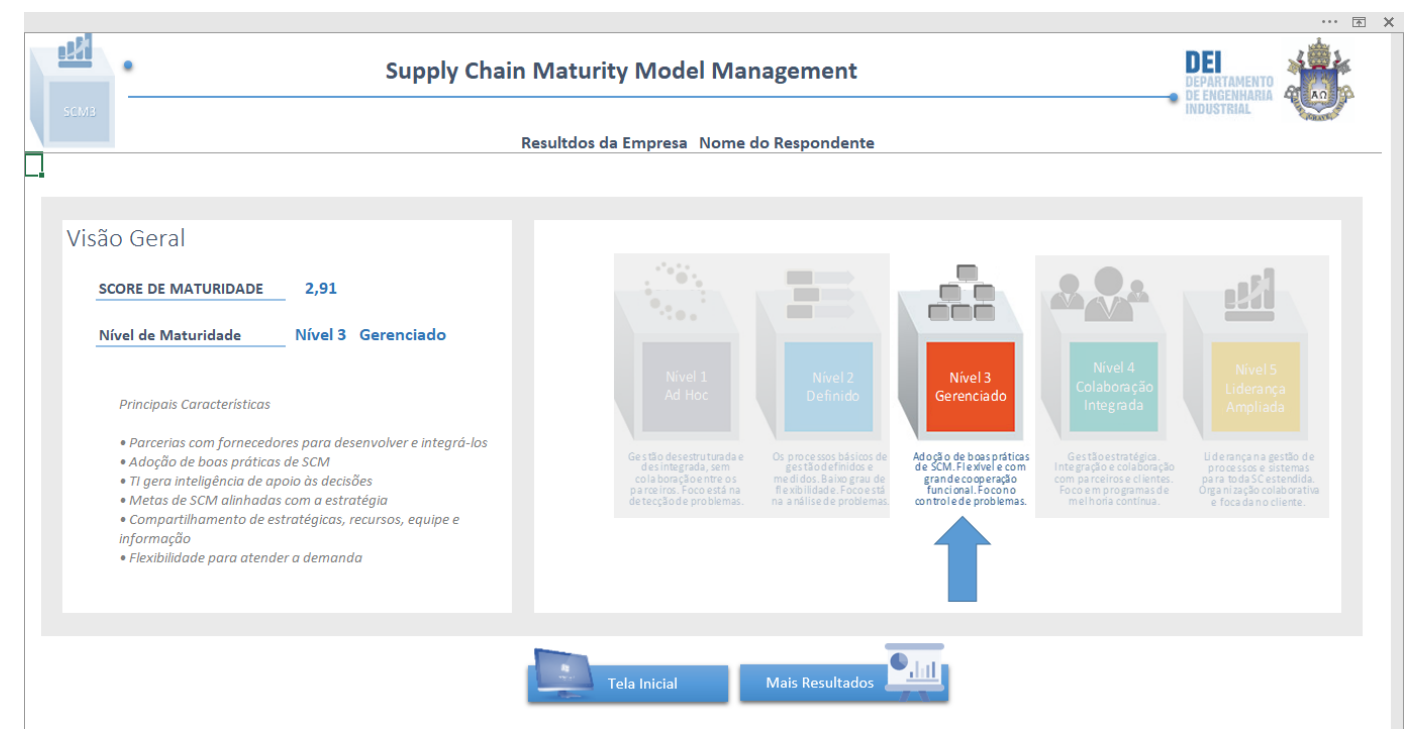

Figura 26: Primeira Tela de Resultados Fonte: Elaborado por este trabalho 
Clicando no botão "Mais Resultados”, será possível visualizar o nível de maturidade da organização estratificado em cada uma das 6 dimensões. A ferramenta atribuirá um escore separadamente para Gestão de Fornecedores, Gestão da Operação e Clientes, Gestão das Atividades Logísticas Primárias, Recursos Humanos, Sistema de Informação e Tecnologia e Sistema de Medição de Performance.

Nesta tela já será possível observar qual aspecto-chave da cadeia está melhor contribuindo degradando o escore geral para baixo ou ainda elevando o patamar de maturidade da organização para cima, conforme demostrado na figura 27.

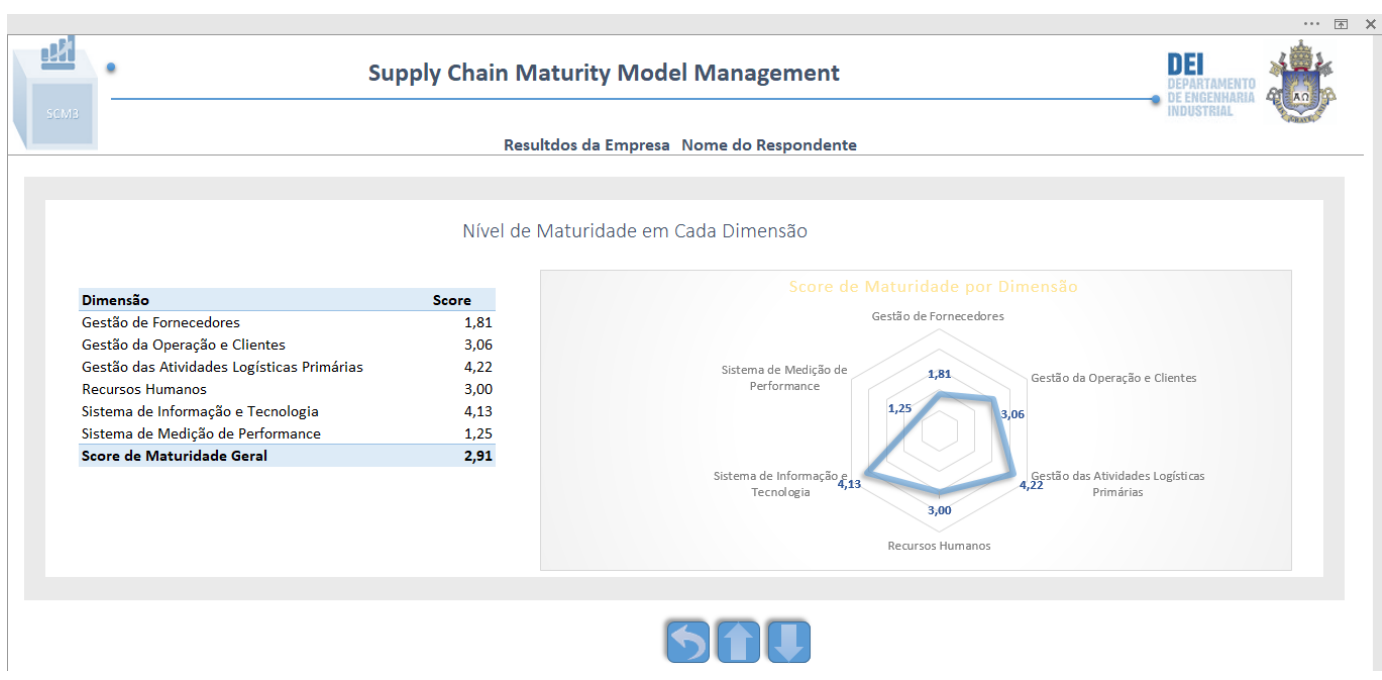

Figura 27: Tela de Resultados por Dimensão Fonte: Elaborado por este trabalho

Na sequência, a ferramenta traz uma seção onde cada dimensão pode ser vista de maneira ampliando, estratificada pelos atributos a ela pertencentes. A figura 28 traz como exemplo a tela da dimensão de Gestão da Operações e Clientes, porém a ferramenta possui uma tela análoga para cada dimensão de maturidade. Aqui já é possível ampliar consideravelmente o entendimento sobre quais atributos precisam ser investigados pela organização. 


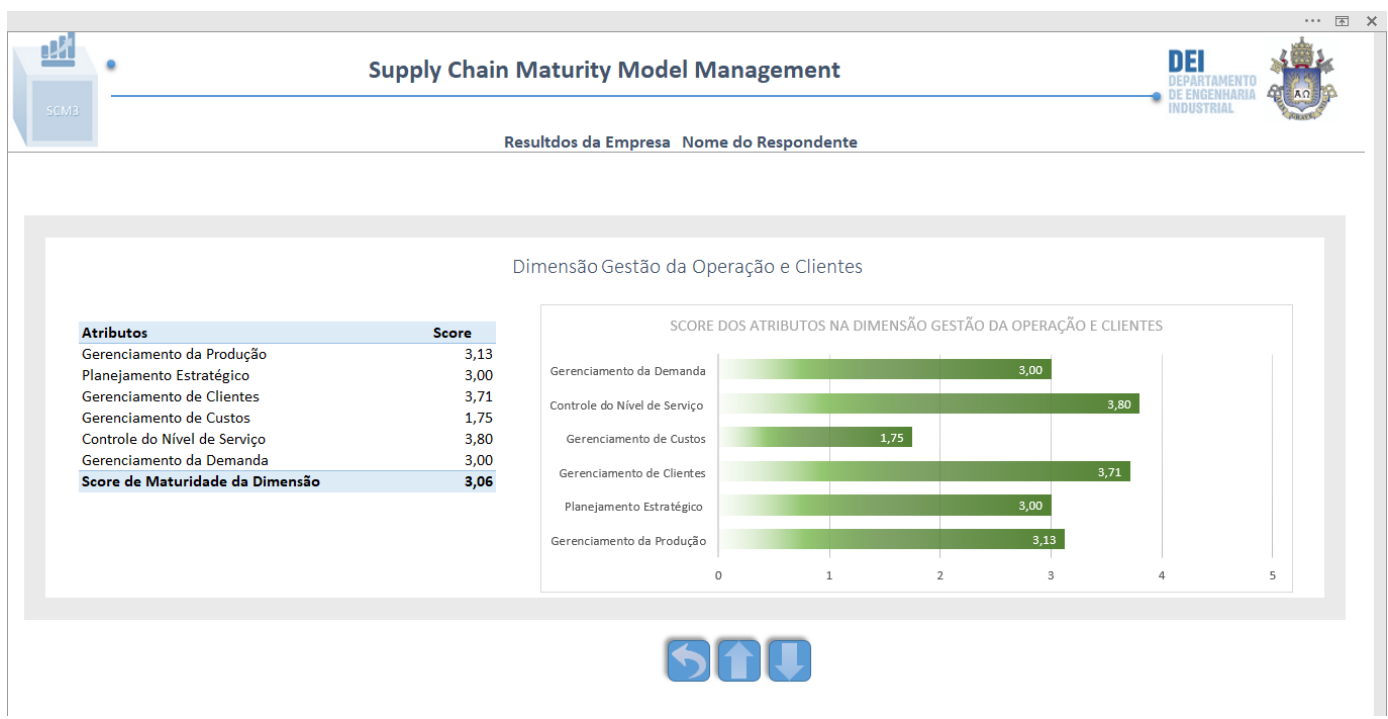

Figura 28: Maturidade dos Atributos por Dimensão

Fonte: Elaborado por este trabalho

\subsubsection{3}

\section{Relatório de Resultados Benchmarking}

Uma importante funcionalidade desenvolvida pela ferramenta é a função de análise de benchmarking. Nesta função a ferramenta é capaz de realizar inúmeras comparações dos níveis de maturidade de diversas empresas em diferentes setores da indústria. A funcionalidade será melhor demonstrada mais à frente.

Esta funcionalidade terá importância para companhias que desejem se reposicionar e reorientar suas estratégias, bem como para acadêmicos que desejarem realizar comparativos de maturidades em pesquisas futuras.

Novamente, para fins de demonstração, a base de dados foi preenchida de forma aleatória, simulando 500 empresas respondentes de variados setores da indústria e de porte distintos.

A primeira tela desta seção (figura 29) permite que sejam observadas as médias de maturidade das diversas indústrias em cada uma das 6 dimensões do modelo. Caso a empresa tenha tido um mal desempenho em uma dimensão especifica, aqui ela poderá facilmente observar como empresas dentro do mesmo setor estiveram na média e qual comportamento de outros mercados.

Para toda esta seção, todas as telas resgatam o resultado da empresa avaliada, para que a mesma possa comparar seu resultado dentre os demais de forma otimizada. Em todas as telas de análises de benchmarking também se encontra um 
campo de comentários, onde a organização já poderá destacar dados que colaborem com suas análises futuras.

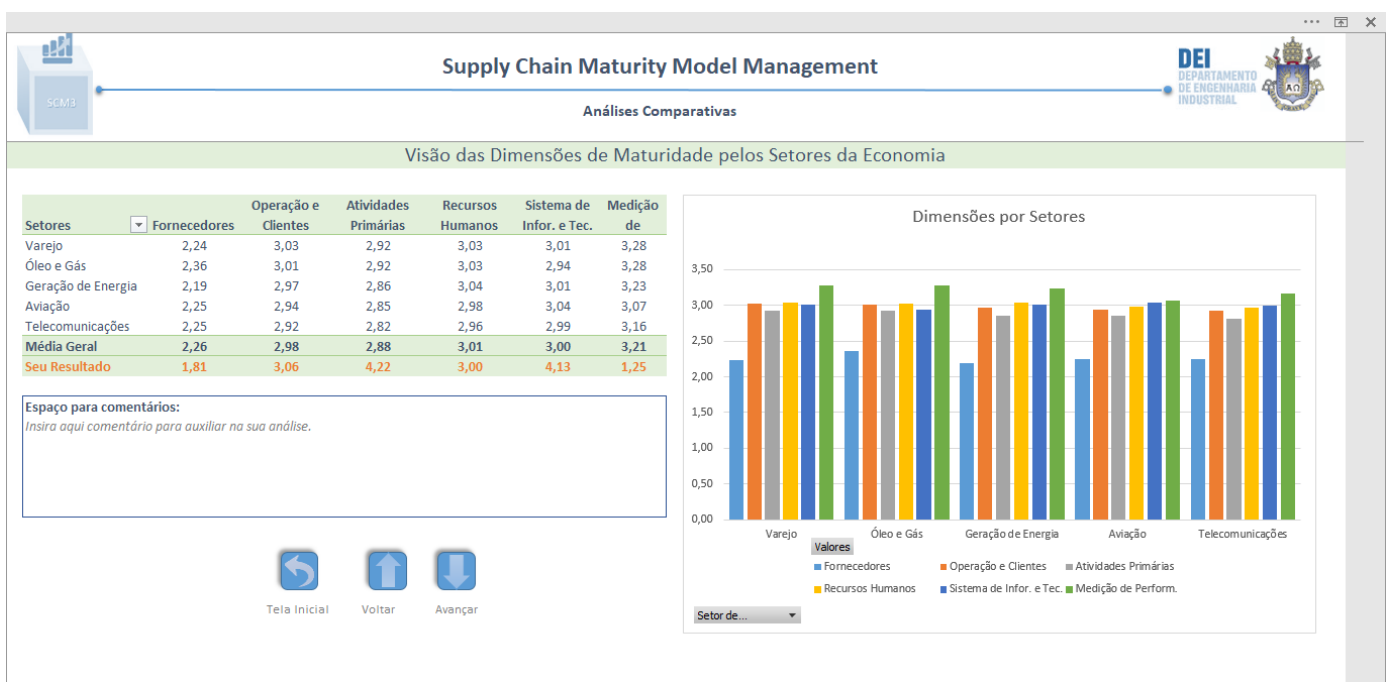

Figura 29: Maturidade por Industria

Fonte: Elaborado por este trabalho

Em seguida, na figura 30 é apresentada a tela de análise comparativa por porte da empresa, onde mais uma vez a empresa avaliada poderá entender o comportamento de empresas com mesmo porte que o seu. Será possível verificar o desempenho das empresas segmentando as de pequeno, médio e grande porte. Para esta estratificação foi utilizada a classificação por receita orientada pelo Serviço Brasileiro de Apoio às Micro e Pequenas Empresas (Sebrae).

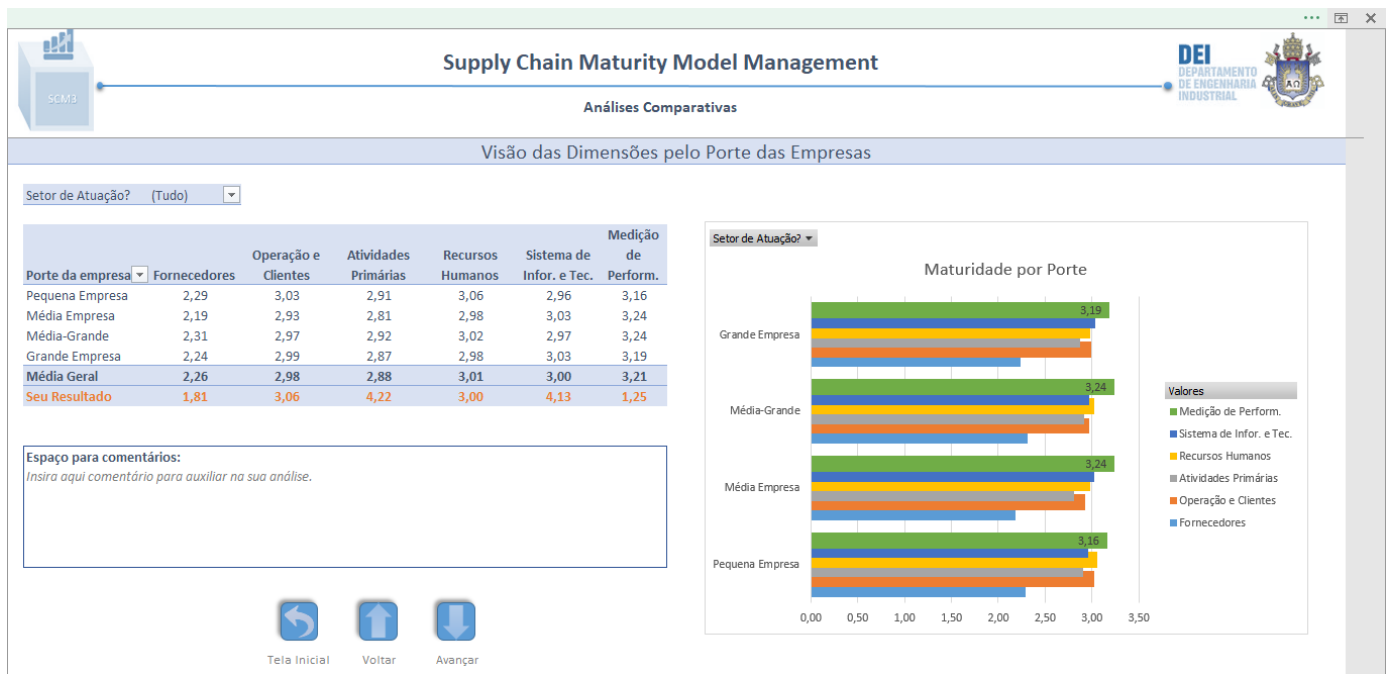

Figura 30: Maturidade por Porte das Empresas Fonte: Elaborado por este trabalho

Na sequência, são realizadas análises por localidade. Sendo possível segmentar o nível de maturidade em cada dimensão variando o local de atuação da empresa. Para fins de demonstração a abertura foi feita pelos estados brasileiros, 
mas a ferramenta pode ser facilmente adaptada para abranger atuação internacional. A figura 31 abaixo representa esta funcionalidade.

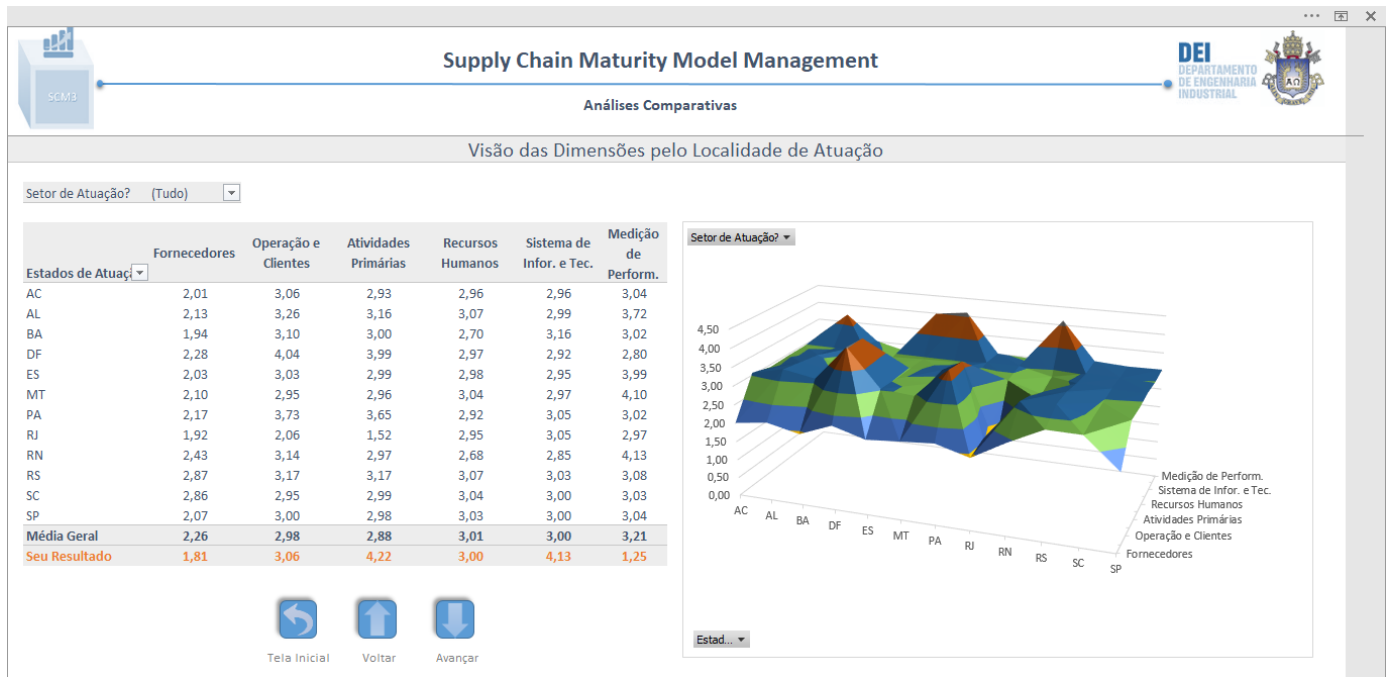

Figura 31: Maturidade por Localidade

Fonte: Elaborado por este trabalho

E as últimas telas desta seção traçam uma relação entre os atributos de uma das dimensões do modelo versus setores da economia. Aqui a ferramenta traz uma tela para cada dimensão de maturidade. Sendo possível aprofundar as análises e realizar comparações detalhadas nas diversas industrias detectado o comportamento interno nos atributos. Caso haja pontos fora da curva, esses poderão ser rapidamente identificados com esses relatórios. A figura 32 ilustra uma das telas desta seção.

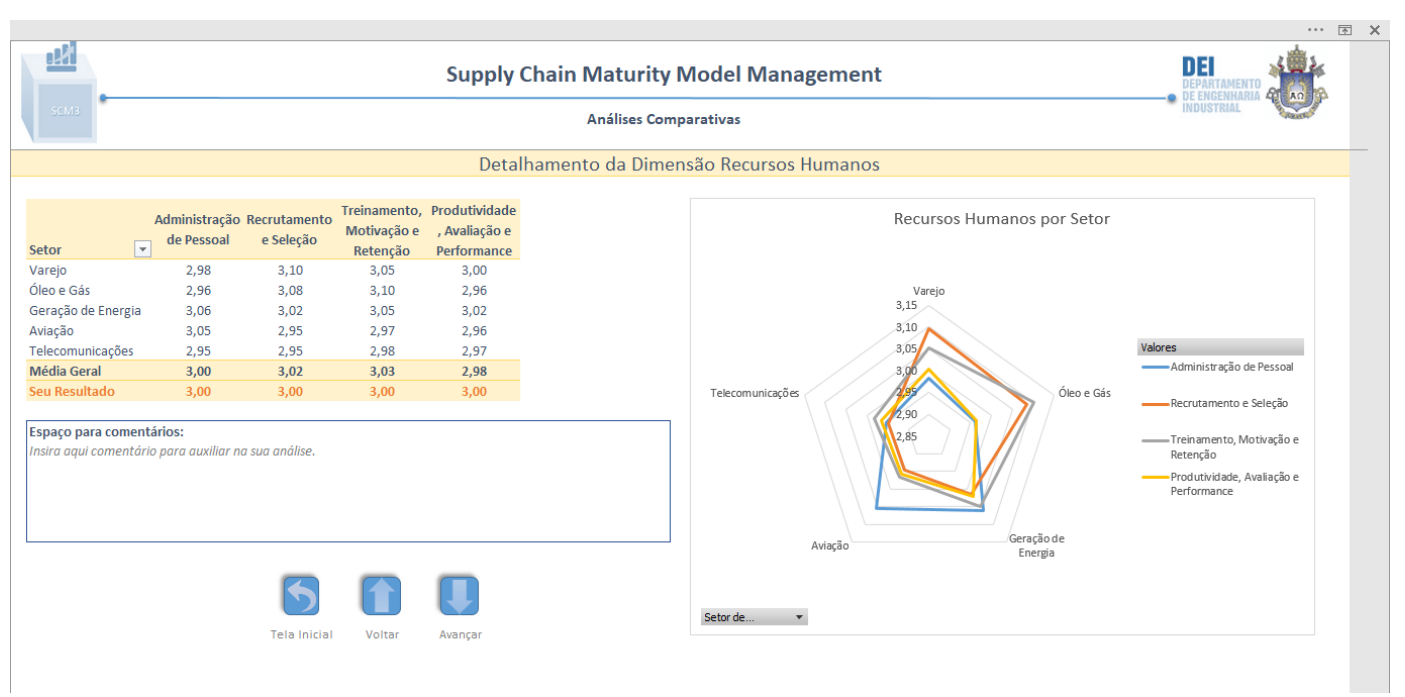

Figura 32: Dimensões Detalhadas por Industria Fonte: Elaborado por este trabalho 


\subsection{2 \\ Método de Implantação do Modelo}

A operacionalização desse modelo exigiu que fosse desenvolvido um método de apoio para auxiliar a sua aplicação nas organizações. Na busca por elementos que balizassem uma aplicação estruturada, além do modelo de referência de Reyes \& Gianchetti (2010), também foram observados os modelos propostos: CMMI pelo SEI (2001), o Project Management Maturity Model desenvolvido por Harold Kerzner(2003) e o Supply Chain Maturity Assessment Test proposto por Netland e Alfnes (2008).

A figura 33 a seguir descreve os procedimentos metodológicos sugeridos para aplicação do modelo. Importante salientar que, orienta-se que esses passos sejam conduzidos por um especialista, preferencialmente externo a cadeia e com experiência neste tipo de aplicação. O método estruturado é dividido em etapas subsequentes e acompanham algumas orientações para implantação, as quais são detalhadas a seguir.

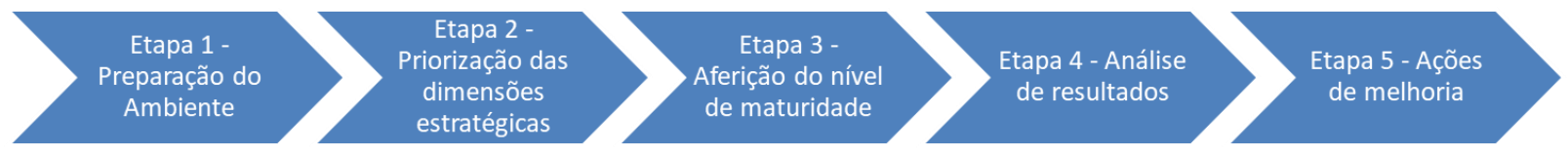

Figura 33: Etapas de implantação do modelo Fonte: Elaborado por este trabalho

$\checkmark$ Etapa 1 - Preparação do Ambiente: A avaliação considera a organização como empresa focal, o centro da cadeia. Nesta etapa, deve-se realizar a formação de uma equipe destinada a avaliação e devem ser discutidos os conceitos e premissas assumidos para implantação. Nesta etapa também sugere-se a confecção do desenho da cadeia de suprimentos, caso a empresa não possua, observando a rede em que a mesma está inserida.

$\checkmark$ Etapa 2 - Priorização das dimensões estratégicas: Nesta etapa deve-se priorizar por grau de importância as dimensões de desempenho da cadeia, de acordo com a estratégica de negócio. Este constructo não determina qual método a empresa deve utilizar, mas aconselha que seja um método de análise multicritério/hierárquica comumente aceito e de domínio da organização, podendo ser o método AHP ou qualquer outro com estrutura 
em forma de árvore de valor, permitindo que sejam hierarquizadas os atributos e dimensões.

$\checkmark$ Etapa 3 - Aferição do nível de maturidade: Compreende os passos para determinação do escore e a classificação de maturidade em cada dimensão de aplicação, a partir da coleta dos dados via preenchimento na ferramenta com os sujeitos escolhidos na etapa 1. Salientando que, orienta-se que a aplicação do questionário seja realizada através de entrevistas presenciais ou semipresenciais liderada por um membro especialista da equipe de aplicação.

$\checkmark$ Etapa 4 - Análise de resultados: Nesta etapa são realizadas análise comparativa dos níveis de maturidade por dimensão e análise gráfica das relações entre os atributos de maturidade de cada dimensão, com o intuito de suportar a geração de um Roadmap para orientar os esforços de melhoria na organização. A ferramenta provê um relatório de resultados, com uma gama de gráficos comparativos, que são insumos para esta etapa.

$\checkmark$ Etapa 5 - Ações de melhoria: Esta etapa se destina a realização da proposição e priorização de ações de melhoria, bem como a implementação e o acompanhamento dessas ações. Após a identificação das dimensões e atributos com baixo rendimento e de maior importância estratégica para o negócio. Este será o momento de desenhar ações relativas as práticas a serem desenvolvidas, alinhadas à estratégia da empresa. Aqui deve-se também determinar o tempo em que a organização pretende voltar a medir a maturidade, gerando acompanhamento da evolução de seus esforços.

\section{4}

\section{Validação Do Modelo}

\subsection{1}

\section{Análise Dos Especialistas}

Conforme apresentado na subseção 3.2.4 - Pesquisa de Campo, quatro especialistas avaliaram o modelo e a ferramenta desenvolvidos por este trabalho, a partir de requisitos gerais e específicos. Todos os critérios foram avaliados pelos especialistas em uma escala de zero a cinco. Os resultados aparecem na Tabela 30. 
Tabela 30: Resultado da avalição do modelo por especialistas

\begin{tabular}{|c|c|c|c|c|c|c|}
\hline \multicolumn{2}{|c|}{ Avaliação de Requisitos Específicos } & $\begin{array}{c}\text { Especialista } \\
1\end{array}$ & $\begin{array}{c}\text { Especialista } \\
2\end{array}$ & $\begin{array}{c}\text { Especialista } \\
3\end{array}$ & $\begin{array}{c}\text { Especialista } \\
4\end{array}$ & Média \\
\hline । & Interface & 5 & 5 & 5 & 5 & 5 \\
\hline li & Conteúdo & 5 & 5 & 5 & 4 & 4,75 \\
\hline lii & Encadeamento lógico & 4 & 4 & 5 & 5 & 4,5 \\
\hline IV & Viabilidade & 5 & 4 & 5 & 5 & 4,75 \\
\hline V & Aceitabilidade & 5 & 4 & 5 & 4 & 4,5 \\
\hline \multicolumn{7}{|c|}{ Avaliação Geral e a Análise da Consistência } \\
\hline 1 & Alcance de Objetivos & 5 & 5 & 5 & 5 & 5 \\
\hline li & $\begin{array}{l}\text { Vantagens do modelo } \\
\text { Oportunidades de Melhoria }\end{array}$ & \multicolumn{5}{|c|}{ Questão Aberta } \\
\hline
\end{tabular}

Fonte: Elaborado por este trabalho

Em relação à interface, onde foi avaliado a estrutura gráfica do modelo, os especialistas atribuíram nota 5. Já ao critério conteúdo, onde se observou a aderência e relevância do conteúdo frente às necessidades de avaliação de cadeia de suprimentos, teve média 4,75. O critério de encadeamento lógico, onde foi examinada a sequência de apresentação de conteúdo do modelo e preenchimento da ferramenta, os especialistas atribuíram em média 4,50. Para o critério viabilidade, onde foi avaliada a capacidade de o modelo ser utilizado de forma efetiva nas organizações, foi atribuída média 4,75. O por último, no critério aceitabilidade, onde foi mensurado o possível nível de aceitação do modelo por parte de profissionais de gestão em cadeia de suprimentos, foi atribuído 4,50.

Como média geral os especialistas atribuíram nota máxima (cinco) ao modelo e ferramenta, destacando como principais vantagens sua boa organização e estruturação dos parâmetros de entrada, bem como a exibição dos resultados e a contribuição para gerentes e profissionais do mercado que atuem na gestão de cadeias de suprimentos.

Como oportunidades de melhoria foram mencionadas ações quanto à experiência do usuário em termos de navegação, como por exemplo, o melhor posicionamento dos botões para reduzir a necessidade de movimentação do mouse e foi sugerida a inserção de um campo aberto para comentários na tela do plano de ação. Todas as alterações sugeridas pelos especialistas foram incorporadas na versão do modelo e ferramenta, acima apresentados.

Um dos especialistas sugeriu, para em um trabalho futuro, o desenvolvimento de uma aplicação web internacionalizada para expandir o alcance da ferramenta e 
poder registrar os níveis de maturidade das empresas espalhadas pelo globo, havendo uma funcionalidade que possibilita visualizar um ranking geral.

\subsection{2}

\section{Aplicação em Ambiente Organizacional}

A aplicação do SCM3 em ambiente organizacional teve como base o modelo de maturidade e os instrumentos de operacionalização (ferramenta e método de aplicação) demonstrados na seção 4.2. A aplicação permitiu, mais uma vez, validar a capacidade do modelo em avaliar a maturidade em gestão da cadeia de suprimentos das empresas.

O SCM3 foi aplicado em duas empresas, pertencentes ao grupo de líderes, do setor telecomunicações e que aceitaram participar deste estudo. Para garantir o sigilo solicitado pelas organizações, o nome das empresas não será revelado neste trabalho, mas, para demostrar a importância das empresas para o país, juntas elas detêm mais de $40 \%$ do market share do mercado de telefonia móvel, fixa e internet banda larga. Para fins de demonstração dos resultados chamaremos de empresa A e B.

A aplicação teve duração de quatro semanas, subdivida em seis sessões, uma para cada dimensão de maturidade, a pesquisa foi conduzida envolvendo a camada gerencial das companhias.

As duas empresas foram classificadas nos níveis mais altos de maturidade, onde a empresa A teve um escore geral de 3,74 e enquadra da no nível 4 de maturidade - 'Colaboração Integrada'. Já a empresa B foi classificada com nível 5 de maturidade, teve um escore de 4,55, sendo considerada uma empresa de 'Liderança Ampliada'.

A Figura 34 consolida os resultados obtidos em cada uma das dimensões de maturidade, demonstrados a partir de um gráfico radar, onde quanto mais longe se está do centro, maior o nível de maturidade daquela dimensão específica.

A dimensão mais madura da empresa A foi Sistema de Medição e Performance, enquanto a empresa B tem maior força na dimensão Gestão de Fornecedores. Em contrapartida, a empresa A obteve o pior escore de maturidade em Gestão de Operações e Cliente e a empresa B em Gestão de Atividades Logísticas Primárias. Em linhas gerais a empresa B se mostrou mais madura em a empresa A em todas as dimensões de maturidade. 


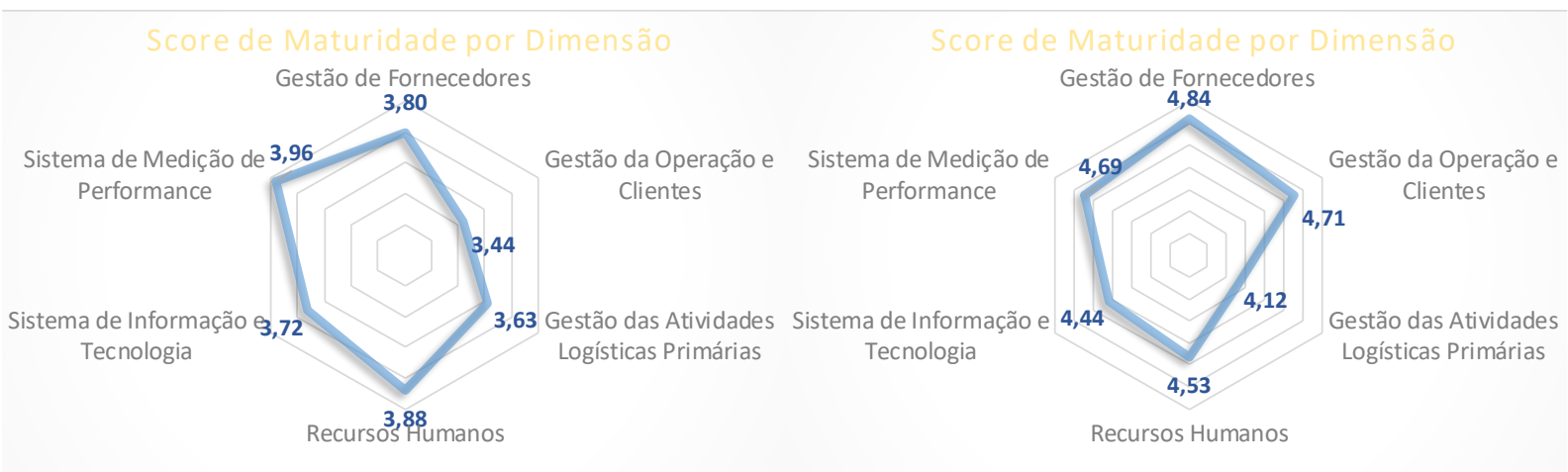

Figura 34: Escores por Dimensão das empresas A e B

Fonte: Elaborado por este trabalho

Analisando mais profundamente os resultados obtidos pelas empresas participantes da pesquisa, veremos cada dimensão de maturidade estratificada em seus diversos atributos, comparando as duas organizações. Por questões de padronização na apresentação dos resultados teremos sempre os resultados da empresa $\mathrm{A}$ à esquerda e o da empresa $\mathrm{B}$ à direita, onde cada barra horizontal dos gráficos representam um atributo de maturidade relacionado a sua dimensão específica. Conforme metodologia, um dos produtos gerados pela aplicação do modelo é o apontamento de oportunidades de melhoria para as empresas que serão comentados juntamente com os resultados a seguir.

Em relação à dimensão Gestão de Fornecedores, conforme figura 35, a empresa A obteve os menores índices nos atributos colaboração e desenvolvimento entre parceiros e controle de fornecedores. Foi identificada oportunidades de melhoria na qualidade da documentação que mapeia os processos e fluxo de fornecimento, de melhoria nos sistemas de controle do desempenho dos fornecedores para possibilitar realização de análises estatísticas do nível de serviço, implementação de um programa de desenvolvimento de parceiros e sistema colaborativo de compartilhamento de informações com fornecedores estratégicos.

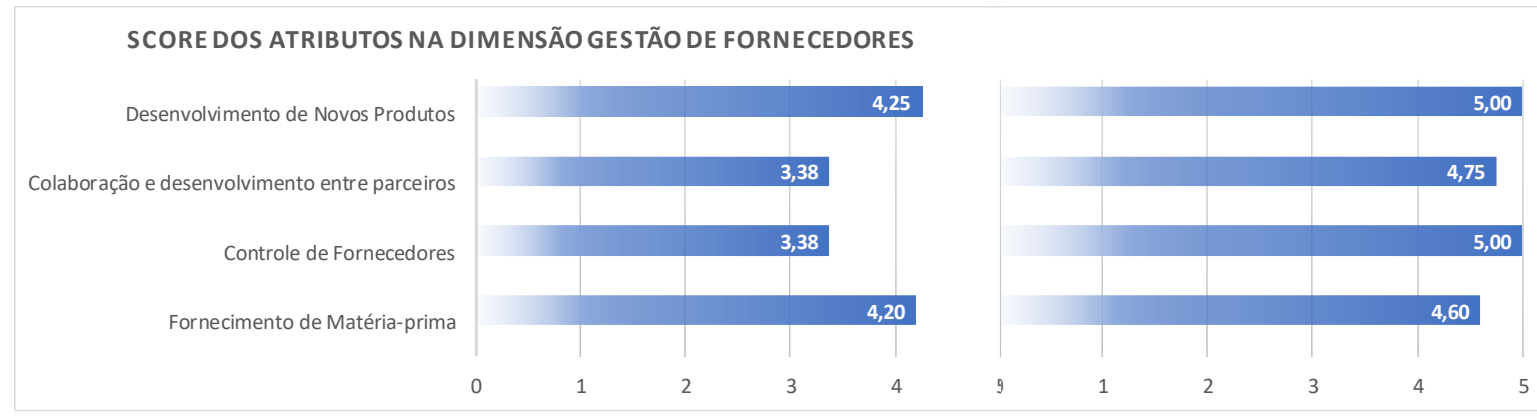

Figura 35: Escores dos atributos de Gestão de Fornecedor Fonte: Elaborado por este trabalho 
Já a empresa B, notadamente bem desenvolvida no que tange a controle de fornecedores e desenvolvimento de parcerias na criação de novos produtos, encontrou oportunidades para melhorar seu desempenho no aprimoramento dos sistemas de avaliação de fornecedores e na melhoria do acompanhamento dos projetos voltados para resolução de problemas de fornecimento.

Na dimensão de Gestão das Atividades Logísticas Primárias, a partir dos resultados detalhados na figura 36, empresa A planeja a modernização de seus métodos de controle de estoque e estudar a implantação de um sistema de reposição automática de estoques. Já a empresa B, apesar do modelo ter apontado como ponto de melhoria a utilização de sistemas de compartilhamento de informações com seus fornecedores, para melhorar o gerenciamento dos pedidos, a companhia não prioriza esse tipo de iniciativa pois estrategicamente não divulga este tipo de dados para fornecedores.

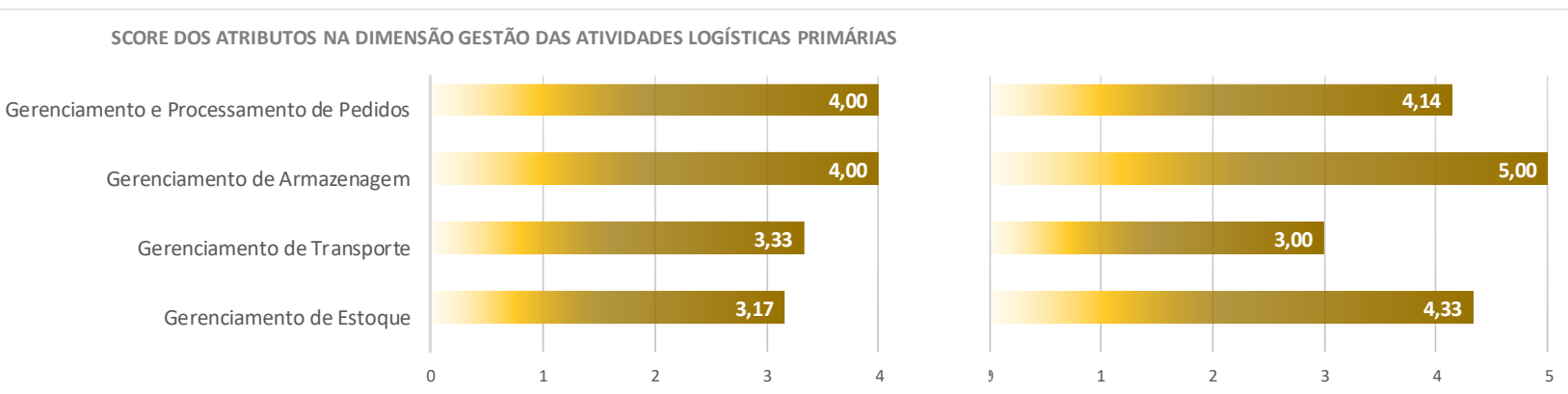

Figura 36: Escores dos atributos de Gestão das Atividades Logísticas Primárias Fonte: Elaborado por este trabalho

As duas empresas demonstraram as mesmas debilidades no gerenciamento de transportes, tendo oportunidade de otimizar o desempenho nesta dimensão, melhorando o relacionamento com seus parceiros que prestam serviços nesta atividade e implementando os métodos de otimização em roteirização, aceleração e despacho.

Em Gestão da Operação e Clientes, conforme os resultados estão detalhados na figura 37, a empresa A demostrou melhores resultados no atributo de controle de nível de serviço, enquanto a empresa $\mathrm{B}$ possui domínio nos atributos de gerenciamento de custos e planejamento estratégico. 
SCORE DOS ATRIBUTOS NA DIMENSÃO GESTÃO DA OPERAÇÃO E CLIENTES

Gerenciamento da Demanda

Controle do Nível de Serviço

Gerenciamento de Custo

Gerenciamento de Clientes

Planejamento Estratégico

Gerenciamento da Produção
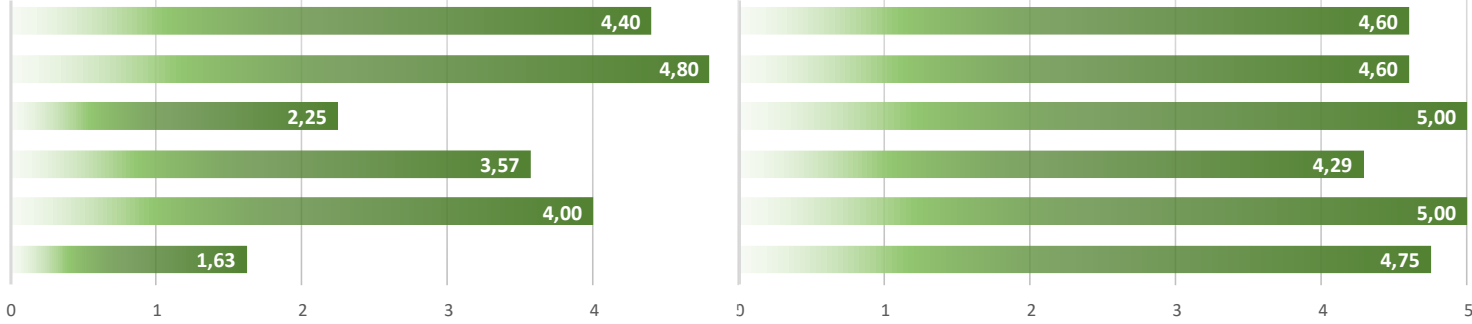

Figura 37: Escores dos atributos de Gestão da Operação e Clientes

Fonte: Elaborado por este trabalho

Dentre as ações mapeadas pela empresa A para melhoria de sua performance nesta dimensão estão: melhoria no processo de renovação do portfólio de serviços; implantação de sistema para reposição de estoque de seus "clientes internos", lojas físicas; implementação de modelos de controle de custos segmentados por produtos e por cliente; implementação de uma política de custo mínimo; e melhorias no processo de previsão de demanda, envolvendo mais ativamente os departamentos de compras, marketing, vendas e logística. Já a empresa B, mapeou como oportunidades de melhoria: a implementação de um programa de melhoria no fluxo reverso de material e ampliação dos estudos de previsão de demanda, incluindo melhores tratativas para o fator sazonalidade.

Na dimensão Recursos Humanos, conforme figura 38, as duas empresas obtiveram mesmo desempenho no atributo administração de pessoal, que foi o atributo mais bem avaliado da empresa A, enquanto a empresa B teve seu melhor desempenho no que tange a recrutamento e seleção.

SCORE DOS ATRIBUTOS NA DIMENSÃO RECURSOS HUMANOS

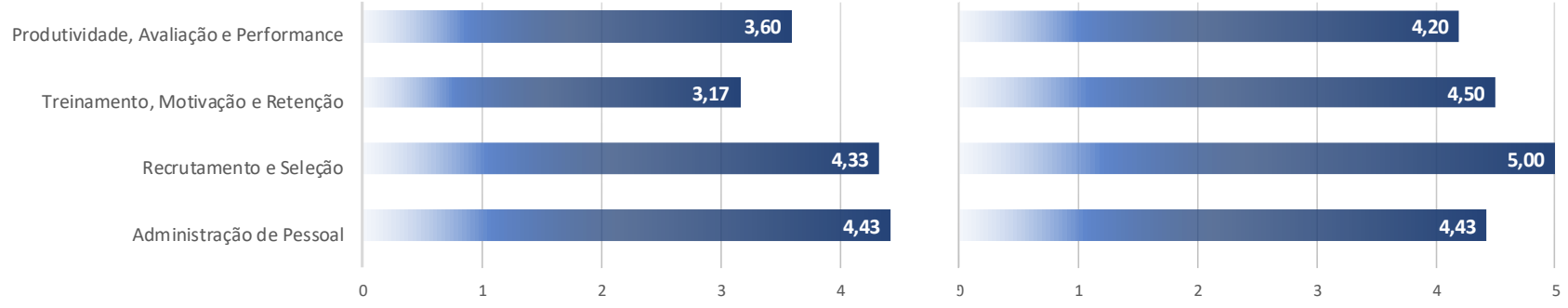

Figura 38: Escores dos atributos de Recursos Humanos

Fonte: Elaborado por este trabalho

Dentre as ações mapeadas para empresa A alcançar melhor nível de maturidade nesta dimensão, estão: melhorar as políticas de terceirização e 
acompanhar claramente os resultados financeiros da política, envolver mais os gestores da área de logística nas contratações que impactam suas operações e realizar análises de perda por turnover de funcionários. Já para empresa $\mathrm{B}$, foram mapeadas as seguintes ações: melhorar o alinhamento do setor de RH com objetivos operacionais e estratégicos da gerência de logística e promover intercâmbios entre funcionários dos entes da cadeia para treinamento e integração nos processos da cadeia de suprimentos.

Na dimensão Sistemas de Informação e Tecnologia as duas empresas tiveram melhores resultados nos sistemas de integração externa e menores resultados no atributo da gestão da informação, conforme figura 39. Para empresa A, foram identificadas as seguintes oportunidade de melhoria: ampliar a capacidade analítica dos sistemas a fim de melhorar o apoio à decisão, implantar tecnologia de RFID para controle automático de SKU e rastreamento de produto e melhoria das plataformas eletrônicas que atuam em business to commerce (B2C).

SCORE DOS ATRIBUTOS NA DIMENSÃO SISTEMA DE INFORMAÇÃOE TECNOLOGIA

Gestão da Informação e do Conhecimento

Sistemas de Apoio à Decisão

Sistemas de Integração Externa

Sistemas de Integração Interna
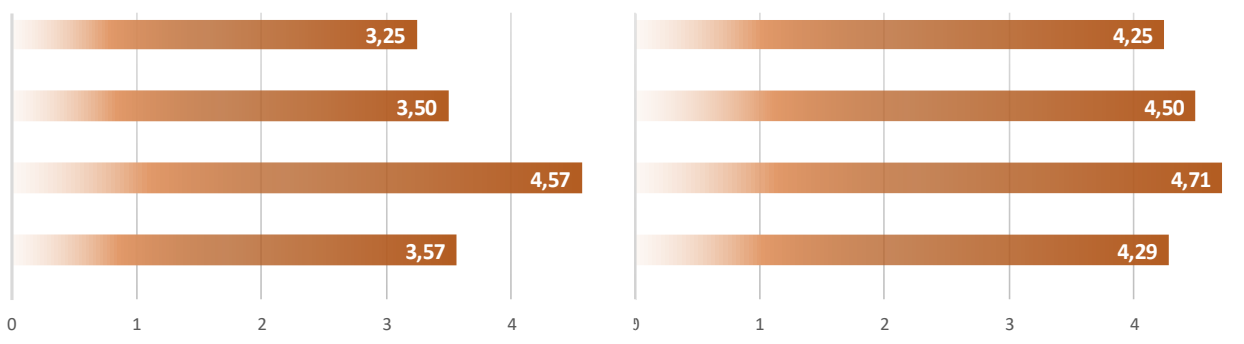

Figura 39: Escores dos atributos de Sistemas de Informação e Tecnologia

Fonte: Elaborado por este trabalho

Já para empresa B, foram identificadas as ações: automatização de parte dos estudos de previsão de demanda e disponibilização de informações de fornecimento em sistemas online de acesso em tempo real. E por fim, apesar do modelo indicar a necessidade a implantação de um sistema em plataforma EDI (Intercâmbio Eletrônico de Dados), a ação não está de acordo com o direcionamento estratégico da empresa.

Na última dimensão avaliada, Sistema de Medição e Performance, as empresas obtiveram menores escores nos atributos indicadores estratégicos e operacionais e melhores resultados em indicadores de custos financeiros e de qualidade, conforme figura 40. 


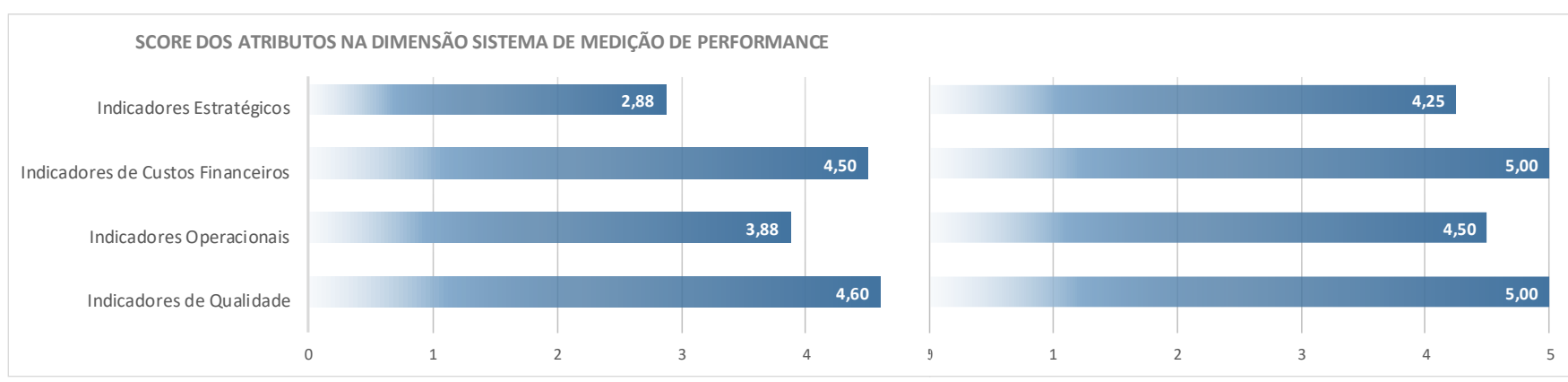

Figura 40: Escores dos atributos de Sistema de Medição e Performance Fonte: Elaborado por este trabalho

A empresa A inseriu em seu plano de ação, as seguintes iniciativas para melhorar a performance nesta dimensão: melhorar o acompanhamento dos indicadores de segurança operacional e de controle de custos e implantar processo que direcione recompensas e penalidades financeiras dos fornecedores a partir do sistema de medição e performance. Já a empresa B, identificou as seguintes ações: acompanhar o sistema de medição de performance interno de seus fornecedores estratégicos, realizar estudo de benchmarking competitivo e colaborativo. 


\section{5 \\ Conclusões}

Este trabalho, de caráter teórico e exploratório, buscou lançar de bases teóricas para a construção de um modelo de maturidade em gestão da cadeia de suprimentos. Para isso, foram necessários estudos aprofundados em cadeias de suprimentos, modelos de maturidade em processos, bem como os modelos de maturidade específicos em gestão de cadeia de suprimentos, permitindo, desta forma, a construção de um modelo teórico.

O resultado da pesquisa culminou na estruturação do Supply Chain Management Maturity Model (SCM3), um modelo de maturidade em gestão de cadeia de suprimentos que descreve uma evolução em cinco níveis, a partir da avaliação de suas 6 dimensões que agrega 26 atributos de maturidade, fornecendo orientações para especificação de um plano de melhoria na organização.

O modelo conta como uma ferramenta associada, que confere tangibilidade a operacionalização do modelo, com cinco funcionalidades principais e que teve seu protótipo desenvolvido em linguagem Visual Basic 14.0 e interface em Excel. O modelo de maturidade proposto agregou o conceito do ponto chave de transição e conta também com um método que suporta às organizações na sua implantação.

A validação de modelo contou com a análise de especialistas e com a aplicação em ambiente organizacional de duas empresas de grande porte do setor de telecomunicações. A aplicação no mundo real, além de validar o modelo, demonstrou a implementação prática do SCM3, verificou a aderência do modelo e sua capacidade efetiva em ajudar os gestores a avaliarem a gestão de suas cadeias de suprimentos, identificando o seu nível de maturidade em cada dimensão de maturidade.

O modelo apresenta uma abordagem inovadora para medição de maturidade de cadeia de suprimentos, além de, proporcionar aos gestores logísticos acesso a uma ferramenta prática que os permite acompanhar o amadurecimento de suas cadeias e direcionar melhor também suas ações de longo prazo. Outra implicação prática, a implementação do modelo traz incremento de competitividade para empresa em setor econômico, uma vez que a pesquisa também fornece meios para 
as empresas avaliarem suas operações de Supply Chain e desenvolver planos de melhoria, aderentes ao planejamento estratégico de empresa, trilhando um caminho de melhoria contínua.

A pesquisa contribuiu para ampliação e aprofundando da literatura sobre o tema. O desenvolvimento de estudos em maturidade gera uma visão abrangente $\mathrm{e}$ impulsiona o desenvolvimento de novas teorias e modelos que contribuem para a compreensão das práticas e estratégias de diferentes organizações.

Com base no exposto neste trabalho, algumas implicações são apresentadas visando pesquisas futuras, tais como: a realização de aplicações em diferentes ramos da indústria, bem como no setor de serviços; ampliação no número de validações em ambiente organizacional real; análise de processos de melhoria contínua após consecutivas aplicações em uma mesma organização; realização dos estudos de benchmarking a partir desta funcionalidade desenvolvida na ferramenta para concreta validação; e virtualização do modelo buscando uma internacionalização e ampliação dos resultados a serem alcançados.

Embora se ressalte a relevância da aplicação do SCM3, há de se destacar as limitações características deste trabalho, salientando que o modelo aqui apresentado é apenas uma proposição e precisa ser testado e validado de forma mais densa, complementando este estudo por meio de testes mais abrangentes que permitam comprovar as premissas apresentadas e o seu refinamento. Outra imitação importante é que a integração interna entre dimensões e atributos não foi considerada por questões de simplificação, apesar de saber que essa simplificação não é o retrato da realidade na gestão das cadeias de suprimentos. Este trabalho também não considera a ponderação de atributos. Em resumo, recomenda-se a replicação desse modelo em diferentes setores da economia, observando seu comportamento após diversas rodadas de aplicação para validação da confiabilidade do instrumento e modelo, consistência interna das dimensões, análise de redundâncias e correlações das dimensões para as medições globais propostas no modelo. 


\section{6 Referências bibliográficas}

APICS. Supply-Chain Operations Reference Model (SCOR). Disponível em: < http://www.apics.org/apics-for-business/frameworks/scor12 >. Acesso em: 10 de julho de 2017.

ARYEE, G.; NAIM, M. M.; LALWANI, C. Supply chain integration using a0020maturity scale. Journal of Manufacturing Technology Management. Birmingham, vol. 19, n. 5. 2008.

AYERS, J. B.; MALMBERG, D. M. Supply Chain Systems: Are You Ready? Information Strategy: The Executive's Journal, 19 (1): 18-27, 2002.

BALlOU, R. H. Gerenciamento da Cadeia de Suprimentos/Logística Empresarial. 5 ed. ed. Porto Alegre: Bookman, 2006.

BARRA, G. M. J; LADEIRA, M. B. Modelo de maturidade para processos de certificação no sistema agroindustrial do café. Revista de Gestão, v. 24, n. 2, p. 134-48, 2017. DOI: 10.1016/j.rege.2017.03.004

BECKER, J; KNACKSTEDT, R; PÖPPELBUß, D. I. J. Developing maturity models for IT management. Business \& Information Systems Engineering, v. 1, n. 3, p. 213-222, 2009.

Blackstone, J.H., 2013. APICS Dictionary. 14th ed. Georgia, USA.

BOWERSOX, D. J.; CLOSS, D. J.; COOPER, M. B. Gestão da Cadeia de Suprimentos

e Logística. Tradução: Cláudia Mello Belhassof, 2a ${ }^{\text {a }}$ Tiragem. São Paulo: Campus/Elsevier, 2007.

BOWERSOX, D. J.; CLOSS, D. J.; COOPER, M. B. Supply chain logistics management. 3. ed. New York: McGraw-Hill, 2010.

BRONZO, M.; OLIVEIRA, M. P. V. Performance and Maturity Models: A theoretical approach of relationships between performance measurement systems and maturity models for logistical processes. IPSERA. San Diego, CA: IPSERA. 2006. 
BRONZO, M.; OLIVEIRA, M. P. V. Sistemas de Mensuração de Performance e Modelos de Maturidade em Processos Logísticos: um estudo exploratório. ENANPAD. Brasília: ANPAD. 2005.

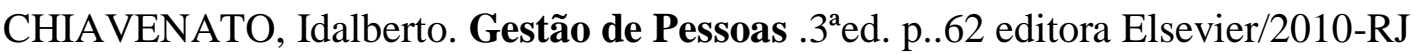

CHOPRA, S.; MEINDL, P. Gestão da Cadeia de Suprimentos: Estratégia, Planejamento e Operações. 4ª edição. São Paulo: Pearson, 2011.

CHRISTOPHER, M. Logística e gerenciamento da cadeia de suprimentos: Criando redes que agregam valor. 2a . Edição. Ed. Thomson Learning: São Paulo, 2007.

CHRISTOPHER, M. Logística e Gerenciamento da Cadeia de Suprimentos. 4 ed. ed. São Paulo: Cengage Learning, 2011.

CROSBY, P. B. Quality is Free: The art of making quality certain. [S.1.]: McGraw-Hill Companies, 1979.

CSCMP, C. O. S. C. M. A. P. Supply Chain Management - Glossary of Terms. Disponível em: <http://cscmp.org/ >. Acesso em: 10/4/2017.

DAOZHI, Z. et al. A New Supply Chain Maturity Model with 3-Dimension Perspective. In: Information Technology and Innovation Conference - ITIC, 2006, Hangzhou. Proceedings: ITIC, 2006.

Espinoza A, Garbajos J (2011). A study to support agile methods more effectively through traceability. Innovations Syst Softw Eng. Disponível em: http://www.springerlink.com/content/gh3j34krh171vp04/fulltext.pdf. Consultado em: $30 / 06 / 2018$

FRASER, P.; MOULTRIE, J.; GREGORY, M. The use of models / grids as a tool in assessing product development capability. Engineering Management Conference, v. 1, p. 244-249, 2002.

GARCIA, H., A capability maturity model to assess supply chain performance. Tese de doutorado, Florida International University, 2009

GIANCHETTI, R. E. Design of Enterprise Systems: Theory, Architecture, and Methods. CRC Press: Boca Raton, FL, 2010.

HAMMER, M. The Process Audit. Harvard Business Review, April 2007. 111-123. 
LAHTI, M.; SHAMSUZZOHA, A. H. M.; HELO, P. Developing a maturity model for Supply Chain Management. International Journal of Logistics Systems and Management, v. 5, n. 6, p. 654-678, 2009.

LAMBERT, D. M. Supply Chain Management. In: Supply chain management: Processes, partnerships, performance. Editor LAMBERT, D. M. Sarasota, FL: Supply Chain Management Institute, 2008.

LAMBERT, D. M.; KNEMEYER, M. Estamos nisso juntos. Gestão da Cadeia de Suprimentos, Harvard Business Review, Rio de Janeiro, Campus, 2008.

LAMBERT, D. M.; COOPER, M. C; PAGH J. D. Supply chain management: implementation issues and research opportunities. The International Journal of Logistics Management, Vol. 9, No. 2, p. 1-19, 1998a.

LAMBERT, D. M.; STOCK, J. R.; ELLRAM, L. M. Fundamentals of Logistics Management. Boston, MA: Irwin/McGraw-Hill, 1998b.

LOCKAMY, A. et al. The impact of process maturity and uncertainty on supply chain performance: an empirical study. International Journal of Manufacturing Technology and Management, 15 (1): 12-27, 2008.

LOCKAMY, A.; MCCORMACK K. "The development of a supply chain management process maturity model using the concepts of business process orientation". Supply Chain Management: An International Journal, vol. 9, no. 4, Abril. 2004. p. 272-278.

McCORMACK, K.; LADEIRA, M. B.; OLIVEIRA, M. P. V. Supply chain maturity and performance in Brazil. Supply Chain Management: An International Journal, 13 (4): 272$282,2008$.

McCORMACK, Kevin et al. A global investigation of key turning points in business process maturity. Business Process Management Journal. Ryiadh, vol..15, n. 5, 2009.

MCCORMACK, K. Supply chain maturity assessement: A roadmap for building the extended supply chain. Supply Chain Practice, v. 3, n. 4, p. 4-21, 2001.

McCormack, K., Johnson, W., \& Walker, W. (2003). Supply chain networks and business process orientation: advanced strategies and best pratices. APICS series on resource management. Boca Raton, Florida: CRC Press LLC. 
METTler, T. A Design Science Research Perspective on Maturity Models in Information Systems. Assessment, 2009.

MENDES, P. Demand Driven Supply Chain. A Structured and Practical Roadmap to Increase Profitability. Springer Heidelberg Dordrecht, London New York, 2011. DOI 10.1007/978-3-642-19992-9

MENDES, P.; LEAL, J. E.; THOME, A. M. T. A maturity model for demand-driven supply chains in the consumer product goods industry. Int. J. Production Economics, No. 179, p. 153-165, 2016.

NETLAND, T. H.; ALFNES, E. A practical tool for supply chain improvement experiences with the supply chain maturity assessment test (SCMAT). In: Manufacturing Fundamentals: Necessity and Sufficiency Proceedings of the 3rd World Conference on Production and Operations Management - TOKYO, 2008.

NETLAND, T. H.; ALFNES, E. Proposing a quick best practice maturity test for supply chain operations. Measuring Business Excellence, v. 15, n. 1, p. 66-76, 2011.

NOVAES, A. N. G. Logística e Gerenciamento da Cadeia de Distribuição: Estratégia, Operação e Avaliação. 3o ed. Rio de Janeiro - RJ: Elsevier, 2007.

OLIVEIRA, M. P. V. Análise estrutural de construtos e relações entre maturidade e desempenho logístico. Belo Horizonte. 2006.

Modelo de Maturidade de Processos em Cadeias de Suprimentos: Precedências e os Pontos-chaves de Transição. Belo Horizonte, 2009

PAES, R. L. Modelo de Avaliação e Melhoria do Gerenciamento da Cadeia de Suprimentos em Condomínios Industriais Automotivos. Tese de Doutorado, Porto Alegre, 2011.

PERFORMANCE MEASUREMENT GROUP (PMG). Competitive Advantage of Best in Class Supply Chains. Pennsylvania, 2007.

PIRES, S. R. I. Gestão da Cadeia de Suprimentos (Supply Chain Management): conceitos, estratégias, práticas e casos. 2. ed. São Paulo, Atlas, 2009.

PMI, P. M. I. Organizational project management maturity model (OPM3): knowledge foundation. Newtown Square, Pa: Project Management Institute, 2003. 
POIRIER, C. C.; QUINN, F. J. How are we doing: A survey of supply chain progress. Supply Chain Management Review, November/December 2004.

POIRIER, C. C.; QUINN F. J.; SWINK, M. L. Diagnosing Greatness: Ten Traits of the Best Supply Chains. Fort Lauderdale, FL: J. Ross Publishing, 2009.

PRAKASH, S.; SONI, G.; RATHORE, A. P. S. Supply Chain Operations Reference (SCOR) model: An Overview and a Structured Literature Review of its Application. International Conference on Smart Technologies for Mechanical Engineering, p. 55-61, 2013.

REYES, G. R.; GIANCHETTI, R. Using Experts to Develop a Supply Chain Maturity Model in Mexico. Supply Chain Management: An International Journal, Vol. 15, No. 6, p. $415-424,2010$.

SEI, S. E. I. Capability Maturity Model Integration (CMMI), Version 1.1. Pittsburgh, 2001 .

SEI. CMMI for System Engineering / Software Engineering, Version 1.02 (CMMI$S E / S W$, V1.02), version 1.02. Technical report CMU/SEI-2000-TR-018. Pittsburgh, Software Engineering Institute - Carnegie Mellon University, 2000.

SIMCHI-LEVI, D.; KAMINSKY, P.; SIMCHI-LEVI, Edith. Desinging and Managing the Supply Chain - Concepts, Strategies and Case studies. 2 ed. Boston, McGraw-Hill, 2003.

SLACK, N.; CHAMBERS, S.; JOHNSTON, R. Administração da produção. $3^{\text {a. }}$ Edição. Trad. Henrique Luiz Corrêa. Editora Atlas: São Paulo, 2009.

STEVENS, G. C. Integrating the Supply Chain. International Journal of Physical Distribution \& Logistics Management, Vol. 19, No. 8, p. 3-8, 1989.

Supply Chain Council. Supply Chain Operations Reference Model Revision 11.0. Washington, DC: APICS, 2012.

Tramarico, C. L. et al. Supply Chain Management: Relação Entre Níveis de Maturidade e Componentes de Um Programa de Certificação Profissional. XXXV Encontro Nacional de Engenharia de Produção: Fortaleza, CE, 2015. 


\section{7 \\ Apêndice}

7.1

\section{Registro no INPI}
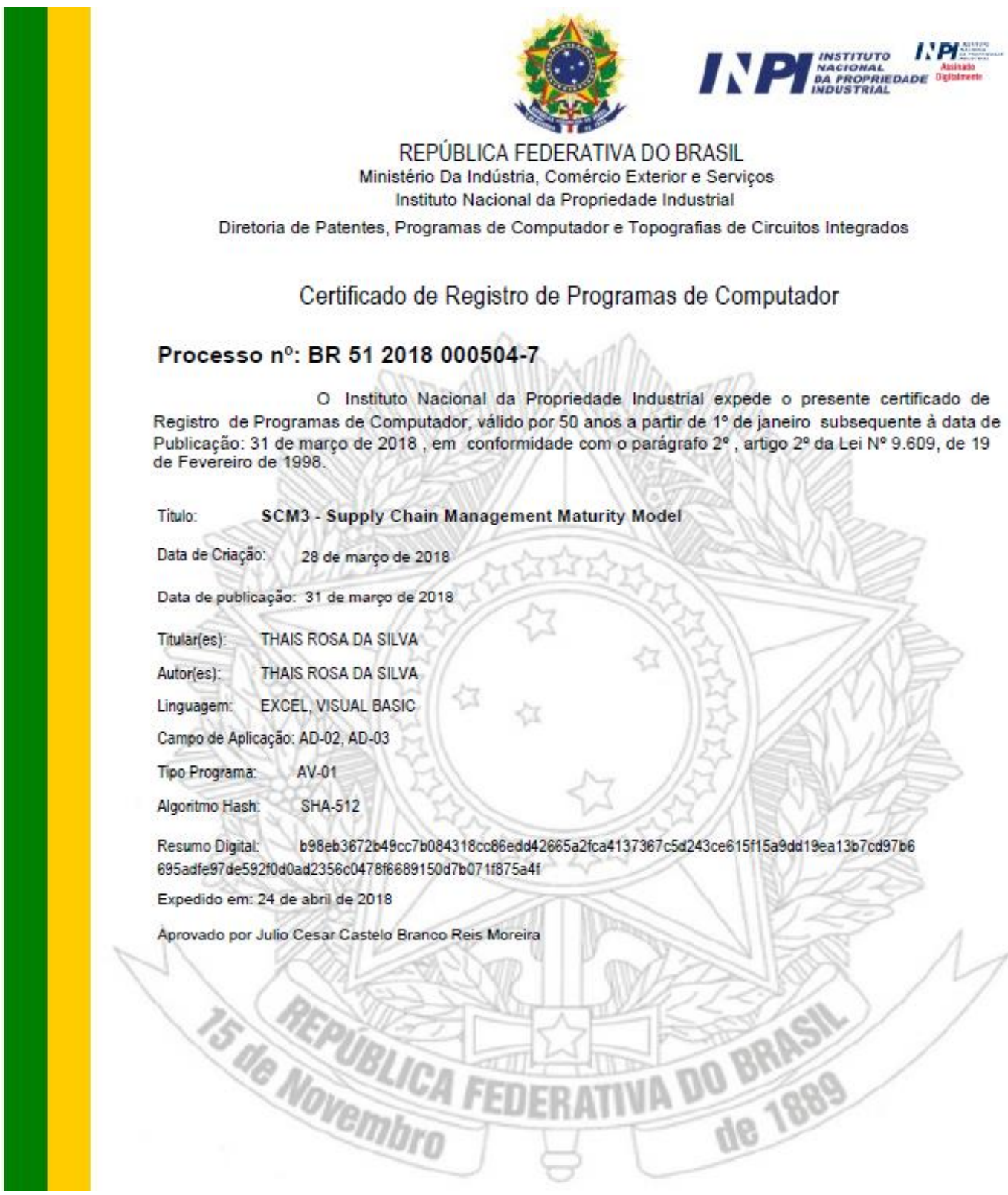

Certificado de Registro de Programas de Computador

Processo no: BR 512018 000504-7

O Instituto Nacional da Propriedade Industrial expede o presente certificado de Registro de Programas de Computador, válido por 50 anos a partir de $1^{\circ}$ de janeiro subsequente à data de Publicação: 31 de março de 2018 , em conformidade com o parágrafo $2^{\circ}$, artigo $2^{\circ}$ da Lei $\mathrm{N}^{\circ} 9.609$, de 19 de Fevereiro de 1998.

Titulo:

SCM3 - Supply Chain Management Maturity Model

Data de Criaçäo: 28 de março de 2018

Data de publicação: 31 de março de 2018

Ttular(es): THAIS ROSA DA SILVA

Autor(es): THAIS ROSA DA SILVA

Linguagem: EXCEL, VISUAL BASIC

Campo de Aplicaçăo: AD-02, AD-03

Tipo Programa: AV-01

Algoritmo Hash: SHA-512

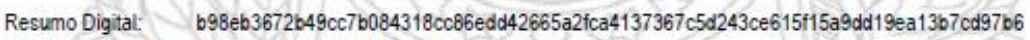

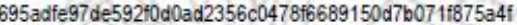

Expedido em: 24 de abril de 2018

Aprovado por Julio Cesar Castelo Branco Reis Moreira

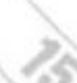

sor 